\title{
Environmental Efficiency Measurement of Grassland Grazing using Stochastic Distance Function on the Qinghai-Tibetan Plateau of China
}

\author{
Dissertation \\ to obtain the $\mathrm{Ph}$. D. degree \\ in the International Ph. D. Program for Agricultural Sciences in \\ Goettingen (IPAG) at the Faculty of Agricultural Sciences, \\ Georg-August-University Göttingen, Germany
}

presented by Huang, Wei

born in Yueyang, China

Göttingen, July 2015 


\section{D7}

1. Name of supervisor: Prof. Dr. Bernhard Brümmer

2. Name of co-supervisor: Prof. Dr. Thomas Glauben

Date of dissertation: 23. 07. 2015 




\section{Contents}

List of Tables

List of Figures

List of Abbreviations

Acknowledgements

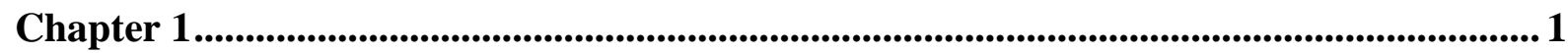

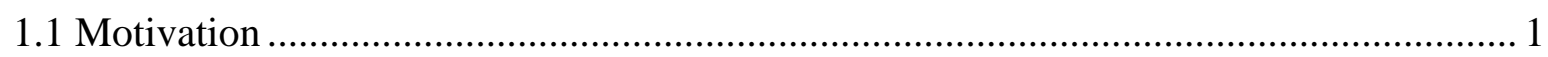

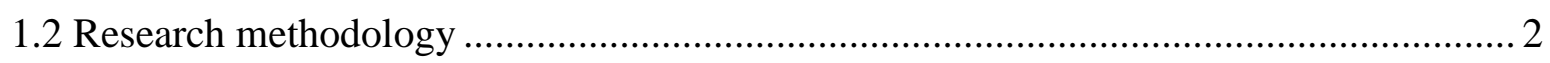

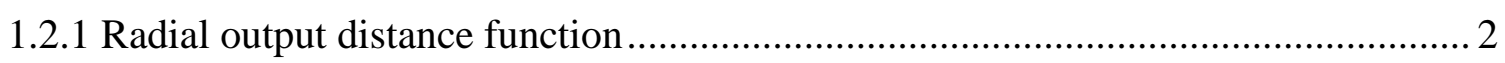

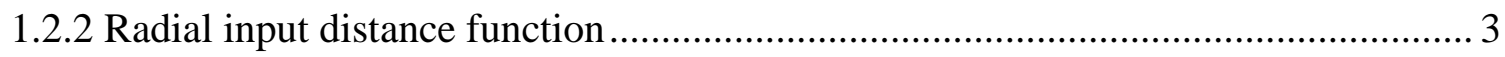

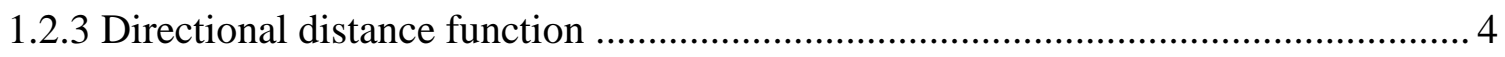

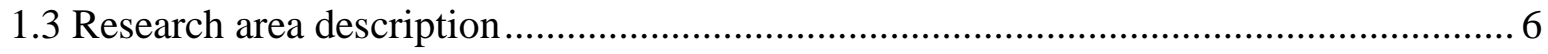

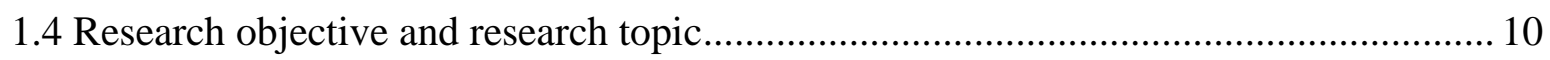

Chapter 2............................................................................................................................................................ 13

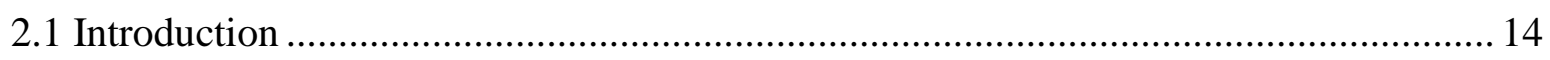

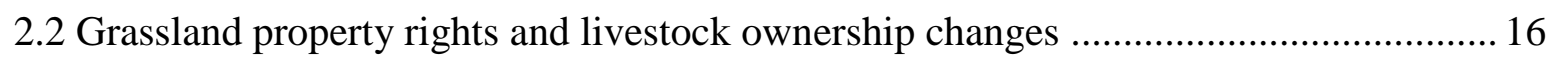

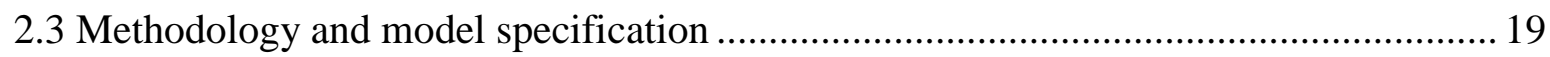

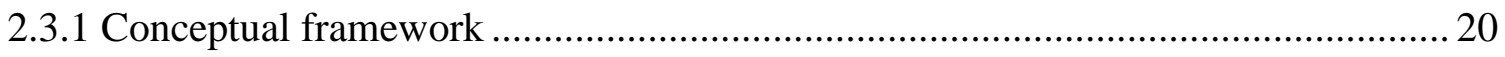

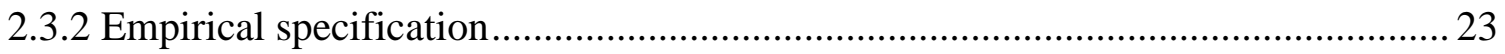

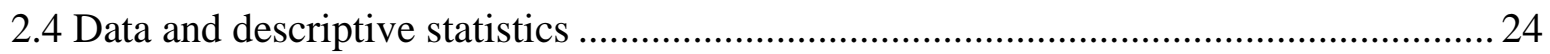

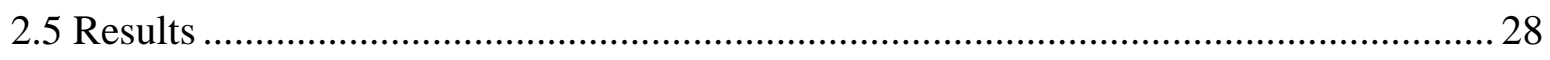

2.5.1 Hypothesis test of the rented-in grassland variable ............................................. 28

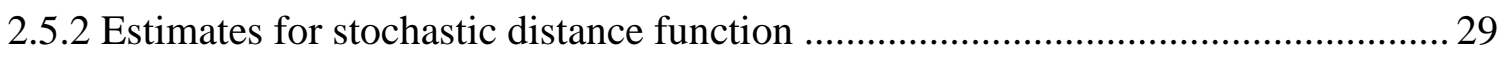

2.5.3 Estimates for the technical inefficiency model and the effect of grassland leasing-in 
Chapter 3....................................................................................................................................39

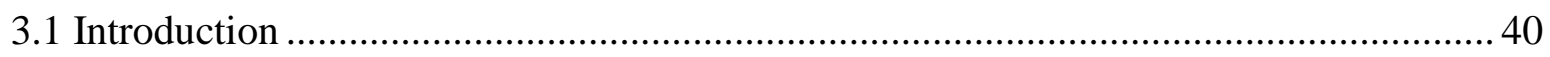

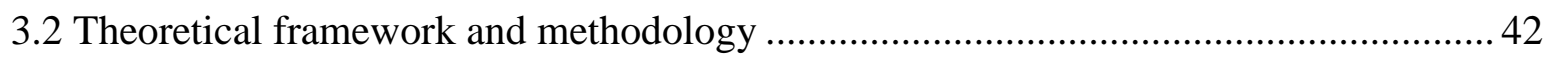

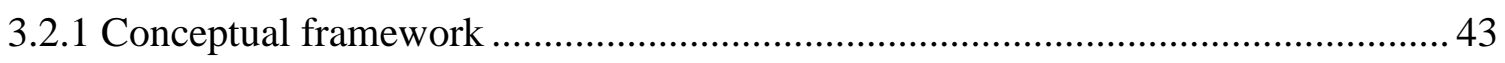

3.2.2 Empirical model specification and estimation measurement ............................... 45

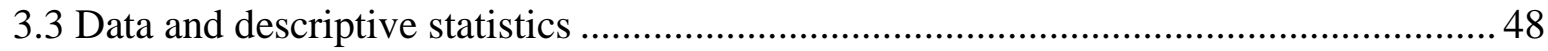

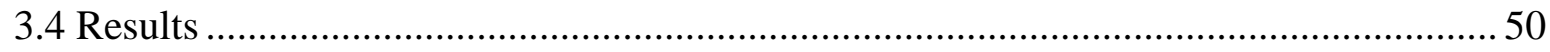

3.4.1 Stochastic distance function estimates .................................................................... 51

3.4.2 Technical inefficiency model estimates and technical efficiency ..........................53

3.4.3 The ecological performance indicator and grassland total NPP efficiency.............54

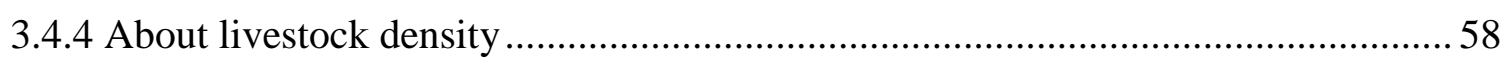

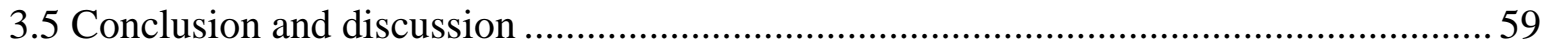

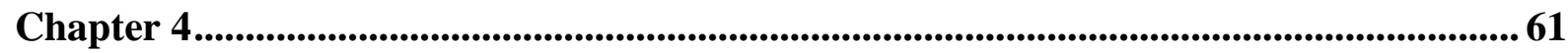

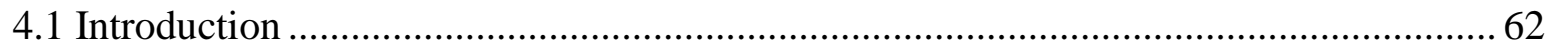

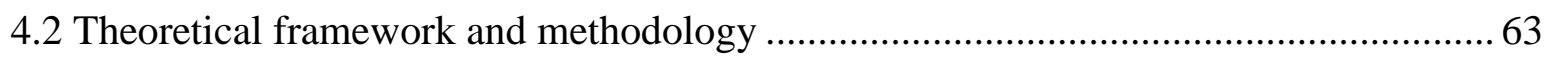

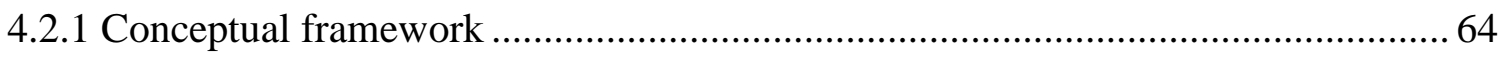

4.2.2 Relative shadow prices and the Morishima elasticity of substitution ......................66 66

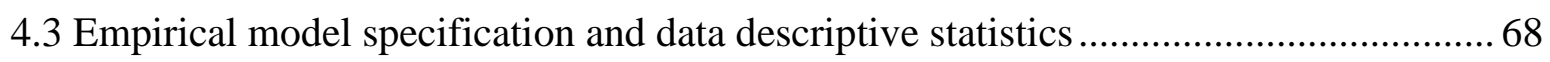

4.3.1 Empirical model specification and estimation measurement .................................6 68

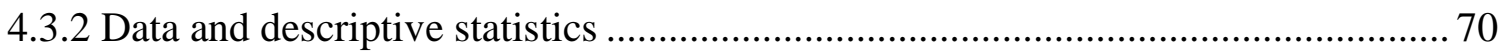

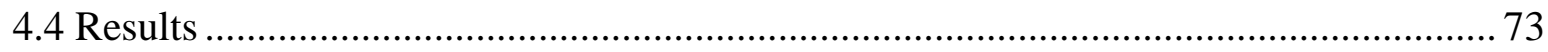

4.4.1 Parameter estimates of directional distance functions .......................................... 75

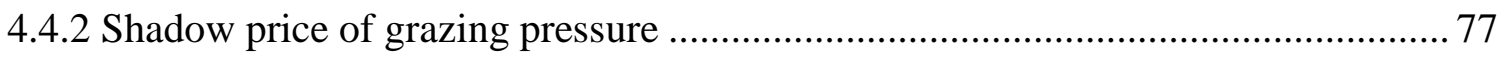

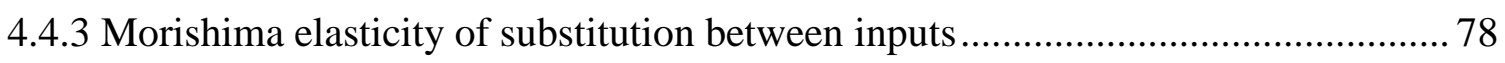

4.4.4 Estimates for the inefficiency model and for efficiency .................................... 78

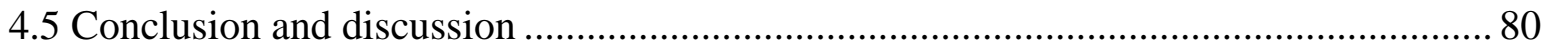

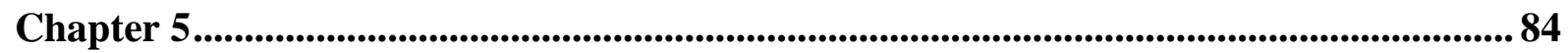

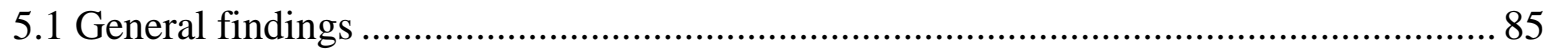

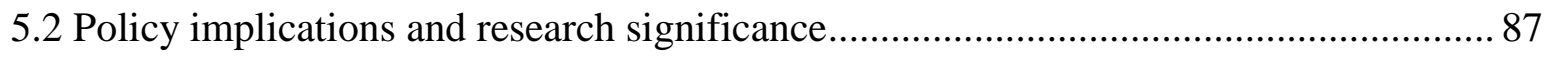

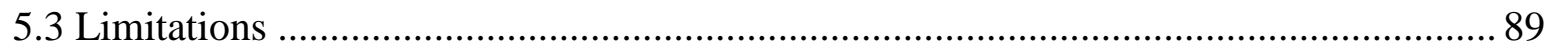

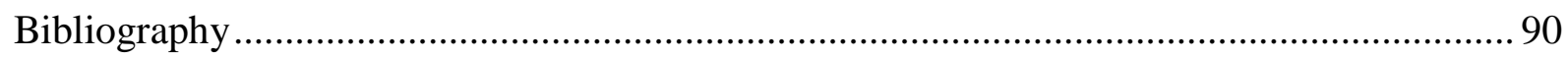

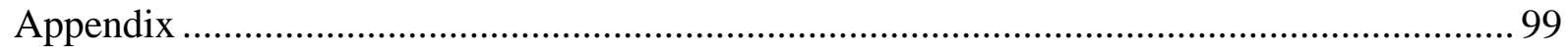




\section{List of Tables}

Table 1.1 Areas of counties in Sanjiangyuan region ......................................................... 7

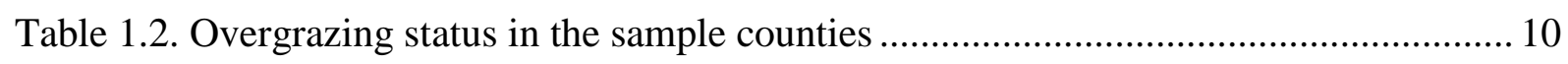

Table 2.1 Summary of variables in the stochastic frontier and technical inefficiency model .26

Table 2.2 Estimates for stochastic distance function and technical inefficiency model .......... 30

Table 2.3 Summary of estimated technical efficiency ….................................................. 33

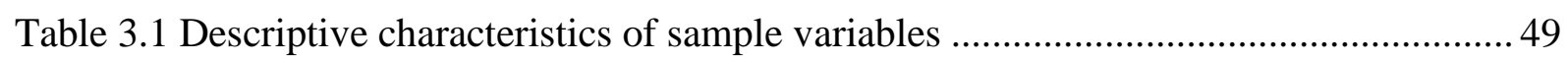

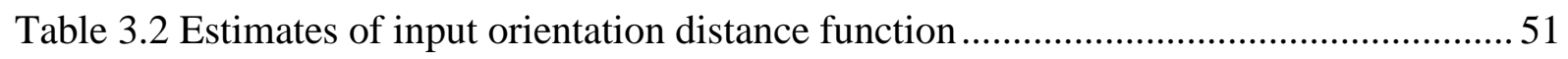

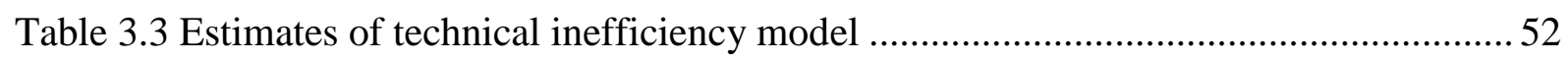

Table 3.4 Statistic summary of ecological performance indicator and total NPP efficiency... 55

Table 3.5 Distribution of technical efficiency by groups of total NPP efficiency and ecological

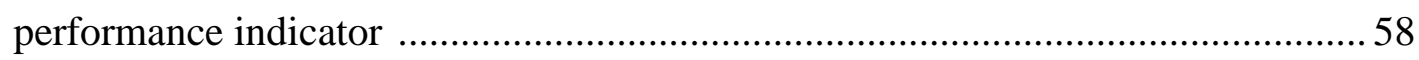

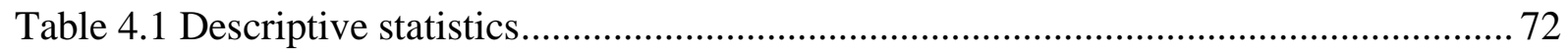

Table 4.2 Directional distance function with different directional vector .............................. 74

Table 4.3 Estimates of directional distance function and technical inefficiency model .......... 75

Table 4.4 Elasticity of distance with respect to inputs and outputs ....................................... 77

Table 4.5 Relative shadow price of outputs and elasticity of transformation ......................... 78

Table 4.6 Morishima elasticity of substitution between inputs ........................................... 78

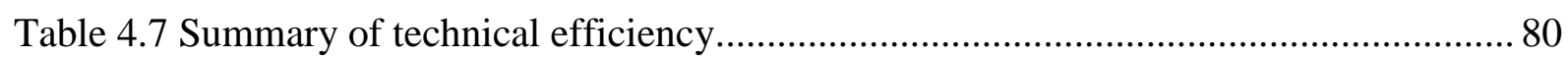





\section{List of Figures}

Figure 1.1 Radial output distance function ..................................................................... 3

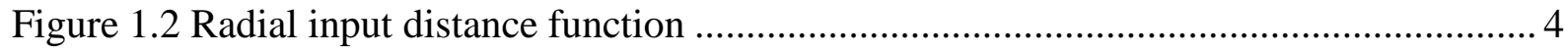

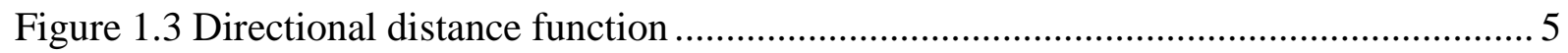

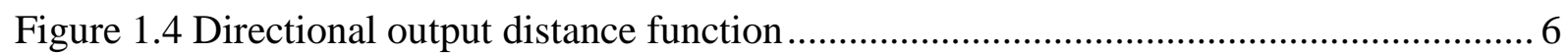

Figure 1.5 Location of the Sanjiangyuan region in China ..................................................... 7

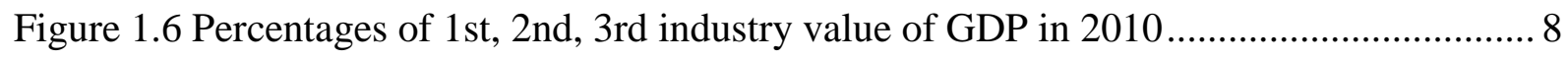

Figure 1.7 GDP of different sectors comprising 1 st industry in 2010 .................................. 9

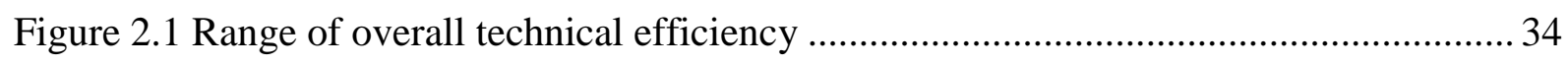

Figure 2.2 Distribution of technical efficiency grouped by dummy variable of rent-in

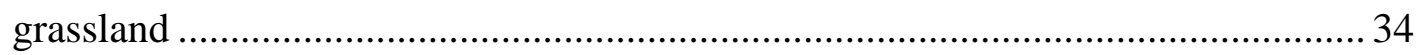

Figure 3.1 Distribution range of technical efficiencies estimated from Model1 and Model2 .54

Figure 3.2 Scatter graph of total NPP efficiency on technical efficiency ..............................56

Figure 3.3 Scatter graph of ecological performance indicator on total NPP efficiency ...........57

Figure 3.4 Scatter graph of ecological performance indicator on technical efficiency............57

Figure 3.5 Scatter graph of ecological performance indicator and total NPP efficiency on

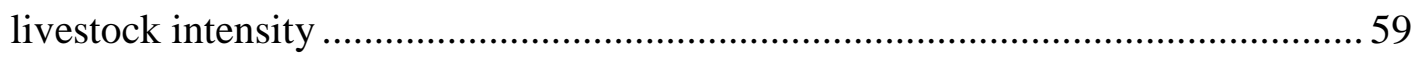

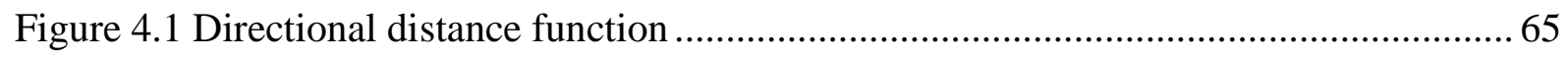

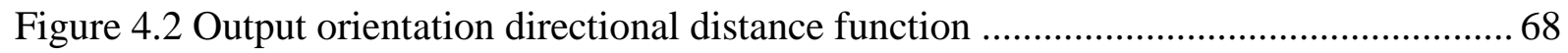

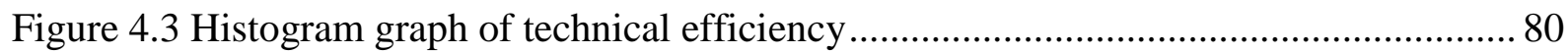

Figure 5.1 Relationship between cumulative grazing pressure, ecological risk and livestock

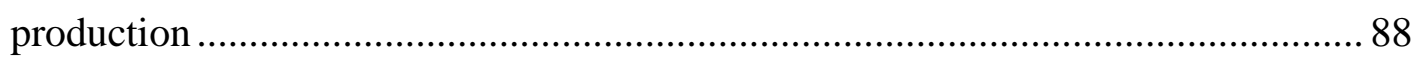





\section{List of Abbreviations}

CCAP Center for Chinese Agricultural Policy

DEA Data envelop analysis

EPI Ecological performance indicator

FAO Food and Agriculture Organization of the United Nations

GDP Gross domestic product

HRS Household Responsibility System

IFPRI International Food Policy Research Institute

LR-test Likelihood ratio test

MES Morishima elasticity of substitution

MLE Maximum Likelihood Estimation

MODIS The Moderate-resolution Imaging Spectroradiometer

NPP Net primary productivity

RMB Renminbi, official currency of the People's Republic of China

SFA Stochastic frontier analysis

SNNR Sanjiangyuan National Nature Reserve

TE Technical efficiency

TNPP Total net primary productivity

TNPPE Total net primary productivity efficiency

UNEP The united nations environment programme

WBCSD World Business Council for Sustainable Development 



\section{Acknowledgements}

It is an exciting moment when I start to think of acknowledgement for the Ph.D. dissertation. The work has been supervised by Prof. Dr. Bernhard Brümmer, whom I would like to thank first. Thanks to Prof. Brümmer for instructive supervising during past years. Every time after discussion with Prof. Brümmer when I was confusing or was in doubt of some headache research questions, the advice from Prof. Brümmer and patient discussion with Prof. Brümmer would point a clear interesting research way for me.

I would like to say thanks to Prof. Dr. Lynn Huntsinger in University of California at Berkeley when I was an exchange Ph.D. student in UC Berkeley. I visited different kinds of grassland and pastures in northern, middle and middle-southern California under the guidance of Prof. Huntsinger, which helped me to think of livestock grazing carefully and thoroughly, and recognize the characteristics of extensive livestock grazing.

I own lots of thanks to Prof. Dr. Deng, Xiangzheng in Center for Chinese Agricultural Policy (CCAP), Chinese Academy of Sciences for data supporting and field survey financial supporting. Prof. Deng also provided helpful ideas and comments on dissertation when I was visiting CCAP. Lots of thanks to Ms. Yin, Fang and Mr. Yuan, Yongwei, they are my research buddies in CCAP. Thank them for teaching me how to use 
ArcGIS to handle with remote sensing data. Special thanks to Ms. Yin, Fang, who helped me in the two rounds of field surveys on the Qinghai-Tibetan Plateau.

I am grateful to my colleagues in the chair group for their friendly help and assistance. Special thanks go to Prof. Yu, Xiaohua, who showed me the way to come to University of Goettingen and introduced me to Prof. Brümmer. I'm quite grateful to Chinese Scholarship Council, where I got financial support. I really appreciate friends in Goettingen, who make my time in Goettingen happier.

Finally, please give my grateful appreciation to my parents and my brother. My parent endorsed me to come to Germany to pursue Ph.D. degree and they make my inner strength strong. I feel not alone every time when I think of my parents, who are the best parent in the world. Thanks to Jingyi, for love.

Huang, Wei (Vivian)

September 2015, Goettingen, Germany 


\section{Chapter 1}

\section{Executive Introduction}

\subsection{Motivation}

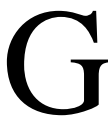
rasslands play an important role in livestock grazing and environmental conservation. Around the globe, grasslands provide livelihoods for nearly 800 million people and are a crucial source of livestock forage and wildlife habitat (White et al. 2000). However, three quarters of the world's grazing lands are so degraded that they have lost more than $25 \%$ of their capacity to support animals (UNEP 2005). Grasslands in China cover nearly 4 million $\mathrm{km}^{2}$, more than $40 \%$ of its total land area. In spite of numerous efforts that have been undertaken to arrest land desertification in China, grassland degradation is advancing over wide areas through overgrazing, cropland misuse and unregulated collection of fuel and medical plants (Akiyama and Kawamura, 2003; 2007).

The Qinghai-Tibetan Plateau is often described as the "Third Pole of the Earth" and "the Roof of the World", a place where both the ecology and the environment are crucially important and grasslands provide people with livelihoods and livestock with forage (White et al. 2000; UNEP 2005). However, research has shown that more than $50 \%$ of the grassland on the Qinghai-Tibetan Plateau has experienced varying degrees of degradation, e.g. reduced production, erosion, loss of species. The Sanjiangyuan Grassland area is one of the largest grassland areas in China. Research results have shown that $90 \%$ of the grassland in the Sanjiangyuan region suffers from varying degrees of degradation, representing an area of 
$1.247 \times 10^{7}$ ha., accounting for $64.7 \%$ total available grassland area of Sanjiangyuan region (Zhang 2008; Lu et al. 2010). The worsening of the grassland in the Sanjiangyuan region directly results in disasters in the lower reaches of the Yangtze and Yellow Rivers, such as flood and drought. Nearly 600 million people who live downstream depend on the proper ecosystem service function of grassland, making the long term protection of these rivers for their livelihood extremely urgent. The ecological environment in the Sanjiangyuan region is important and friable; it is vital to research the technical efficiency, economic efficiency and most importantly the environmental efficiency of livestock grazing on the "Third Pole of the Earth".

The productivity and efficiency of firms have been researched for about 60 years, but environmental effects have only been taken into account over the last 20 years. Most research papers which look at environmental efficiency analysis focus on developed countries. In this study, we aim to measure the environmental efficiency and productivity of livestock grazing on the Qinghai-Tibetan Plateau to reflect the relationship between grassland property rights, livestock grazing productivity, overgrazing, grazing pressure and grassland degradation.

\subsection{Research methodology}

More recently, there has been a growing interest in using a distance function approach to incorporate environmental outputs into efficiency measurements. We will follow and extend the production and efficiency analysis to link the environment-livestock relationship by a radial stochastic distance function and a directional stochastic distance function.

Both the radial distance function and directional distance function are based on the distance function introduced by Shephard (1970). Denoting a vector of inputs by $x=\left(x_{1}, \cdots, x_{K}\right) \in$ $\mathfrak{R}^{K+}$ and a vector of outputs by $y=\left(y_{1}, \cdots, y_{M}\right) \in \mathfrak{R}^{M+}$, a feasible multi-input multi-output production technology can be defined using the output possibility set $P(x)$, which can be produced using the input vector $x: P(x)=\{y: x$ can produce $y\}$. This is assumed to satisfy the set of axioms depicted by Färe and Primont (1996).

\subsubsection{Radial output distance function}

An (radial) output distance function is an output radially expanding approach for the measurement of the distance function from a producer to the boundary of production 
possibilities. It shows the minimum amount by which an output can be radially expanded and still remain producible with a given input vector. In panel A of Figure 1.1, scalar output $y$ can be produced with input $x$, but so can the larger output $(y / \mu)$, and so $D_{O}(x, y)=\mu<1$. In panel B of Figure 1.1, the output vector y can be produced with input $x$, but so can the radially expanded output vector $(y / \mu)$, and so $D_{O}(x, y)=\mu<1$.

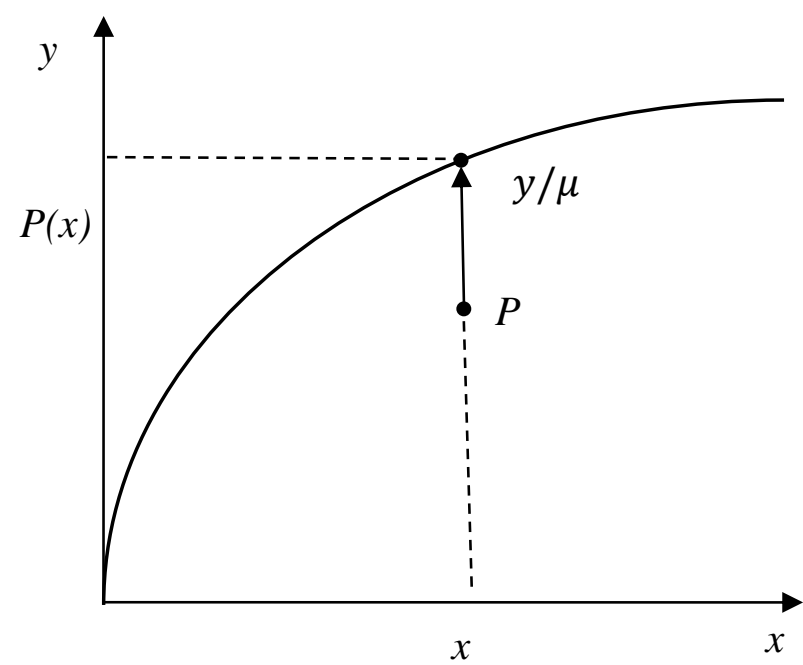

Panel A $(K=1, M=1)$

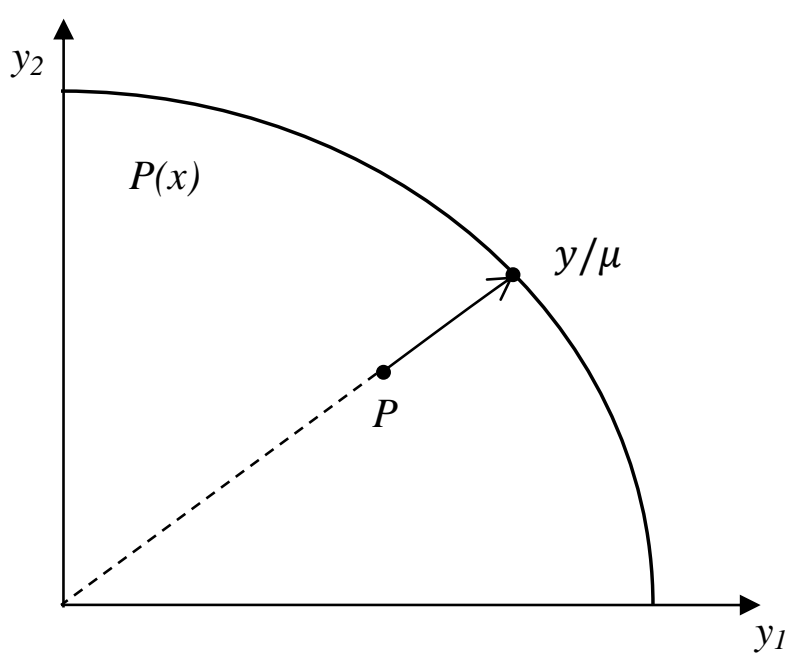

panel B $(\mathrm{M}=2)$

Figure 1.1 Radial output distance function

Since the output distance function $\mathrm{D}_{0}(x, y)$ is defined in terms of the output set $P(x)$, which satisfies certain properties, the output distance function also satisfies these properties. As noted in Lovell et al. (1994), $D_{O}(x, y)$ is non-decreasing, positively linearly homogeneous, convex in $\mathrm{y}$, and decreasing in $\mathrm{x}$. It should be clear from the definition and figures that $P(x)=\{y: x$ can produce $y\}$ and that Isoquant $P(x)=\left\{y: D_{O}(x, y)=1\right\}$. If $D_{O}(x, y)<1$, then (x,y) belongs to the production set $P(x) ; D_{O}(x, y)=1$ if $y$ is located on the outer boundary of the output possibility set (Kumbhakar and Lovell 2000).

\subsubsection{Radial input distance function}

Given that the output remains unchanged, the radial input distance function focuses on the idea of radially reducing the inputs. The radial input distance is defined in the input set, $L(y)$, as $D_{I}(x, y)=\sup \{\rho:(x / \rho) \in L(y)\}$. Households can be defined using the input sets, $L(y)$; this represents the set of all inputs $x \in \mathfrak{R}^{K+}$ can be produced by outputs $y \in \mathfrak{R}^{M+}$, which can 
be written in terms of the input possibility set $L(y)=\{x: x$ can produce $y\}$. This is assumed to satisfy the set of axioms depicted by Färe (1996). $D_{I}(x, y)$ is non-decreasing, positively linearly homogeneous, concave in $\mathrm{x}$, and increasing in $\mathrm{y}$. The distance function $D_{I}(x, y)$ takes a value greater than 1 (or equal to 1 ) if the input vector $\mathrm{x}$ is located inside the feasible input set boundary (or located on the production frontier). Consequently, a smaller radial distance from the boundary to the $\mathrm{x}$ vector indicates a closer proximity and greater technical efficiency (Kumbhakar and Lovell, 2000; Morrison Paul and Nehring, 2005).

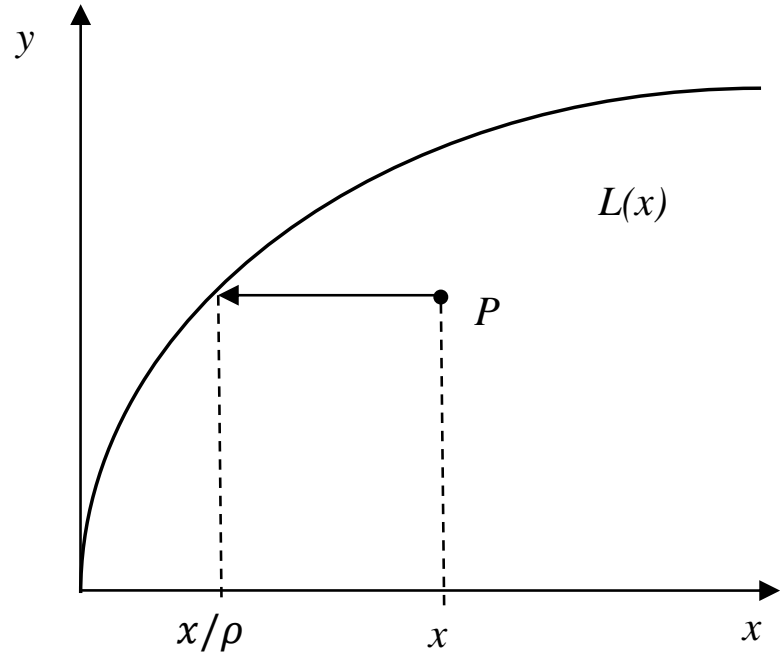

Panel A $(\mathrm{K}=1, \mathrm{M}=1)$

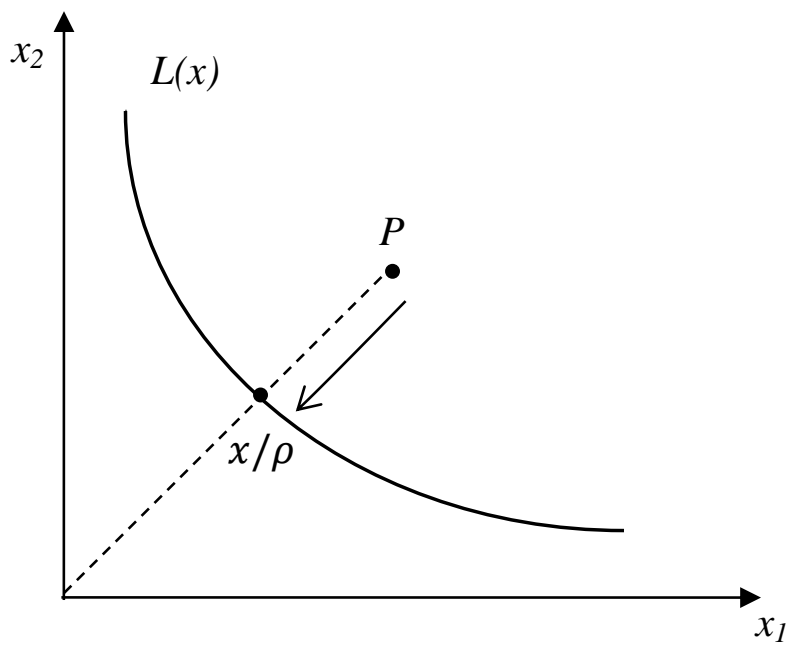

Panel B $(\mathrm{K}=2)$

Figure 1.2 Radial input distance function

The radial input distance function gives the maximum amount by which an input can be radially decreased and still remain producible with a given output vector. In panel A of Figure 2.1, scalar output $y$ can be produced with input $x$ at the producing point $\mathrm{P}$, but so can smaller input $(x / \rho)$, and so $D_{I}(x, y)=\rho>1$. In panel $\mathrm{B}$ of Figure 2.1, the output vector $\mathrm{y}$ is producible with input $x$, but so is the radially reduced input vector $(x / \rho)$ and so $D_{I}(x, y)=$ $\rho>1$ as well.

\subsubsection{Directional distance function}

The directional distance function measures the distance from the production unit to the efficiency boundary along with a directional vector. Given the directional vector, $g=$ $\left(-g_{x}, g_{y}\right)$ with $g_{x} \in R_{+}^{N}$ and $g_{y} \in R_{+}^{M}$, the inputs would be contracted and the outputs would 
be expanded, as described in Figure 1.3, when firm adjust the production behavior along the vector from producing point $\mathrm{A}$. Then, the directional distance function is given by

$$
\vec{D}\left(x, y ; g_{x}, g_{y}\right)=\sup \left\{\vartheta:\left(x-\vartheta g_{x}, y+\vartheta g_{y}\right) \in P\right\}
$$

where $\vec{D}\left(x, y ; g_{x}, g_{y}\right) \geq 0, \vartheta \in R$, which inherits all the properties from the directional distance function described in Chambers et al. (1998) and Färe et al. (2005). This property indicates the producer decreases the distance to the efficiency boundary by the scalar $\vartheta$, while the output is improved by $\vartheta g_{y}$ and the input is reduced by $\vartheta g_{x}$ simultaneously, as long as the technology is available. It is radial input distance function if $g_{y}=0$, when firm moves close to efficient frontier from point A to point B. It is radial output distance function if $g_{x}=0$, when firm moves the producing point from point $\mathrm{A}$ to point $\mathrm{C}$. As a result, the radial distance function is a special case of the directional distance function (Färe and Grosskopf, 2000).

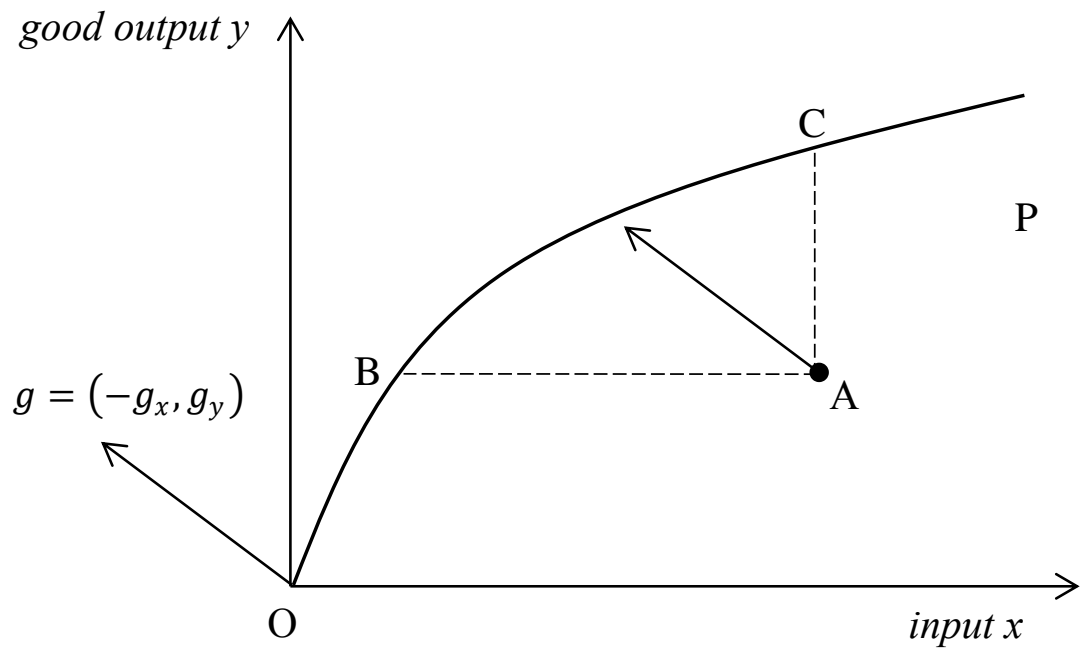

Figure 1.3 Directional distance function

The advantage of the directional output oriented distance function is that it allows us to expand the good output while contracting the bad output, assuming inputs are unchanged. As shown in Figure 1.4, by assuming point $\mathrm{A}$ is the production point of a household, then the household will improve production along the directional vector $g=\left(g_{y},-g_{b}\right)$, adding $\vartheta g_{y}$ to good output y, while subtracting $\vartheta g_{b}$ from the bad output b. 


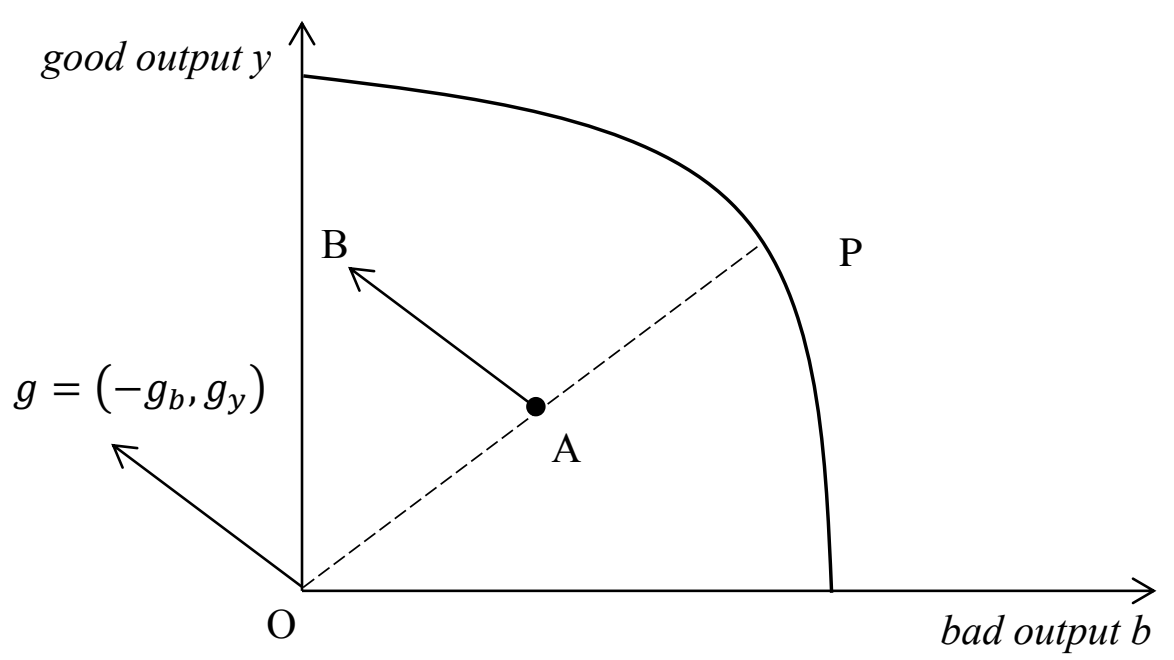

Figure 1.4 Directional output distance function

\subsection{Research area description}

The Sanjiangyuan region in China, known as "Three-River Headwaters" in English, is the region of China's Qinghai province which contains the headwaters of the Yellow River, the Yangtze River, and the Mekong River. The region includes - wholly or partially - Tanggula County and 16 counties of the four Tibetan Autonomous Prefectures Yushu, Guoluo, Hainan, and Haungnan. The Sanjiangyuan National Nature Reserve (SNNR) was legally established in May 2000. The establishment aims to protect the Tibetan Plateau ecosystem, with an emphasis on the alpine swamp meadow and the natural habitat of the unique wildlife in the region, as well as the promotion of sustainable economic development. SNNR is the second largest nature reserve in the world, in addition to being the world's highest and most extensive wetland protected area. It has a population of approximately 200000 people living within its $152300 \mathrm{~km}^{2}$, larger than the areas of England and Wales combined. The Sanjiangyuan region has a long reputation as being the "Water Tower of China". There may not be another area where three rivers all have their origins so close to each other (Figure 1.5). Although both the "Sanjiangyuan Ecological Protection Program" and "Return Pasture to Grassland" programs have been implemented as of 2003, overgrazing and the conflicts among people regarding grass and livestock still remain a significant problem in the Sanjiangyuan. 


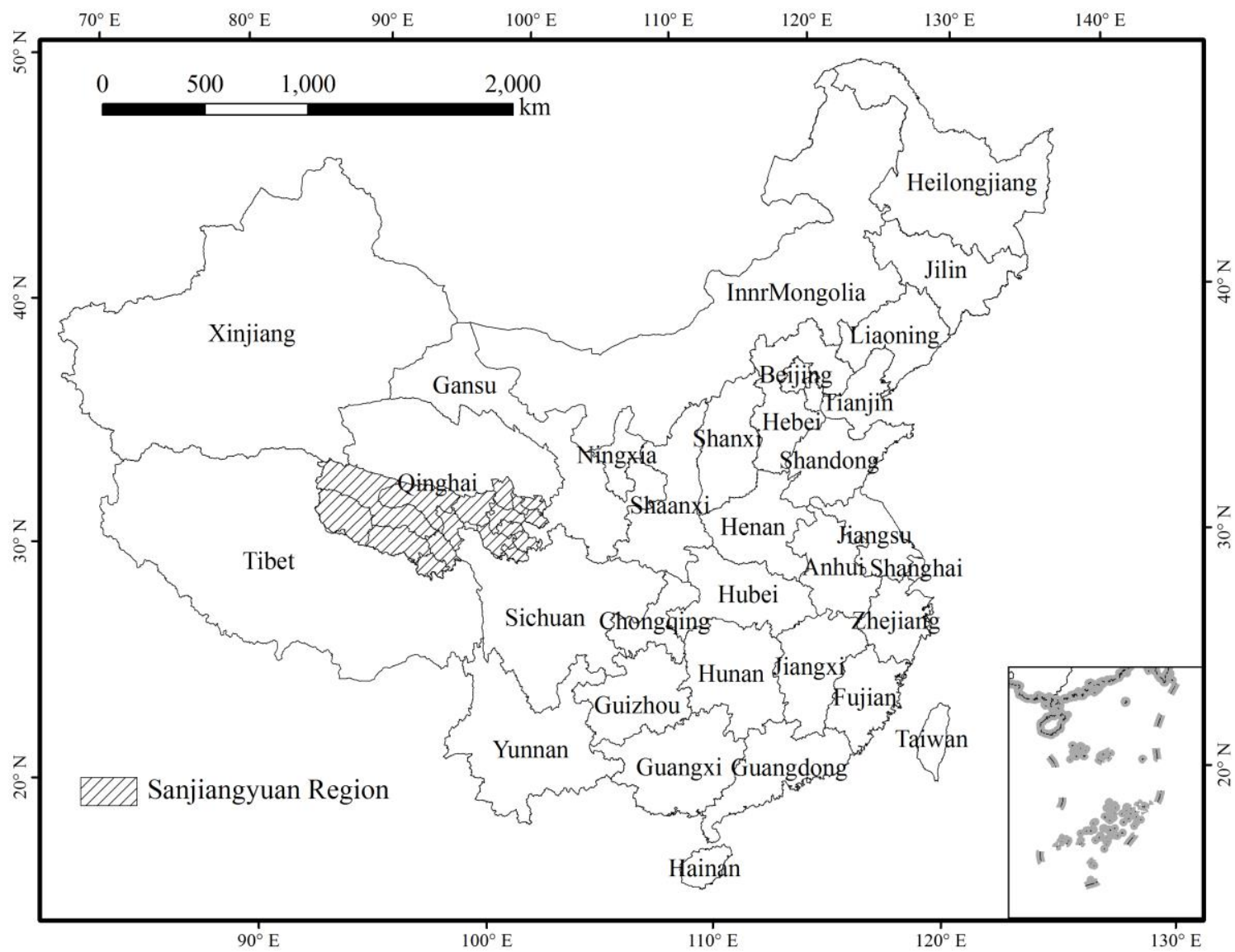

Figure 1.5 Location of the Sanjiangyuan region in China

The average income in the Sanjiangyuan region was about 2000 RMB (roughly \$350) in 2008, lower than the average of 2358RMB in Qinghai Province and 3587RMB in China, respectively. The arable area in the Sanjiangyuan Region is small, and no arable land exists the nine of the counties in the area (Table 1.1).

Table 1.1 Areas of counties in Sanjiangyuan region

\begin{tabular}{cccccc}
\hline County Name & Area $\left(\mathrm{km}^{2}\right)$ & Arable land $\left(\mathrm{km}^{2}\right)$ & County Name & Area $\left(\mathrm{km}^{2}\right)$ & Arable land $\left(\mathrm{km}^{2}\right)$ \\
\hline Henan County & 6997.4 & 0 & Chengduo County & 14744 & 1686 \\
Maqin County & 13307.04 & 44 & Jiuzhi County & 8708.2 & 0 \\
Zeku County & 6658.06 & 0 & Tongde County & 5001 & 3090 \\
Geermu City & 119174 & 2414.3 & Maduo County & 26541 & 0 \\
Banma County & 6138.66 & 455 & Zaduo County & 34170.8 & 0 \\
Yushu County & 17595.7 & 2302.8 & Xinghai County & 12182 & 3308.5 \\
Qumalai County & 47516 & 0 & Dari County & 14629.7 & 0 \\
Nangqian County & 12741 & 5333.3 & Zhiduo County & 93000 & 0 \\
Gande County & 7046 & 0 & & & \\
\hline
\end{tabular}

Data source: Qinghai Statistical Yearbook 2011 
Animal husbandry is the primary source of income, and many people are nomadic. With the exception of Geermu County, where the second industry is the primary GDP resource, the first industry values are primary source of GDP in other counties in Sanjiangyuan region (Figure 1.6). What's more, animal husbandry income mostly contributes to the value of the first industry, in comparison to forest, grain planting, fishing and service for agriculture, with the exception of Geermu County (Figure 1.7). As reported, Geermu County is the only county with no overgrazing.

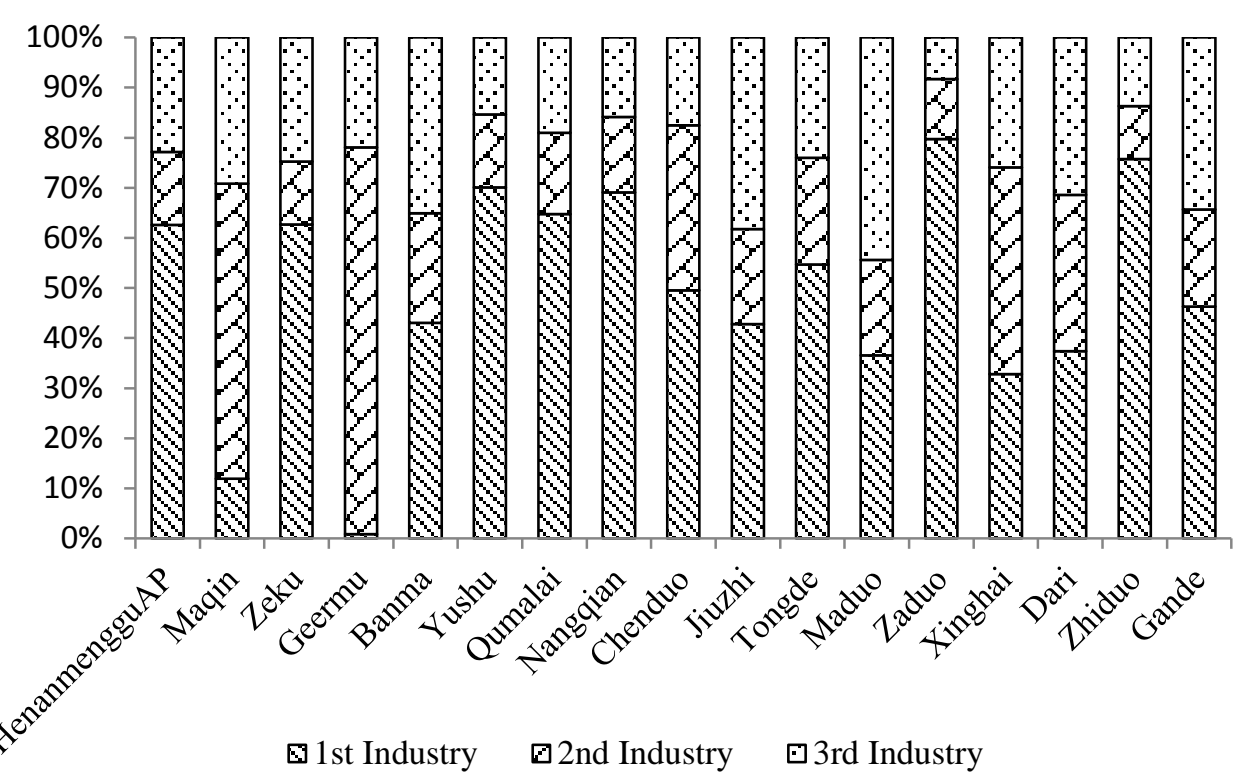

Data source: Qinghai Statistical Yearbook 2011

Figure 1.6 Percentages of 1st, 2nd, 3rd industry value of GDP in 2010

After the introduction of both the "Reform and Open Policy" and land policy reform, the economy has gradually shifted - starting in the 1980s - from a collective production system to an individual production system. Grassland was also allocated to individual households under a contract system with the government in most parts of Qinghai province. Grazing is done individually on open access land; the number of livestock is determined according to the individual farmers. Selling takes place through direct negotiations between farmers and livestock dealers. Traditional animal husbandry and original animal husbandry are the main forms of husbandry. "Summer full, Autumn fat, Winter thin and Spring dead" is still an accurate description of the vicious circle of animal husbandry: Low productivity rates and the serious wasting of resources both restrict pastoral income and the efficiency of animal husbandry in the Sanjiangyuan region 


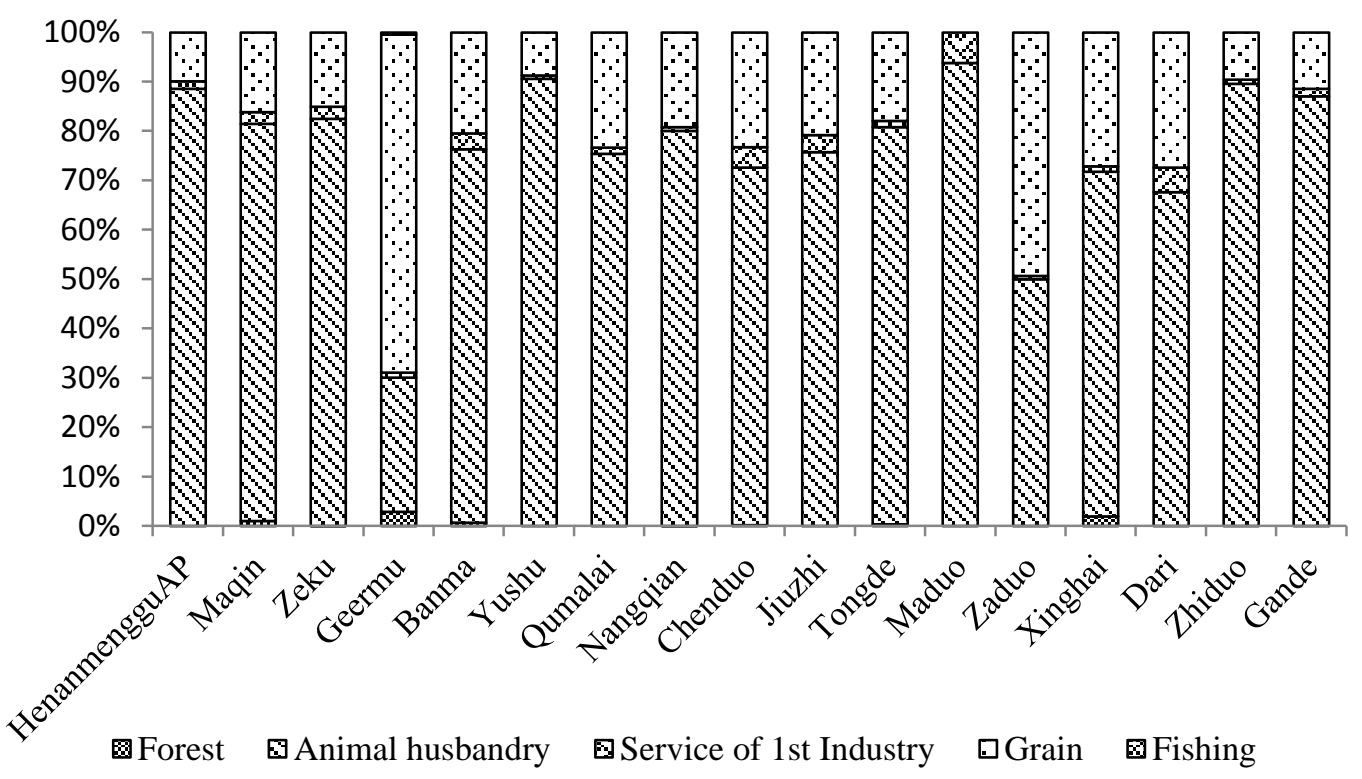

Data source: Qinghai Statistical Yearbook 2011

Figure 1.7 GDP of different sectors comprising 1st industry in 2010

Further statistics show that, when contrasted with comparable data from the 1980s, the growth height of alpine meadow in the 1990s dropped by $30 \%$ to $50 \%$ and the average yield declined by $20 \%$ to $60 \%$ - only in Qinghai province (Qin 2003). Zhou et al. (2006) reviewed the situation of alpine meadows in the Sanjiangyuan region. Results from field investigations revealed approximately $357 \times 10^{4}$ ha ( $34 \%$ of the entire study area) of degraded grassland in the area; heavily degraded grasslands covered $74 \times 10^{4}$ ha $(21 \%$ of the total degraded grassland area). Based on these results, long-term overgrazing was spotlighted as one of the principal factors thought to cause grassland degradation. Overgrazing was discovered in the Sanjiangyuan region after an analysis of temporal-spatial dynamics of grazing pressure during the period from 1988 to 2005 by Fan et al., (2011). Although the grazing pressure was steadily reduced, overgrazing was considered to be one of the main factors behind the degradation of the grassland ecosystem. In recent research, , overgrazing was found to still exist in the Sanjiangyuan region in 2010 (Zhang, Zhang and Liu et al., 2014). Combining the data from the field survey, it is clear that overgrazing is still a serious issue in the sample counties (Table 1.2). Furthermore, overgrazing status is highly correlated with grazing pressure. 
Table 1.2. Overgrazing status in the sample counties

\begin{tabular}{llll}
\hline \multicolumn{1}{c}{ Grazing status relate variable } & \multicolumn{2}{c}{ County } \\
\hline Proper carrying capacity (SU/km ${ }^{2}$ ) (Zhang, Zhang, Liu et al., 2014) & Tongde & Zeku & Maqin \\
Overgrazing ratio of 2010 (\%) (Zhang, Zhang, Liu et al., 2014) & 112.25 & 323.5 & 47.34 \\
Overgrazing ratio from 1988 to 2005 (\%) (Fan et al., 2010) & 600 & 500 & 300 \\
Overgrazing ratio from our field survey (\%) & 347 & 490 & 568 \\
\hline Note: The proper carry capacity is referred to Zhang, Zhang, Liu et al., 2014 & & &
\end{tabular}

\subsection{Research objective and research topic}

We analyze the productivity and efficiency of livestock grazing on the Qinghai-Tibetan Plateau using the radial output distance function, radial input distance function and directional output distance function to catch the policy-environment-livestock relationship.

\subsubsection{Research topic 1}

\section{Technical Efficiency and Impact of Grassland Property Right on Yak Production of China}

This research topic is presented in Chapter 2. Chapter 2 reviews the changes in grassland property rights and measures the productivity and efficiency of yak production on China's Qinghai-Tibetan Plateau. A cross sectional data set from a 2012 field survey of 197 yakrearing households is used to develop a stochastic translog distance function and technical inefficiency model; variables for livestock intensity and property rights are both incorporated. The overall average technical efficiency is estimated to be 0.618 , implying that yak production can be increased by $38.2 \%$ without any requirement for additional resources. This is lower than the value of 0.666 for households who have leased-in grassland from other households.

\subsubsection{Research topic 2}

\section{Incorporating Measures of Grassland Productivity into Efficiency Estimates for Livestock Grazing on the Qinghai-Tibetan Plateau in China}

Incorporating an ecological variable into the production function for the productive capacity of the grazing area available to a household is a new step toward conducting technical 
efficiency analysis for livestock producing households. This variable is generated using remotely sensed net primary productivity data (NPP) of available grassland area, and referred to as grassland total NPP. With the one-step approach of using a multi-output, multi-input stochastic input-oriented distance function based on field survey data combined with NPP and grassland area data, we estimate the productivity and technical efficiency of livestock grazing on the Qinghai-Tibetan Plateau. The estimations utilize two measurements related to ecological efficiency - the ecological performance indicator and the grassland total NPP efficiency. The average technical efficiency is estimated to be 0.837 when considering grassland productive capacity in terms of total NPP, implying that the cost of livestock grazing inputs can be decreased by $16.3 \%$ without any reduction in outputs. The average ecological performance indicator is estimated to be 0.013 , representing the effects in association with NPP. It is good to see the comparatively low total NPP capacity efficiency, which is about 0.123; this indicates that livestock grazing is under control without any overuse in terms of grassland area or NPP. The total NPP of the available grassland plays a significant role in the stochastic distance function and technical inefficiency model, but grassland total NPP tends to be less important for households with comparatively higher technical efficiencies. This research topic is presented in Chapter 3.

\subsubsection{Research topic 3}

\section{Productivity and Efficiency Analysis for Livestock Grazing under Grazing Pressure using Directional Distance Function}

With the use of first hand field survey data from 193 yak grazing households combined with remote sensing data for Net Primary Productivity (NPP) on the Qinghai-Tibetan Plateau, a directional output-orientation distance function is developed. The function uses four inputs grassland area, labor, capital and initial livestock stocking - and two outputs, good output of livestock grazing revenue and undesirable output of grazing pressure. The average technical efficiency is estimated to be 0.82 under the control of grazing pressure and the shadow price of grazing pressure to livestock revenue is estimated to be -1.8 . According to Morishima elasticity of substitution between inputs, there is a significant complementary relationship between grassland area, labor and capital. Elasticity of substitution between grassland and initial livestock stocking is estimated to be 0.50 . Grazing pressure is treated as an undesirable output of livestock grazing in the directional distance function for livestock grazing. This is a 
Chapter 1

new step in the general direction of better accounting for natural resource use/depletion in efficiency and production analysis. This research topic is mainly introduced in Chapter 4. 


\section{Chapter 2}

\section{Technical Efficiency and Impact of Grassland Property Right on Yak Production of China}

This paper reviews the changes in grassland property rights and measures the efficiency of yak production on China's Qinghai-Tibetan Plateau. A cross sectional data set from a 2012 field survey of 197 yak-rearing households is used to develop a stochastic translog distance function and technical inefficiency model; variables for livestock intensity and property rights are both incorporated. The overall average technical efficiency is estimated to be 0.62 , lower than the value of 0.67 found for households who have rented-in grassland. We found that renting-in grassland would improve the technical efficiency of livestock grazing and that both household size and livestock intensity have an effect on technical efficiency. 


\subsection{Introduction}

$\mathrm{T}$

The Qinghai-Tibetan Plateau is often described as the "Third Pole of the Earth" and "the Roof of the World", a place where both the ecology and the environment are crucially important (White et al., 2000; UNEP, 2005). However, research has shown that more than $50 \%$ of the grassland on the Qinghai-Tibetan Plateau has experienced varying degrees of degradation, e.g. reduced production, erosion, loss of species. This has resulted in grassland slowly losing the capacity to support livestock. Climatic change and overgrazing are perceived as two of the main causes of grassland degradation (Qin, 2003; Zhou et al., 2006; Akiyama and Kawamura, 2007; Li et al., 2007; Zhang, 2008). In the case of the QinghaiTibetan Plateau, a number of other causes have also been suggested, including a growth in the concentration of livestock in winter-spring pasture, a breakdown of traditional regulatory mechanisms such as reduced mobility due to restrictive pasture tenure (Richard, 2002; Foggin and Torrance-Foggin, 2011), and a lack of government investment in rangeland and livestock marketing infrastructure (Miller, 2006). All of these issues are closely related to local policies, especially grassland use rights. As a result, we are interested in researching the productivity and efficiency of yak production with an emphasis on the relationship between grassland property rights and livestock grazing.

The relationship between land property rights and agricultural productivity is not a new topic in China. After the Household Responsibility System (HRS) was introduced in China as part of a post-1978 reform, farmers were given the right to exchange, transfer, lease, and rent their land use rights. This change was treated as a huge social experiment of institution change (McMillan et al., 1989). Comparatively secure land property systems like the HRS can increase agricultural productivity in China. This is accomplished by increasing the incentives available to farmers so they are encouraged to make investments on their land and take more individual responsibility. The HRS can also facilitate the transfer of land resources to the more productive farmers (Gaynor and Putterman, 1993; Li et al., 1998; Deininger and Jin, 2005; Brümmer et al., 2006; Feng et al., 2010; Zhang et al., 2011; Deininger et al., 2014). The increase of land productivity due to privatization of land rights is a major research finding found not only in China, but also in other developing countries. A key example is Vietnam, where land titling provides farmers with greater incentives to invest in land improvements (Newman et al., 2015). Further evidence has been found in Guinea, where the land tenure form is correlated with farm level productivity (Chand and Yala, 2009), as well as other 
developing countries in Africa (Deininger and Jin, 2006; Deininger and Ali, 2008; Place, 2009; Abdulai and Goetz, 2011). At the same time, there are divergent results that show land property rights have no significant impact on productivity (Place and Peter Hazell, 1993). However, almost all the literature reviewed emphasizes cases of cropland or farming land; it is rare to find research which focuses on the relationship between grassland property and land productivity on China's Qinghai-Tibetan Plateau from an economic perspective.

Aside from research which focuses on the relationship between land productivity and land property rights, there are a number of publications which shed light on the total factor productivity growth and technical efficiency analysis for China (Fan, 1991; Huang and Rozelle, 1996; Zhang and Brümmer, 2011; Tian and Yu, 2012; Wang et al., 2013). Furthermore, there is some research about yak production in the central Asian highlands both on the Tibetan-Qinghai Plateau in China and in Nepal, as well as Kyrgyzstan with an animal sciences view (Brower and Dennis, 2000; Chertkov and Kasmaliev, 2000; Wangchuk and Wangdi, 2015). Productivity and efficiency analysis of livestock products or livestock husbandry are of interest worldwide (Paul et al., 2000; Brümmer and Loy, 2000; Latruffe et al., 2005; Weikard and Hein, 2011), especially concerning the issues of productivity and technical efficiency of the dairy industry in the Netherlands (Reinhard et al., 1999; 2002; Brümmer et al., 2002). However, to the best of our knowledge, few papers focus on livestock grazing in China from an agricultural economics perspective (Rae et al., 2006), and almost no research focuses on yak grazing in the Sanjiangyuan region on the Qinghai-Tibetan Plateau or even in the central Asian highlands.

The Sanjiangyuan region is one of the largest grassland areas in China, where livestock husbandry is the dominant source of income for households. Livestock husbandry income is the main contributor to primary industry GDP and yak is the dominant livestock species in this extensive grazing system (Qinghai Statistical Yearbook, 2011). From our data set, 96\% of all households rear yak. As a result, yak production is a good representation of livestock husbandry as a whole; this allows us to research livestock husbandry by looking at the productivity and technical efficiency of yak production. We aim to analyze the productivity and technical efficiency of yak production and inefficiency determinants by shedding light on the impact of grassland property rights. 
This paper is devoted to the productivity and efficiency analysis of yak production and the impact of grassland property rights on grassland leasing. A parametric, output-oriented stochastic distance function and technical inefficiency model are estimated by using data from 197 individual pastoral households collected from a field survey in 2012. We extend the current literature along the following lines: First, we use data from individual pastoral households to estimate the multi-input multi-output yak production technology of livestock grazing. Second, the distance function approach does not require behavioral assumptions, cost minimization, or profit maximization in order to provide a valid representation of the underlying production technology. This might be advantageous for the Sanjiangyuan region because the livestock husbandry there still relies on traditional nomadic pastoralism (Davies and Hatfield, 2007; Harris, 2010). Third, factors of grassland property rights and livestock intensities are incorporated into the classic stochastic translog distance function and technical inefficiency model to see how these pastoral characteristics affect production potential and the technical efficiency of extensive yak grazing production. We seek to develop a deeper understanding of the performance of pastoral yak grazing behavior to help anticipate and evaluate the impact of policy relating to grassland property rights.

The structure of the paper is as follows. Section 2.2 reviews grassland property rights and livestock ownership changes in the Sanjiangyuan region. Section 2.3 specifies the theoretical framework and empirical models. Section 2.4 contains data and statistical descriptions. The hypothesis tests and empirical model analysis results are presented in section 2.5 , followed by section 2.6 which concludes with discussions and grassland property policy implementation suggestions.

\subsection{Grassland property rights and livestock ownership changes}

Pastoralists have probably been raising livestock for 4000 years in the Sanjiangyuan region, northeast of the Qinghai-Tibetan Plateau. It is an area of traditional transhumant herding (Blench, 2001; Kreutzmann, 2013), where the grassland is divided into winter-spring pasture (winter pasture) and summer-autumn pasture ${ }^{1}$ (summer pasture). Herders use the summerautumn pasture for nomadic grazing from June to October while living in tents, and the

\footnotetext{
${ }^{1}$ Pasture is a more likely general terminology for grassland for livestock grazing, but in this paper, we use "grassland" for general grassland in the Sanjiangyuan region, and "pasture" for specific grassland of every household.
} 
winter-spring pasture from November to the following May for grazing while living in permanent homesteads. The institutional framework of livestock husbandry on the QinghaiTibetan Plateau has undergone fundamental changes in the past half century, from feudalism, through a collective period, to privatized livestock ownership in common accessed grassland, and finally to privatized livestock ownership with privatized exclusive access grassland use rights.

\subsubsection{Before 1949}

Before the foundation of the People's Republic of China, a feudalism-based social system was in place in the Sanjiangyuan region with land controlled by monasteries (including incarnate lamas), aristocracy, and government officials (including tribal leaders). These groups of leaders are sometimes referred to as the feudal landlords. Livestock, pastoral production materials and rangeland were controlled by the feudal lords. As rulers, the monasteries controlled most of the rangeland and livestock, with peasants hereditarily bound to grassland. For the government controlled grassland, pastoralists had to rent livestock and rangeland for their livelihood while the government levied taxies on them (Ma, 2007; Fan, 2008; Ma, 2012; $\mathrm{Li}$, 2012). During that time, natural features like mountain ridges and streams marked boundaries. There was no "common" pasture open to all and the gain or loss of pasture was dependent on the force of the landlords (Miller, 2006).

\subsubsection{9 - 1978}

Since 1949, the state has introduced profound changes in land tenure and the social organization of pastoral communities. In the 1950s, when land reform was being implemented throughout China, pasture was nationalized and ownership was transferred from the feudal lords to the collective or the state. However, during the early 1950s, the Sanjiangyuan region state government was too remote to act in its new ownership role so in practice, county governments took responsibility for allocating grassland use rights, which meant that formal changes in ownership did not seriously affect actual grassland use. When people's communes were established in the late 1950s and 1960s, the Sanjiangyuan region underwent political and economic reform. The people's commune time was described in Chinese as "chi da guo fan", literally "eat from the same wok", meaning that all pastoral households shared production materials, livestock, and grassland: They worked together and they ate together. Food and benefits were distributed evenly according to the number of people, no matter what their 
contribution was (Foggin and Torrance-Foggin, 2011; Ma, 2012; Li, 2012). The system resulted in decreased work incentives for herders and reduced the productivity of China's grasslands (Guo and Ma, 2005; Li and Huntsinger, 2011).

\subsubsection{Post 1978}

With the introduction of the HRS in the Chinese agriculture sector, the household was reestablished as the basic unit of production and decision-making in the early 1980s. The HRS model was copied from cropland to grassland in the Sanjiangyuan region in 1984 with the promulgation of China's Grassland Law in 1985 (Ma, 2007; Foggin and Torrance-Foggin, 2011; Li and Huntsinger, 2011). State or collectively owned livestock was divided into equal parts for each household or collective, according to the household or collective population size. Herders managed their own livestock with their own decisions, and households were entitled to residual income after meeting certain quotas and tax obligations (Banks, 2003; Banks et al., 2003). This was a form of household livestock privatization that still maintained state ownership of grassland. All livestock was privatized and could be grazed on state or collectively owned grassland. This was proposed to stimulate the herders to work hard and increase the livestock husbandry productivity in China. Unfortunately, the special case of livestock privatization in the Sanjiangyuan region led to a scenario of a grassland "tragedy of the commons" (Hardin, 1968; Foggin, 2000; Ma, 2007; Ma, 2012).

\subsubsection{Since 1994}

Starting in 1994, the second round of promulgation of the grassland HRS included regulations to contract grassland use rights to households. The grassland was inventoried and classified after the evaluation of the forage quality of different pasture. It was then divided and contracted to each household based on the household size and the number of livestock in each household. The grassland use rights allocation took a long time to accomplish, in contrast to the cropland HRS which was essentially accomplished overnight. The contractual duration of grassland use rights for state or collective owned grassland leased to households could be as long as 30 years, and in some special circumstances even 50 years. To accomplish the grassland use rights privatization procedure, households were required to fence the pasture and construct shelters for livestock and homes for nomads in their winter pasture site (in Chinese, "si pei tao"). These activities were undertaken on a large scale, with substantial government and donor investment in almost all pastoral areas in China (Miller, 2006; Foggin, 
2008; Cencetti, 2010). In our dataset, more than $60 \%$ of households have fenced pastures, livestock shelters, and plots for hay and forage production in the corrals.

\subsubsection{Currently}

There has been no institutional change in grassland property and livestock privatization rights since 1994. However, after the HRS was implemented on the Qinghai-Tibetan Plateau, and especially after the promulgation of the Law of the Rural Contracted Land in China in 2003, two new forms of pastoral management evolved within the private grassland use rights mechanism. Both of these cases were founded voluntarily and their members are usually relatives or friends. The first form was household cooperative groups. These groups use their summer-autumn grasslands collectively and fence them as a whole. Herders move livestock between pastures as a group, and young families or men in the group take care of their supervision, while others help each other to prepare yak hair and cut autumn hay. The second form is grassland use rights turnover or leasing. Some households rent grassland use rights by oral or written contract and the negotiated price is based on contract duration and grassland quality. Households are not required to report the grassland use rights leasing to the local government (Banks, 2003; Banks, et al. 2003; Richard et al., 2006; Li and Huntsinger, 2011; $\mathrm{Li}, 2012$ ). As shown by the data analysis in this paper, about $22.3 \%$ of householders rent-in grassland in the sample regions.

In this paper, we focus on grassland property rights using the variable of whether grassland is rented-in from other households and how the renting of grassland impacts technical efficiency. We expect the impact of renting-in grassland on technical efficiency to be positive, because we believe herders would choose the optimal beneficial production behavior given the permission of grassland use rights lease or turnover.

\subsection{Methodology and model specification}

A multi-input multi-output yak production function is developed in the livestock husbandry sector in order to measure the production performance of yak production and to examine the impact of renting-in grassland on yak production and technical inefficiency. The livestock grazing system on the Qinghai-Tibetan Plateau is extensive, suggesting that we should rely on an approach which does not require behavioral assumptions. We adopt the stochastic distance 
function approach instead of a deterministic approach in order to simultaneously accommodate random noise and systematic differences in technical efficiency.

\subsubsection{Conceptual framework}

The output distance function introduced by Shephard (1970) treats the inputs as given and looks at the potential proportional expansion of outputs, as long as the outputs are technologically feasible. Denoting a vector of inputs by $x=\left(x_{1}, \cdots, x_{K}\right) \in \mathfrak{R}^{K+}$ and a vector of outputs by $y=\left(y_{1}, \cdots, y_{M}\right) \in \mathfrak{R}^{M+}$, a feasible multi-input multi-output production technology can be defined using the output possibility set $P(x)$, which can be produced using the input vector $x: P(x)=\{y: x$ can produce $y\}$. This is assumed to satisfy the set of axioms depicted in Färe and Primont (1996). The output distance function is defined as: $D_{O}(x, y)=$ $\min \{\mu: y / \mu \in P(x)\}$.

Since an output distance function $\mathrm{D}_{\mathrm{o}}(x, y)$ is defined in terms of the output set $P(x)$, satisfying certain properties, the output distance function is required to satisfy analogous conditions. As noted by Lovell et al. (1994), $D_{O}(x, y)$ is non-decreasing, positively linearly homogeneous, convex in $\mathrm{y}$, and decreasing in $\mathrm{x}$. It should be clear from the definition and figures that $P(x)=\{y: x$ can produce $y\}$ and that on the iso-quant, $P(x)=\left\{y: D_{O}(x, y)=1\right\}$. If $D_{O}(x, y)<1$, then $(\mathrm{x}, \mathrm{y})$ belongs to the production set $P(x), D_{O}(x, y)<1$ if $y$ is located on the outer boundary of the output possibility set (Kumbhakar and Lovell, 2000).

In order to estimate the distance function in a parametric setting, a translog functional form is assumed. According to Coelli and Perelman (2000), the translog output distance function for the case of $\mathrm{k}$ inputs and $\mathrm{m}$ outputs is specified as:

$$
\begin{aligned}
\ln D_{o i}(x, y)= & \alpha_{0}+\sum_{m=1}^{M} \alpha_{m} \ln y_{m i}+\frac{1}{2} \sum_{m=1}^{M} \sum_{n=1}^{M} \alpha_{m n} \ln y_{m i} \ln y_{n i}+\sum_{k=1}^{K} \beta_{k} \ln x_{k i} \\
& +\frac{1}{2} \sum_{k=1}^{K} \sum_{l=1}^{K} \beta_{k l} \ln x_{k i} \ln x_{l i}+\sum_{k=1}^{K} \sum_{m=1}^{M} \delta_{k m} \ln x_{k i} \ln y_{m i}, \quad i=1,2, \cdots, T
\end{aligned}
$$


where $i$ denotes the $i_{\text {th }}$ household in the sample and $\mathrm{T}$ is the sample size. The restrictions required for linear homogeneity in outputs are:

$\sum_{m=1}^{M} \alpha_{m}=1, m=1,2, \cdots, M$,

$\sum_{m=1}^{M} \alpha_{m n}=0, m, n=1,2, \cdots, M$,

$\sum_{m=1}^{M} \delta_{k m}=0, k=1,2, \cdots, K$

and those required for symmetry are:

$\alpha_{m n}=\alpha_{m n}, m, n=1,2, \cdots, M$,

$\beta_{k l}=\beta_{l k}, k, l=1,2, \cdots, K$.

According to Lovell et al. (1994), the homogeneity implies that $D_{O}(x, \vartheta y)=\vartheta D_{O}(x, y)$, for any $\vartheta>0$. Hence, if we arbitrarily choose one of the outputs as the dominated output $y_{D}$, and set $\vartheta=1 / y_{D}$, we obtain $D_{O}\left(x, y / y_{D}\right)=D_{O}(x, y) / y_{D}$. For the translog form, this provides:

$$
\begin{aligned}
\ln \left(D_{o i}(x, y) / y_{D i}\right) & =\alpha_{0}+\sum_{m=1}^{M-1} \alpha_{m} \ln y_{m i}^{*}+\frac{1}{2} \sum_{m=1}^{M-1} \sum_{n=1}^{M-1} \alpha_{m n} \ln y_{m i}^{*} \ln y_{n i}^{*}+\sum_{k=1}^{K} \beta_{k} \ln x_{k i} \\
+ & \frac{1}{2} \sum_{k=1}^{K} \sum_{l=1}^{K} \beta_{k l} \ln x_{k i} \ln x_{l i}+\sum_{k=1}^{K} \sum_{m=1}^{M-1} \delta_{k m} \ln x_{k i} \ln y_{m i}^{*}
\end{aligned}
$$

where $y_{m}^{*}=y_{m} / y_{D}$ when $y_{m} \neq y_{D}^{2}$. This equation may be more concisely expressed as:

$\ln \left(D_{o i}(x, y) / y_{D i}\right)=T L\left(x_{k i}, y_{m i} / y_{D i}, \alpha, \beta, \delta\right)$

and hence $-\ln \left(y_{D i}\right)=T L\left(x_{k i}, y_{m i} / y_{D i}, \alpha, \beta, \delta\right)-\ln \left(D_{o i}(x, y)\right)$.

where $-\ln \left(D_{o i}(x, y)\right)$ corresponds to the radial distance function from the boundary. Hence we can set $u_{i}=\ln \left(D_{o i}(x, y)\right)$.

2 There is a possible endogeneity problem when using the distance function as the normalized output as the regressor might not be exogenous. We argue that the normalized output creates a mixed output vector, which should be assumed to be exogenous. Similar arguments are confirmed in page 95 of the book Stochastic Frontier Analysis (Kumbhakar and Lovell 2000). 
According to Aigner, Lovell and Schmidt (1977), the stochastic frontier model is obtained by adding a term $v_{i}$ to capture noise. Thus the stochastic output distance function is:

$-\ln \left(y_{D i}\right)=T L\left(x_{i}, y_{m i} / y_{D i}, \alpha, \beta, \delta\right)+v_{i}-u_{i}$

As usual, the $v_{i}$ term is assumed to be a two-sided random disturbance and is distributed as i.i.d. $N\left(0, \sigma_{v}^{2}\right), u_{i}$ is a random negative term derived from an independent distribution $N\left(\mu_{i}, \sigma_{u}^{2}\right)$, truncated above zero of the normal distribution with mean $\mu_{i}$ and variance $\sigma_{u}^{2}$ (Battese and Coelli, 1988; 1995; 1996; Coelli, 1995; Coelli and Battese, 1996). The mean $\mu_{i}$ is defined as:

$\mu_{i}=Z_{i} * \tau$

where $Z_{i}$ is a vector of explanatory variables associated with the technical inefficiency effects which could include socioeconomic and farm management characteristics. $\tau$ is a vector of unknown parameter to be estimated. MLE could be used to estimate the parameters of the stochastic output distance function given appropriate distributional assumptions for $v_{i}$ and $u_{i}$ (Aigner, Lovell and Schmidt, 1977).

The production frontier is specified as follows:

$\mathrm{y}_{i}=f\left(x_{i}, \beta\right) \cdot \exp \left(v_{i}-u_{i}\right)$

where, for all households indexed with a subscript $i$, the measure of technical efficiency of the $i_{t h}$ farm denoted by $\mathrm{TE}_{\mathrm{i}}$ is defined as the ratio of the observed output to the corresponding potential output, written as:

$T E_{i}=\frac{f\left(X_{i}, \beta\right) \cdot \exp \left(v_{i}-u_{i}\right)}{f\left(X_{i}, \beta\right) \cdot \exp \left(v_{i}\right)}=\exp \left(-u_{i}\right)=D_{o i}(x, y)$

The predicted value of the output distance $D_{o i}(x, y)$ is not directly observable because $u_{i}$ only appears as part of the composed error term $\varepsilon_{i}=v_{i}+u_{i}$. It may be obtained using the conditional expectation 
$D_{o i}=E\left(\exp \left(-u_{i}\right) \mid \varepsilon_{i}\right)=\frac{1-\Phi\left(\sigma_{A}-\gamma \varepsilon_{i} / \sigma_{A}\right)}{1-\Phi\left(\gamma \varepsilon_{i} / \sigma_{A}\right)} \exp \left(\gamma \varepsilon_{i}+\sigma_{A}^{2} / 2\right)$

where $\sigma_{A}=\sqrt{\gamma(1-\gamma) \sigma^{2}}, \sigma^{2}=\sigma_{v}^{2}+\sigma_{u}^{2}, \gamma=\sigma_{u}^{2} / \sigma^{2}$, and $\Phi(\cdot)$ represents the distribution function of a standard normal random variable. Once the parameters of model (2-1) are estimated, it is both interesting and easy to calculate the meaningful elasticity.

\subsubsection{Empirical specification}

In agricultural economics literature, output is frequently treated as a stochastic variable because of weather conditions, diseases, and other exogenous random forces. We assume that the decision variables are fixed in the short term and that the production level follows common and reasonable assumptions when estimating production relationships in agriculture. We therefore build the production frontier and auxiliary technical inefficiency model with a one-step approach.

$\mathrm{y}_{i}=f\left(x_{i}, \beta\right) \cdot \exp \left(v_{i}-u_{i}\right)$

where $\mathrm{y}_{\mathrm{i}}$ denotes the vector of outputs. The first output describes the output of yak production, denoted by the amount of yak meat produced in the year. The second output denotes the revenue of the other outputs, including the revenue of Tibetan sheep, milk, yak hide, Tibetan sheep wool, and so on. T describes the sample size, which is equal to 197 households in this study.

$x_{i}$ is a vector of inputs of grassland area, labor, household capital, and initial yak.

$\beta$ are technological parameters to be estimated for $x_{i}$.

$v_{i}$ is a random error term, independently and identically distributed as $N\left(0, \sigma_{v}^{2}\right)$. It is intended to capture events beyond the control of the herdsman.

$u_{i}$ is a non-negative random error term, independently and identically distributed as $N\left(\mu, \sigma_{u}^{2}\right)$, truncated above zero and intended to capture technical inefficiency in production. This is measured as the ratio of observed outputs to maximum feasible output. 
According to the conceptual framework described above, the translog functional form for the parametric distance function of yak production for the two outputs and four inputs is written as follows:

$$
\begin{aligned}
-\ln \left(y_{1 i}\right)=\alpha_{0} & +\alpha_{1} \ln \left(y_{2 i} / y_{1 i}\right)+\frac{1}{2} \alpha_{11} \ln \left(y_{2 i} / y_{1 i}\right) \ln \left(y_{2 i} / y_{1 i}\right)+\sum_{k=1}^{4} \beta_{k} \ln x_{k i} \\
& +\frac{1}{2} \sum_{k=1}^{4} \sum_{l=1}^{4} \beta_{k l} \ln x_{k i} \ln x_{l i}+\sum_{k=1}^{4} \delta_{k 1} \ln x_{k i} \ln \left(y_{2 i} / y_{1 i}\right)+v_{i}-u_{i}
\end{aligned}
$$

the empirical technical inefficiency model, as described in equation (2-7), is written in equation (2-11),

$\mu_{i}=z_{i} * \tau=\tau_{0}+\sum_{h=1}^{9} \tau_{h} z_{h i}$

where $z_{i}$ is a vector of explanatory variables associated with the technical inefficiency effects, including household size, variables relating to livestock intensity and variables relating to grassland property rights of renting-in grassland. These variables are described in more detail in the following section. We used the maximum likelihood estimation method to estimate the "one-step" model, which specifies both the stochastic frontier and technical inefficiency model.

\subsection{Data and descriptive statistics}

The Sanjiangyuan region in China, known as the Three-River Headwaters in English, is located on the northeastern Qinghai-Tibetan Plateau, where more than $90 \%$ of the local people are of Tibetan ethnic minority. It has long since been reputed to be the "Water Tower of China", containing the source of the Yellow River, the Yangtze River, and the Mekong River. The average elevation is between 3500 and 4800 meters. Like other parts of the Tibetan plateau, a cold season from around November to the following May and a warm season from June to October can be identified. The annual mean temperature is about 1-2 degrees Celsius, and the annual precipitation ranges from $600 \mathrm{~mm}$ to $800 \mathrm{~mm}$. The data used 
in this paper was drawn from field survey data in the Sanjiangyuan region in Qinghai province, recorded in August and October 2012 by the Center for Chinese Agricultural Policy (CCAP), part of the Chinese Academy of Sciences. The Sanjiangyuan region includes wholly or partially - 16 counties, with an area of $3.03 \times 10^{5} \mathrm{~km}^{2}$ and a population of $5.56 \times 10^{5}$. The weighted average ranking score for each county was calculated according to the ranking of pasture farm area per capita and GDP per capita to guarantee the selected counties can be representative of the Sanjiangyuan region in terms of economic development and grassland area size. We therefore selected the counties with the comparatively higher, middle, and lower scores as representative samples. The sample observation proportion was calculated to be 1:1:2 for these three counties, according to the total land area. Three towns from each county, one village from Tongde County and Zeku County, and two villages from Maqin County were picked at random. Within the villages, individual livestock husbandry households were sampled randomly. In total, our sample comprises 197 households.

The household data contains detailed information on livestock grazing including pasture information, market channels, forage use, labor demand, manure, chemical fertilizer, and health care for the livestock. Household-specific attributes were collected as well, such as home demographics, income from governmental subsidies, land use situation, household social relationships, household loans and credits, and household fixed property. For estimating the translog distance function, we have to decide between modeling more technical details by applying more inputs and running the risk of multi-collinearity on the one hand, or aggregating the inputs and sacrificing potentially useful information on the other hand. Classic inputs are aggregated into four categories (grassland area, labor, capital, and initial yak) and outputs are aggregated into two categories (yak meat and the revenue from the other outputs). Grassland area is the sum of the summer pasture area and the winter pasture area for each household. Labor consists of family labor, measured by person. Capital consists of productive machinery (irrigation equipment, transportation vehicles, and so on). It is calculated by summing up the individual items obtained from the questionnaires. Initial yak means the initial yak input at the beginning of the year and is calculated by multiplying the average weight of a yak by the number of yak per household. Output denotes the yak meat produced in the year, which is calculated by meat weight at the end of the year plus the sale weight of yak during the year, subtracting the initial number of yak. Output represents the revenue from other outputs, including the revenue from Tibetan sheep meat, output of milk, 
yak hide ${ }^{3}$, Tibetan sheep wool, and so on. Outputs, inputs, and farm-specific variables considered in this paper are described in Table 1.

Table 2.1 Summary of variables in the stochastic frontier and technical inefficiency model

\begin{tabular}{|c|c|c|c|c|}
\hline Variable & Unit & Symbol & Mean & Std. Dev. \\
\hline \multicolumn{5}{|l|}{ Continuous variables } \\
\hline Yak output & $1000 \mathrm{~kg}$ & $y_{1}$ & 5.69 & 6.93 \\
\hline Others revenue & 1000yuan & $y_{2}$ & 9.43 & 22.31 \\
\hline Grassland area & $\mathrm{mu}$ & $x_{1}$ & 938 & 1409 \\
\hline Labor & herd & $x_{2}$ & 2.30 & 1.27 \\
\hline Capital & 1000yuan & $x_{3}$ & 133.30 & 192.44 \\
\hline Initial yak at the beginning of 2011 & $1000 \mathrm{~kg}$ & $x_{4}$ & 7.91 & 11.58 \\
\hline Household size & herd & $z_{1}$ & 4.71 & 1.66 \\
\hline Livestock intensity of summer pasture & herd/mu & $z_{2}$ & 1.18 & 3.66 \\
\hline Livestock intensity of winter pasture & herd/mu & $z_{3}$ & 2.50 & 9.51 \\
\hline Dummy variables & & & No. of 1 & No. of 0 \\
\hline $\begin{array}{l}\text { Dummy variable pasture plot }(1=\text { the winter pasture and } \\
\text { summer pasture are different plots; } 0=\text { other })\end{array}$ & - & $z_{4}$ & 152 & 45 \\
\hline $\begin{array}{l}\text { Dummy variable of rented-in grassland ( } 1=\text { the household } \\
\text { has rented-in grassland; } 0=\text { not) }\end{array}$ & - & $z_{5}$ & 44 & 153 \\
\hline
\end{tabular}

Operational and farm-specific variables that were considered include a set of continuous values (e.g. household size, livestock intensity of summer pasture, livestock intensity of winter pasture) and dummy variables of whether the summer pasture and winter pasture are located in the same (or adjacent) plot. Household size denotes the number of persons in the household. Livestock intensity of summer pasture (winter pasture) is the average intensive degree of the sheep herd (equivalent unit) on the summer pasture (winter pasture), which is finally measured as the number of herds per mu of the year. The dummy variable of pasture plot means whether the summer pasture uses the same plot (or adjacent plots) for winter pasture. Generally speaking, the summer pasture is located far away from the fixed brick home, in deep mountainous regions or alongside a river; during that time the herder lives in a tent. In the cold season, herders move back to winter pasture, which is located near a fixed brick house in the nearest regional village or town. From our data set, 152 households have their summer and winter pastures in different location plots, while the remaining 45

\footnotetext{
${ }^{3}$ Yak hide is calculated by sold hide from slaughtered yak and other sold yak hides during this year, not including the hide from live yak in the inventory.
} 
households only use one pasture plot for both warm and cold seasons. There is an old saying, 'full in summer, fat in autumn, thin in winter and dead in spring' which accurately describes the extensive grazing system. Summer pasture is a critical source of high quality forage for livestock each year; generally speaking, the size of summer pasture area is likely to be larger than the winter pasture area, thus whether the summer pasture and winter pasture are located in the same (or adjacent plots) pasture plot would affect the livestock intensity in both summer and winter pasture. We have therefore introduced the dummy variable of pasture plot.

The important household specific variable we focus on is grassland use rights lease, a dummy variable which indicates whether grassland is rented-in. 44 households out of the 197 in our data set have rented-in grassland. The average grassland area for households who have rentedin grassland is $1643 \mathrm{mu}^{4}$, while the average grassland area for households who have not rented-in grassland is $734 \mathrm{mu}$. With the promulgation of the law on contracted land in rural areas in China since 2003, legal systems on land use rights lease or turnover started to be set up, although informal land use rights lease or turnover still occurred before the promulgation of the law.

With the release of an article on grassland use rights lease or turnover in Qinghai province in 2001 and a similar article on contracted grassland property rights lease or turnover in 2012 followed by the "New Three Grazing" policies for grassland (rest-grazing, prohibiting grazing, rotational grazing), grassland use rights lease or turnover became increasingly popular. This led to an adjustment of the industrial structure of animal husbandry and the transfer of surplus labor in rural regions of China.

According to field survey reports, grassland use rights lease or turnover started to be implemented over the last decade. The duration of grassland property rights lease or turnover generally lasts for around 10 to 20 years (Wu, 2012).

Because of the traditional pastoral system in the Sanjiangyuan region, we can see from our dataset that more than $99 \%$ of the pastures are natural pasture, and less than $1 \%$ are artificial. There is almost no input of chemicals, grass seeds, fertilizer, and pesticides to natural pasture. Thanks to the local policy for Tibetan households, both treatment and medicine for sick livestock are free. These are the primary reasons why there are no variables relating to grassland quality improvement and veterinary expenditure in this paper. According to grassland policy, the stocking rates or carrying capacity for pasture should be derived,

\footnotetext{
${ }^{4} \mathrm{mu}$, measurement unit of land area size in China, $1500 \mathrm{mu}=1 \mathrm{~km}^{2}$
} 
monitored, and enforced by local government. However, although official stocking rates or carrying capacity have been derived for some regions, they are not monitored or enforced by the state, village, or pasture groups (Banks, 2003). This is also the case in the Sanjiangyuan region, and the primary reason why we do not consider either a quota for livestock rates or carrying capacity limitation in this paper.

\subsection{Results}

\subsubsection{Hypothesis test of the rented-in grassland variable}

Before deciding on the specifications for the final version of the model, we considered further variables relating to household characteristics according to the literature. These included regional dummy variables concerning variation in household characteristics across the three counties, total direct subsidy from government to households, weather variables such as precipitation and temperature, nonproductive capital, educated status, and the grazing experience of the household head herder. We first estimate a model including all these variables according to literature and theory (Appendix table 2.1), and then we drop the least significant variable according to the likelihood ratio test and estimate the model again. This variable selection method is consistent with the general-to-specific modeling ${ }^{5}$ method (Hendry, 2000; Campos et al., 2005), widely used in applied econometrics for deciding on a model specification. This procedure is repeated until only significant variables that pass the likelihood ratio test at the $10 \%$ level remain.

We tested the hypothesis for the model specification and variable selection, e.g. whether to choose a Cobb-Douglass production function or translog production function and how variables in the technical inefficiency model are selected. The Likelihood ratio test is designed to examine the effect of rental of grassland use rights on technical inefficiency (Test 5 in Appendix table 2.2). The null hypothesis states that rental of grassland use rights has no effect on technical inefficiency; the likelihood ratio value is -138.41 with a degree of freedom of 27 , in comparison to the unlimited model which has a likelihood ratio value of -136.09 with degree of freedom of 28 . The null hypothesis was rejected, indicating that technical inefficiency is affected by whether or not grassland is rented-in from other households.

\footnotetext{
${ }^{5}$ General-to-specific modeling is also called "Gets modeling" or "Hendry's methodology" in literature.
} 


\subsubsection{Estimates for stochastic distance function}

Maximum likelihood estimates of the stochastic distance function are presented in Table 2.2. In order to facilitate the interpretation of the parameter estimates, the two output variables and the four input variables are divided by their respective sample means. Hence, the estimated first-order parameters of the translog production frontier can be interpreted as partial production elasticities at the sample mean (Brümmer et al., 2002). Model1 is the production function without specifying the technical inefficiency. In Model1, the sigma_u is estimated to be 0.81 and the squared sigma is estimated to be 0.69 , meaning that the variance in the household specific error term is greater than the variance in the stochastic error term. This result reveals that the one-sided random inefficiency component dominates the measurement error and other random disturbances. Model2 is the final model specification of the production function complete with the technical inefficiency. The overall model quality seems satisfactory, according to both likelihood ratio tests and statistics. Both Model1 and Model2 are estimated using the whole sample, while Model3 is given the same settings as Model2. The observations only include households who have rented-in grassland. All first order and second order coefficients of the inputs and second output have the expected sign, and estimated results meet the regularity conditions (Morey, 1986). 
Table 2.2 Estimates for stochastic distance function and technical inefficiency model

\begin{tabular}{|c|c|c|c|c|c|c|c|}
\hline \multirow{2}{*}{ Parameters } & \multirow{2}{*}{ Symbol } & \multicolumn{2}{|c|}{ Model1 } & \multicolumn{2}{|c|}{ Model2 } & \multicolumn{2}{|c|}{ Model3 } \\
\hline & & Coef. & Std. Err. & Coef. & Std. Err. & Coef. & Std. Err. \\
\hline \multicolumn{8}{|c|}{ Dependent variable: $\ln \left(y_{1}\right)$} \\
\hline Constant & $\alpha_{0}$ & $0.39 * * *$ & 0.10 & $0.34 * * *$ & 0.10 & $0.35 * * *$ & 0.11 \\
\hline $\ln \left(x_{1}\right)$ & $\beta_{1}$ & -0.12 & 0.07 & $-0.12 *$ & 0.07 & -0.08 & 0.15 \\
\hline $\ln \left(x_{2}\right)$ & $\beta_{2}$ & -0.13 & 0.11 & -0.14 & 0.11 & -0.09 & 0.09 \\
\hline $\ln \left(x_{3}\right)$ & $\beta_{3}$ & $-0.15^{* *}$ & 0.07 & $-0.15^{* *}$ & 0.07 & $-0.27 * * *$ & 0.08 \\
\hline $\ln \left(x_{4}\right)$ & $\beta_{4}$ & $-0.66 * * *$ & 0.07 & $-0.67 * * *$ & 0.07 & $-0.69 * * *$ & 0.04 \\
\hline $\ln \left(y_{2} / y_{1}\right)$ & $\alpha_{1}$ & 0.07 & 0.03 & $0.07 * *$ & 0.03 & 0.06 & 0.04 \\
\hline $0.5 \ln \left(x_{1}\right)^{2}$ & $\beta_{11}$ & $-0.10 * *$ & 0.05 & $-0.09 *$ & 0.05 & -0.06 & 0.17 \\
\hline $0.5 \ln \left(x_{2}\right)^{2}$ & $\beta_{22}$ & -0.42 & 0.30 & -0.42 & 0.30 & -0.31 & 0.03 \\
\hline $0.5 \ln \left(x_{3}\right)^{2}$ & $\beta_{33}$ & $-0.11^{*}$ & 0.07 & -0.10 & 0.07 & 0.01 & 0.04 \\
\hline $0.5 \ln \left(x_{4}\right)^{2}$ & $\beta_{44}$ & 0.01 & 0.07 & -0.02 & 0.07 & 0.00 & 0.00 \\
\hline $0.5 \ln \left(y_{2} / y_{1}\right)^{2}$ & $\alpha_{11}$ & 0.01 & 0.01 & 0.01 & 0.01 & 0.01 & 0.11 \\
\hline $\ln \left(x_{1}\right) \ln \left(x_{2}\right)$ & $\beta_{12}$ & -0.08 & 0.08 & -0.08 & 0.08 & -0.04 & 0.08 \\
\hline $\ln \left(x_{1}\right) \ln \left(x_{3}\right)$ & $\beta_{13}$ & -0.01 & 0.06 & -0.02 & 0.06 & -0.04 & 0.07 \\
\hline $\ln \left(x_{1}\right) \ln \left(x_{4}\right)$ & $\beta_{14}$ & $0.11 *$ & 0.06 & $0.12 * *$ & 0.06 & 0.08 & 0.11 \\
\hline $\ln \left(x_{2}\right) \ln \left(x_{3}\right)$ & $\beta_{23}$ & -0.07 & 0.08 & -0.05 & 0.08 & 0.02 & 0.09 \\
\hline $\ln \left(x_{2}\right) \ln \left(x_{4}\right)$ & $\beta_{24}$ & 0.08 & 0.08 & 0.08 & 0.07 & 0.07 & 0.05 \\
\hline $\ln \left(x_{3}\right) \ln \left(x_{4}\right)$ & $\beta_{34}$ & 0.04 & 0.05 & 0.04 & 0.05 & 0.01 & 0.02 \\
\hline $\ln \left(y_{2} / y_{1}\right) \ln \left(x_{1}\right)$ & $\delta_{11}$ & 0.00 & 0.01 & 0.00 & 0.01 & 0.01 & 0.02 \\
\hline $\ln \left(y_{2} / y_{1}\right) \ln \left(x_{2}\right)$ & $\delta_{21}$ & $0.04 * *$ & 0.02 & $0.04 * *$ & 0.02 & $0.04 * *$ & 0.02 \\
\hline $\ln \left(y_{2} / y_{1}\right) \ln \left(x_{3}\right)$ & $\delta_{31}$ & -0.01 & 0.01 & -0.01 & 0.01 & $-0.03 * *$ & 0.01 \\
\hline $\ln \left(y_{2} / y_{1}\right) \ln \left(x_{4}\right)$ & $\delta_{41}$ & 0.01 & 0.01 & 0.01 & 0.01 & 0.00 & 0.11 \\
\hline \multicolumn{8}{|l|}{$\operatorname{lnsig} 2 v$} \\
\hline Constant & & $-3.00 * * *$ & 0.38 & $-2.86 * * *$ & 0.35 & $-2.73 * * *$ & 0.376 \\
\hline \multicolumn{8}{|l|}{$\ln \operatorname{sig} 2 \mathrm{u}$} \\
\hline Constant & $\omega_{0}$ & $-0.44 * * *$ & 0.17 & $-1.05 * * *$ & 0.33 & $-1.34 * * *$ & 0.43 \\
\hline Household size & $\omega_{1}$ & & & $0.20 * *$ & 0.09 & $0.33 * * *$ & 0.11 \\
\hline $\begin{array}{l}\text { Livestock intensity of } \\
\text { summer pasture }\end{array}$ & $\omega_{2}$ & & & -0.02 & 0.03 & -0.07 & 0.07 \\
\hline $\begin{array}{l}\text { Livestock intensity of } \\
\text { winter pasture }\end{array}$ & $\omega_{3}$ & & & -0.02 & 0.02 & -0.02 & 0.02 \\
\hline $\begin{array}{l}\text { Dummy variable of pasture } \\
\text { plot }\end{array}$ & $\omega_{4}$ & & & $0.74 * *$ & 0.31 & $0.86 * *$ & 0.37 \\
\hline $\begin{array}{l}\text { Dummy variable of rent-in } \\
\text { grassland }\end{array}$ & $\omega_{5}$ & & & $-0.67 * *$ & 0.31 & & \\
\hline Sigma_v & & 0.22 & 0.04 & 0.24 & 0.04 & 0.26 & 0.05 \\
\hline Sigma_u & & 0.80 & 0.07 & & & & \\
\hline Sigma $^{2}$ & & 0.69 & 0.10 & & & & \\
\hline Lambda & & 3.59 & 0.10 & & & & \\
\hline \multicolumn{8}{|l|}{ Statistics } \\
\hline Number of observation & & 197 & & 197 & & 153 & \\
\hline Log likelihood & & -143.55 & & -136.09 & & -103.54 & \\
\hline Wald $\operatorname{chi}^{2}(20)$ & & 1128.65 & & 1100.21 & & 993.37 & \\
\hline Prob $>\mathrm{chi}^{2}$ & & 0.000 & & 0.000 & & 0.000 & \\
\hline
\end{tabular}

Notes: a. Statistically significant at levels of $* 0.10, * * 0.05$, and $* * * 0.01$. 2. Model 1 and Model 2 are estimated for all observed 197 households, while Model 3 is estimated for 153 households who don't have rent in-grassland. 
In model1, the distance function is specified without the technical inefficiency model. Two first orders of input capital and initial yak and the second order estimate of grassland area size are estimated to be statistically significant with expected signs. These are both consistent with estimations from the final specification of Model2. However, with the combination of the technical inefficiency model and production function in Model2, we can see that both first order and second order estimates of grassland area size are estimated to be statistically significant, in particular the second output is estimated to be statistically significant at the 5\% level. This is consistent with the finding that the total land area size could affect land holders' production decisions (Sauer et al., 2012). When considering the magnitude of elasticity at the sample mean, inputs of grassland area, capital, and initial yak along with the second output are all important for yak production. A partial production elasticity of -0.12 is observed for grassland area size, meaning that a $1 \%$ extension of grassland area will increase yak production by $0.12 \%$. The partial production elasticity of capital is estimated to be -0.15 , which means a $1 \%$ increase of capital will increase yak production by $0.15 \%$. The biggest partial production elasticity comes from initial yak input at the beginning of the year: -0.67 significance at the $1 \%$ statistical level. This is reasonable as the initial yak number at the beginning of the year is important for multi-year growth in animal grazing. All of the second order coefficients of the inputs have positive signs as expected, particularly the grassland area input, which is found to be statistically significant to the production.

\subsubsection{Estimates for the technical inefficiency model and the effect of grassland leasing-in}

The determinants for the variation of a household's technical inefficiency are estimated in the technical inefficiency model (lower part of Table 2.2). Because technical inefficiency is the dependent variable in the technical inefficiency model, a negative parameter coefficient for the variables indicates a negative effect on technical inefficiency, but a positive effect on technical efficiency. In terms of household size, the estimates of household size are significant in both Model2 and Model3, implying that household size is significant for technical inefficiency. The positive sign in the estimate of household size means that the bigger the household, the lower the technical efficiency. This can be explained as a larger household size would diffuse the attention or divert the energy of the household head from grazing, thus resulting in lower technical inefficiency. It is interesting to see both livestock intensity of summer pasture and winter pasture are negatively related to technical inefficiency, which 
means higher livestock intensity of pasture would increase the technical efficiency. Although livestock intensity is not statistically significant in Model2 and Model3, the dummy variable of pasture plot is estimated to be statistically significant. When the pasture plot dummy variable is equal to 1 , the locations of summer pasture and winter pasture are different. As a result, the estimated positive sign of the dummy variable in the technical inefficiency model means that different locations of summer and winter pasture would decrease the technical inefficiency of yak grazing. This can be understood by considering that different locations would increase the cost of moving yak grazing between the warm and cold seasons, as well as the added cost due to moving from a tent to a brick house. This may therefore result in technical inefficiency which could also contribute to the controversial discussion about the idea of forced sedentarization of nomads on the Qinghai-Titean Plateau and Central Asian Highlands (Kreutzmann, 2012).

The variable of interest which relates to grassland use rights lease or turnover is the dummy variable of whether the household has rented-in grassland. This is estimated to be significant at the $10 \%$ statistical level with -0.67 , indicating that renting-in grassland would affect the technical inefficiency: rent-in grassland would increase the technical efficiency of yak grazing. As we know, traditional regulatory mechanisms for seasonal nomadic extensive grazing were in use for about 4000 years on the Qinghai-Tibetan Plateau (Banks et al., 2003; Yan et al., 2005; Li and Huntsinger, 2011; Kreutzmann, 2013). This was also adapted to compensate for the arid and semiarid climatic pattern, especially on the high altitude of the Qinghai-Tibetan Plateau. Due to its location, the plateau is subject to high spatial and temporal variability in the distribution of rainfall as well as unpredictable climatic extremities such as droughts and snowstorms which have the potential to lead to a different distribution of forage. As a result, flexibility and mobility are important characteristics of yak grazing. With the grassland law promulgation and grassland household contract system implemented for the Sanjiangyuan grassland, grassland has been divided into small pieces and the usage rights of every piece of grassland are exclusive. Privatization of grassland use rights has weakened the pastoralist's ability to benefit from mobility. It has become more difficult to access water resources or to use better quality grassland if the pastoralist's own grassland lacks quality because of climatic disasters, thus resulting in an increased number of boundary conflicts. This shock stemming from the transition from traditional livestock husbandry to a modern production style is a challenge for yak grazing production in the region and may result in the reduction of the technical inefficiency. 


\subsubsection{Technical Efficiency}

After estimation of the stochastic distance function and technical inefficiency model, we calculate the technical efficiency for each household based on Model2. The average estimated technical efficiency for households in the Sanjiangyuan region is 0.62 (Table 2.3), indicating that on average, yak rearing households produced $62 \%$ of the potential output given the present state of technology and the input level. Therefore, the possibility of increasing yak production in the Sanjiangyuan region by an average of $38 \%$ can be achieved in the short term by adopting the practices of the best performing households. After splitting the whole sample into two groups according to the dummy variable of whether grassland is rented-in by the household, the average technical efficiency for households who rent-in grassland is 0.67 , higher than the average technical efficiency of 0.60 for households who don't rent-in grassland. This is consistent with estimates from the technical inefficiency model where the dummy variable of rent-in grassland rental status showed a statistically significant impact on technical inefficiency.

Table 2.3 Summary of estimated technical efficiency

\begin{tabular}{cccccc}
\hline Item & Obs. & Mean & Std. Dev. & Min. & Max. \\
\hline Technical efficiency (overall) & 197 & 0.62 & 0.19 & 0.01 & 0.94 \\
Technical efficiency (without rent-in grassland) & 153 & 0.60 & 0.19 & 0.01 & 0.94 \\
Technical efficiency (with rent-in grassland) & 44 & 0.67 & 0.18 & 0.16 & 0.92 \\
\hline
\end{tabular}

About $18.78 \%$ of households have a technical efficiency score greater than 0.80 (Figure 2.1), whereas $19.80 \%$ of households have efficiency scores greater than 0.70 and less than or equal to 0.80 . About $20.30 \%$ of households have efficiency scores more than 0.60 and less than or equal to $0.70,14.2 \%$ of the households have efficiency scores more than 0.50 and less than or equal to 0.60 , and $26.40 \%$ households operate with a technical efficiency score equal to or below 0.50 . In terms of kernel density distribution of technical efficiency, grouped by whether grassland is rented-in or not (Figure 2.2), we can see that the technical efficiency distribution is closer to the peak of kernel density for the group with rent-in grassland; furthermore, the density is distinctly higher for this group. 


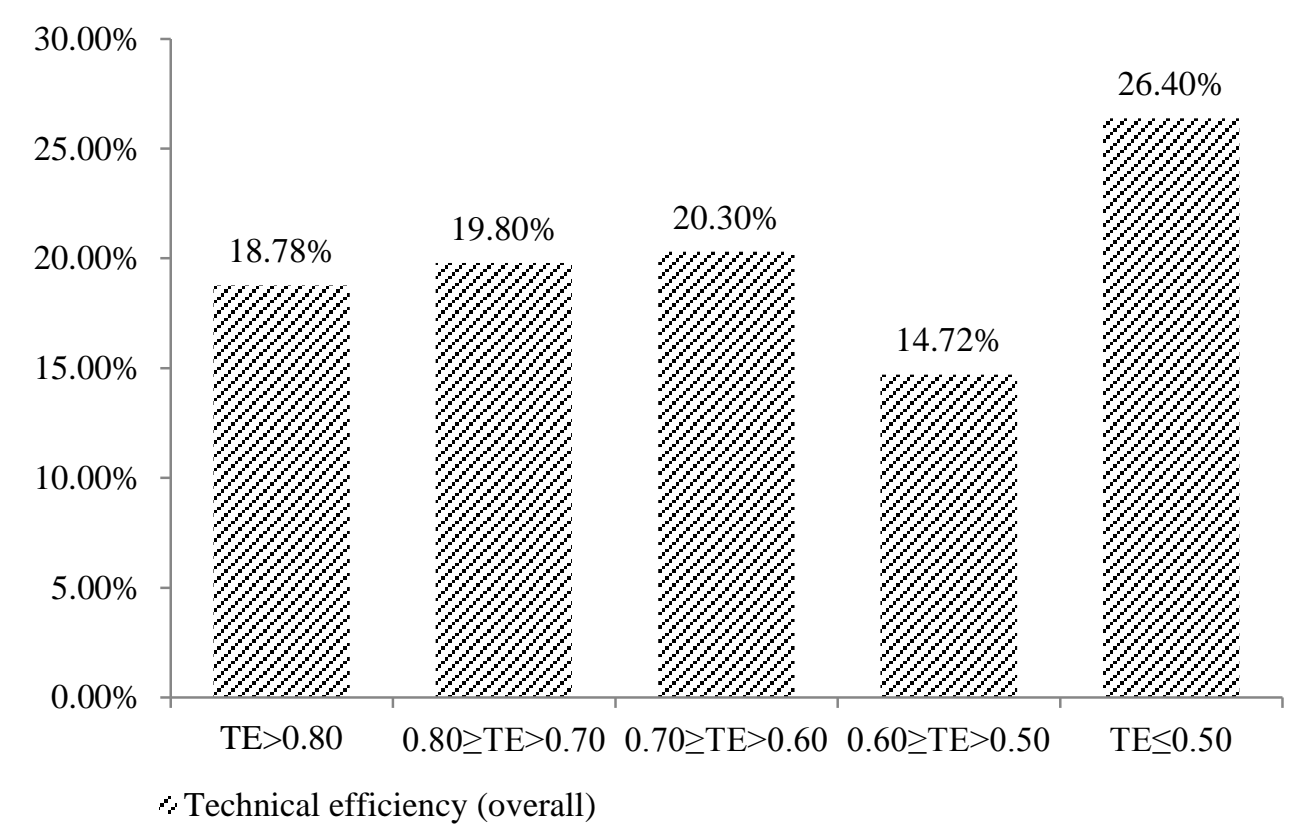

Figure 2.1 Range of overall technical efficiency

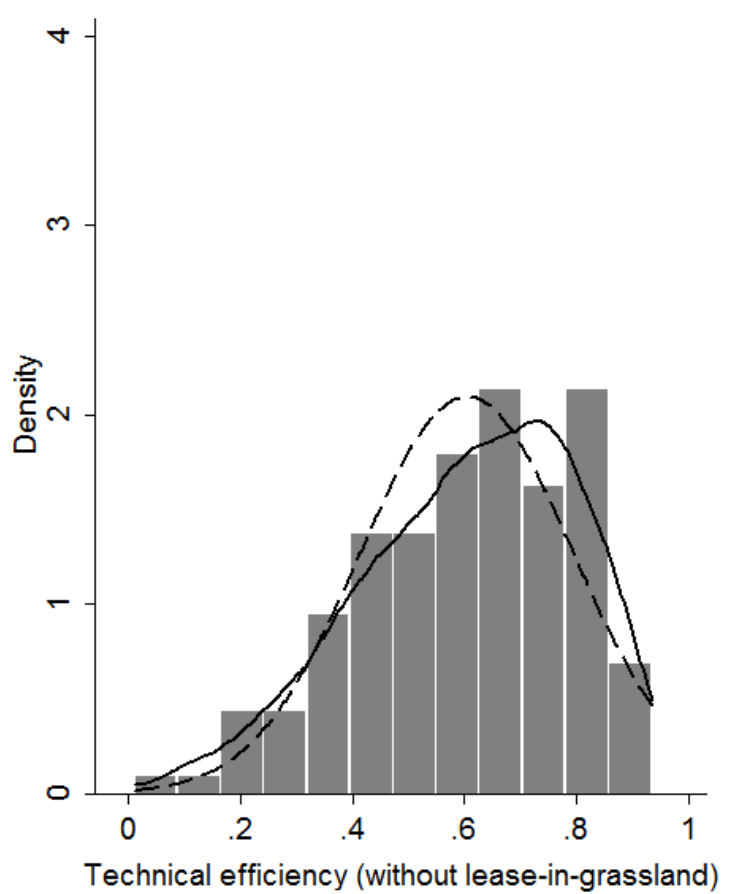

Kernel density

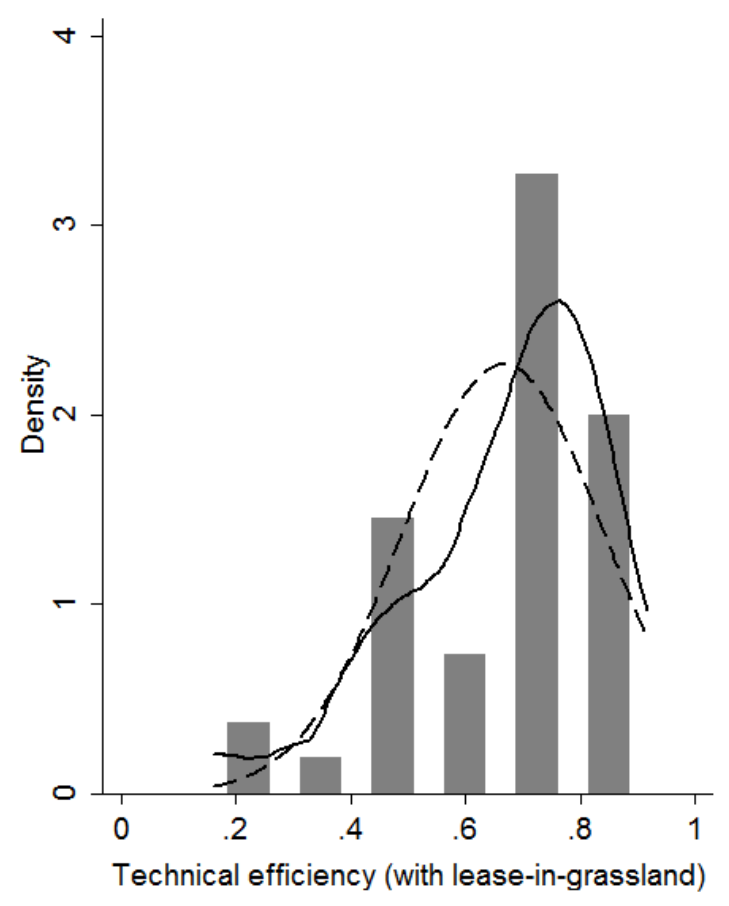

- - - Normal density

Figure 2.2 Distribution of technical efficiency grouped by dummy variable of rent-in grassland 


\subsection{Conclusion and discussion}

This paper reviews grassland property rights changes and highlights a new productivity and efficiency analysis for yak grazing in the Sanjiangyuan region on the Qinghai-Tibetan Plateau. An in-depth understanding of the performance of yak production and what factors determine technical inefficiency of yak grazing could help policy makers introduce more targeted rural development policies. The average technical efficiency of yak production is estimated to be 0.62 , implying that yak production can be increased by $38 \%$ without any additional resources given the current production input level.

We have found that whether grassland is rented-in has a clear impact on the technical inefficiency. Renting-in more grassland than originally assigned improves the technical efficiency of yak grazing. It seems that fragmented grasslands, when in small pieces, reduce the technical efficiency of livestock husbandry in the Sanjiangyuan region because of obstacles caused by grassland use rights privatization, e.g. difficulty of access to livestock drinking water, fuzzy boundaries, and obstacles to grazing mobility. This is also consistent with other research on alpine grasslands, grasslands in arid or semiarid regions, or grasslands in the Central Asian Highlands (Kreutzmann, 2013). An unclear definition of grassland use rights could also be behind the unsatisfactory outcome from the grassland HRS. By considering rented-in grassland as an example, a lack of investment on the rented-in area can lead to over grazing. The short term economic revenue goals of pastoralist households are in conflict with the government's long term sustainable development for ecological and environmental goals. China's policy makers should take into account various characteristics of different regions and the grassland property rights policy should be implemented appropriately.

The variables of livestock intensity of pasture play a significant role in yak grazing, especially the dummy variable of whether the summer pasture is located in the same plot as winter pasture. This might indicate that the government and household should pay more attention to pasture location distribution and grassland over-grazing. There is an assumption that the quality of yak meat is the same for different livestock age groups. This in turn implies that the estimates might be more reasonable if we were provided with data on the quality of yak meat. However, even if yak production is technically efficient, it may still lead to degradation of grasslands, thus there is a tradeoff between traditional livestock grazing production and 
ecological and environmental protection of grassland in the Sanjiangyuan region. This is due to the fact that the traditional livestock grazing production system relies on grassland area use; it is important to research how to improve production potential under the sustainable grassland use. Although our study has been limited to the Sanjiangyuan region, the issues discussed could be of relevance to a wider range of livestock grazing on the Qinghai-Tibetan Plateau, even extending to livestock grazing on the central Asian highlands as well as extensive grazing in Africa and Latin America. 


\section{Chapter appendix}

Appendix table 2.1 Original setting of production function and technical inefficiency model

\begin{tabular}{|c|c|c|c|c|c|}
\hline Parameters & Coef. & Std. Err. & Parameters & Coef. & Std. Err. \\
\hline Stochastic distance function & & & Technical inefficiency model & & \\
\hline Dependent variable: $\ln (y 1)$ & & & Dependent variable: $\ln s i g 2 u$ & & \\
\hline Constant & 0.31 & 0.10 & Constant & $-1.42 * *$ & 0.66 \\
\hline $\ln \left(x_{1}\right)$ & -0.09 & 0.08 & Dummy of education & -0.15 & 0.39 \\
\hline $\ln \left(x_{2}\right)$ & $-0.19 *$ & 0.11 & Subsidy & 0.00 & 0.01 \\
\hline $\ln \left(x_{3}\right)$ & $-0.16^{* *}$ & 0.08 & Nonproductive capital & 0.00 & 0.00 \\
\hline $\ln \left(x_{4}\right)$ & $-0.68 * * *$ & 0.07 & Household size & $0.23 * *$ & 0.10 \\
\hline $\ln \left(y_{2} / y_{1}\right)$ & $0.09 * * *$ & 0.03 & Grazing experience & -0.01 & 0.01 \\
\hline $0.5 \ln \left(x_{1}\right)^{2}$ & $-0.09 *$ & 0.05 & Distance to summer pasture & 0.01 & 0.01 \\
\hline $0.5 \ln \left(x_{2}\right)^{2}$ & -0.39 & 0.31 & Grassquality & 0.80 & 1.57 \\
\hline $0.5 \ln \left(x_{3}\right)^{2}$ & -0.09 & 0.07 & $\begin{array}{l}\text { Summer pasture grazing month in } \\
2011\end{array}$ & 0.07 & 0.10 \\
\hline $0.5 \ln \left(x_{4}\right)^{2}$ & -0.02 & 0.07 & Summer pasture area & -0.23 & 0.36 \\
\hline $0.5 \ln \left(y_{2} / y_{1}\right)^{2}$ & $0.01 *$ & 0.01 & Winter pasture area & 0.44 & 0.35 \\
\hline $\ln \left(x_{1}\right) \ln \left(x_{2}\right)$ & -0.08 & 0.08 & $\begin{array}{l}\text { Years of having accessed using } \\
\text { rights of the pasture }\end{array}$ & -0.02 & 0.02 \\
\hline $\ln \left(x_{1}\right) \ln \left(x_{3}\right)$ & -0.02 & 0.06 & Dummy variable of pasture plot & 0.71 & 0.44 \\
\hline $\ln \left(x_{1}\right) \ln \left(x_{4}\right)$ & $0.13 * *$ & 0.06 & $\begin{array}{l}\text { Livestock intensity of summer } \\
\text { pasture }\end{array}$ & 0.00 & 0.04 \\
\hline $\ln \left(x_{2}\right) \ln \left(x_{3}\right)$ & -0.07 & 0.08 & $\begin{array}{l}\text { Livestock intensity of winter } \\
\text { pasture }\end{array}$ & -0.01 & 0.02 \\
\hline $\ln \left(x_{2}\right) \ln \left(x_{4}\right)$ & 0.06 & 0.07 & $\begin{array}{l}\text { Dummy variable of rent-in } \\
\text { grassland }(1=y e s ; 0=\text { no })\end{array}$ & $-0.85^{* *}$ & 0.38 \\
\hline $\ln \left(x_{3}\right) \ln \left(x_{4}\right)$ & 0.04 & 0.05 & Temperature in January 2011 & 0.01 & 0.02 \\
\hline $\ln \left(y_{2} / y_{1}\right) \ln \left(x_{1}\right)$ & 0.01 & 0.01 & Precipitation in January 2011 & -0.02 & 0.03 \\
\hline $\ln \left(y_{2} / y_{1}\right) \ln \left(x_{2}\right)$ & $0.04 * * *$ & 0.02 & Dummy of county1 & 0.39 & 0.64 \\
\hline $\ln \left(y_{2} / y_{1}\right) \ln \left(x_{3}\right)$ & -0.01 & 0.01 & Dummy of county3 & 0.53 & 0.57 \\
\hline $\ln \left(y_{2} / y_{1}\right) \ln \left(x_{4}\right)$ & 0.01 & 0.01 & sigma_v & 0.25 & 0.04 \\
\hline $\ln \operatorname{sig} 2 v$ & & & Prob. $>$ chi $2=0.000$ & \multicolumn{2}{|c|}{ Wald $\operatorname{chi}^{2}(20)=909.05$} \\
\hline Constant & $-2.79 * * *$ & 0.33 & Log likelihood = -132.41 & \multicolumn{2}{|c|}{ Number of obs. $=197$} \\
\hline
\end{tabular}

Notes: Here we describe the variables not mentioned in the main text. Dummy of education (-, no measurement unit) is the dummy variable of whether the household head has been educated. Subsidy (1000yuan) means a direct subsidy received from government. Nonproductive capital (yuan) is capital wealth not related to production. Grazing experience (year) means how many years the household has been grazing. Distance to summer pasture $(\mathrm{km})$ measures the distance from the fixed home to the summer pasture. Grass quality $(\%)$ means the percentage of the grass that can be eaten by animals in the summer pasture. Summer pasture grazing month (month) in 2011 denotes the number of months that the summer pasture could be used for grazing in 2011. Summer pasture area (1000mu) is the area size of the summer pasture. Winter pasture area $(1000 \mathrm{mu})$ is the area size of the winter pasture. Years of having accessed using rights of the pasture (year) denotes how many years the household has had access to the specific location of the pasture. Temperature in January $2011\left(0.1^{\circ} \mathrm{C}\right)$ is the average temperature in January and precipitation in January $2011(0.1 \mathrm{~mm})$ indicates precipitation in January 2011. Dummy of county1(-) means dummy variable of whether the household is administratively in Zeku County, and Dummy of county3(-) means whether the household is administratively in Maqin County. 
Appendix table 2.2 Hypothesis tests for model specification and statistical assumptions

\begin{tabular}{|c|c|c|c|c|c|}
\hline Test & Null hypothesis & Log-likelihood value & D.F. & AIC & BIC \\
\hline \multicolumn{6}{|c|}{ For selection of production function (without setting technical inefficiency model) } \\
\hline \multirow{2}{*}{1} & $\mathrm{H}_{0}$ : Cobb-Douglass production function & -154.64 & 8 & 325.28 & 351.54 \\
\hline & $\mathrm{H}_{1}:$ Translog production function & -143.55 & 23 & 333.10 & 408.62 \\
\hline \multicolumn{6}{|c|}{ Testing for specification of technical inefficiency model } \\
\hline & $\mathrm{H}_{1}$ : Unlimited model & -136.09 & 28 & 328.19 & 420.12 \\
\hline 2 & $\mathrm{H}_{0}$ : No technical inefficiency & -143.55 & 23 & 333.10 & 408.62 \\
\hline 3 & $\mathrm{H}_{0}: \omega_{1}=0$ & -138.89 & 27 & 331.77 & 420.42 \\
\hline 4 & $\mathrm{H}_{0}: \omega_{2}=\omega_{3}=\omega_{4}=0$ & -139.29 & 25 & 328.57 & 410.65 \\
\hline 5 & $\mathrm{H}_{0}: \omega_{5}=0$ & -138.41 & 27 & 330.82 & 419.47 \\
\hline 6 & $\begin{array}{l}\mathrm{H}_{0} \text { : Coefficients of four inputs and the } \\
\text { second output in technical inefficiency are } 0 .\end{array}$ & -132.78 & 33 & 331.55 & 439.90 \\
\hline
\end{tabular}




\section{Chapter 3}

\section{Incorporating Measures of Grassland Productivity into}

\section{Efficiency Estimates for Livestock Grazing on the}

\section{Qinghai-Tibetan Plateau in China}

Incorporating an ecological variable for the productive capacity of the grazing area available to a household into the production function is a new step toward conducting technical efficiency analysis for livestock producing households. This variable is generated using remotely sensed net primary productivity data (NPP) and available grassland area, and referred to as grassland total NPP. We estimated the productivity and technical efficiency of livestock grazing on the Qinghai-Tibetan Plateau, using two measurements related to ecological efficiency, the ecological performance indicator and the grassland total NPP efficiency. The average technical efficiency is estimated to be 0.837 when considering grassland productive capacity in terms of total NPP, implying that the cost of livestock grazing inputs can be decreased by $16.3 \%$ without any reduction in outputs. The average ecological performance indicator is estimated to be 0.013 , representing the effects in association with NPP. It is good to see the comparatively low total NPP capacity efficiency, which is about 0.123 , meaning livestock grazing is under control, without overuse in terms of grassland area or NPP. The total NPP of the available grassland plays a significant role in the stochastic distance function and technical inefficiency model, but grassland total NPP tends to be less important for households with comparatively higher technical efficiencies. 


\subsection{Introduction}

$\mathrm{L}$ ivestock grazing is of importance worldwide economically but also for ecosystem services. Livestock production faces pressures from increasing demand for meat, food safety, and environmentally sound management (McDowell, 2008). Grassland production can produce meat with relatively little use of synthetic fertilizers, chemicals or water, but at the same time, overstocking can cause erosion through trampling and treading, as well as through decreased plant cover (Taboada et al., 2011). Although grasslands support livestock grazing and provide ecosystem services, three-quarters of the world's grazing lands have lost more than $25 \%$ of their capacity to support animals (White, et al., 2000; UNEP, 2005). The Sanjiangyuan grassland area is one of the biggest grassland areas in China. Located on the Qinghai-Tibetan Plateau, it has been heavily affected by overgrazing, inappropriate cultivation, and abuse from collection of fuel and medical plants (Akiyama, et al., 2003; 2006; Zhou, et al., 2006; Zhang, 2008). Similar conditions are found elsewhere on the QinghaiTibetan plateau, as well as in other central Asian highlands. Livestock grazing, of yaks, and Tibetan sheep, is the most widespread land use on the Qinghai-Tibetan Plateau and long-term overgrazing has been criticized as one of the principal problems. Annual loss of Net Primary Productivity (NPP) has been used to define land degradation (Nkonya et al., 2011). The potentially strong relationship between NPP decline and livestock grazing led to our interest in researching the productivity and technical efficiency of livestock grazing incorporating ecological factors, specifically, the productivity of grasslands.

"Eco-efficiency" and "environmental efficiency" have become heated topics within the field of productivity and efficiency analysis in the economics literature. These terms were developed to express the performance of ecological factors and environmental factors in meeting human demand (OECD, 1998; Huppes and Ishikawa, 2005). The formal definition of eco-efficiency can probably be attributed to the World Business Council for Sustainable Development (WBCSD) in the beginning of the 1990s (WBCSD, 1992). They described ecoefficiency as the ratio of reduced environmental impact to increased value of production. However, in the last 30 years, standardized definitions of ecological efficiency or environmental efficiency have failed to materialize. This has resulted in a range of empirical results, the origins of which can be divided into three main approaches. First, ecological efficiency is usually measured by environmental performance. Lots of empirical environmental methodologies have been proposed for measurement of the environmental 
performance of production units (Yaisawarng and Klein, 1994; Färe , et al., 1996; Tyteca, 1996; Picazo-Tadeo, et al., 2014). In the second approach, environmentally detrimental inputs and pollution may be treated as inputs into the production function (Pittman, 1981; Reinhard, et al., 1999; Reinhard, et al., 2000; Reinhard, et al., 2002). Third, environmentally detrimental effects may be treated as undesirable outputs, or "bad outputs", in the production function (Färe, et al., 1986, 1989, 2005; Van Ha, et al., 2008; Cuesta, et al., 2009; Picazo-Tadeo, et al., 2014). Both nonparametric (e.g. data envelope analysis, non-parametric hyperbolic distance function) and parametric approaches (e.g. distance function, directional distance function) have been used frequently in the measurement of ecological efficiency and environmental efficiency. In this chapter, we contribute to ecological efficiency analysis by incorporating an ecological variable into the production function, treating total net primary productivity of the available grassland as one input of the production function.

Typically land size is one of the necessary inputs in assessing agricultural crop farming or livestock farming. There are lots of research publications that use the size of the land area available to a household as one of the inputs, including for crop farming (Pascual, 2005; Brümmer, et al., 2006; Galdeano-Gómez and Céspedes-Lorente, 2008; Chen, et al., 2009; Zhang, et al., 2011; Asante, et al., 2014) livestock grazing, and dairy farming (Morrison Paul, et al., 2000; Brümmer, et al., 2002; Lansink, et al., 2002; Morrison Paul and Nehring, 2005; Otieno, et al., 2014; Sauer and Latacz-Lohmann, 2014). However, few chapters consider the heterogeneity of land quality as influenced by soil nutrients, soil type, or soil conservation (Reinhard, et al., 2002; Latruffe, et al., 2004; Bozoglu and Ceyhan, 2007; Hoang and Alauddin, 2012; Marchand, 2012; Rao, et al., 2012). To the best of our knowledge, even fewer chapters focuses on the ecological performance of livestock grazing, and take grassland quality into account for grazing on the Qinghai-Tibetan Plateau. As is characteristic in the grasslands of the Qinghai-Tibetan Plateau, the average pasture area is about 54 hectare for each grazing family; grassland quality is heterogeneous in terms of species diversity, vegetation biomass, soil nutrients and so on ( $\mathrm{Li}$, et al., 2013). Unlike dairy farming, where capital and human management play important roles in production potential, livestock grazing relies heavily on the grassland itself, especially in the case of extensive livestock grazing on unfertilized native grassland in the Qinghai Tibetan Plateau. Therefore, we consider both grassland area and grassland quality in this chapter, using grassland net primary productivity (NPP) is treated as representative of grassland quality. We refer to this combination as a measure of "total NPP capacity", which is equaled to be NPP per unit grassland multiplying grassland area. 
We extend the contribution of Reinhard et al. $(1999,2002)$ for environmental efficiency by incorporating the NPP of the available grassland as the input of grassland quality into the production function as well as available grassland size, and define the ecological performance indicator by comparing the technical efficiency estimated from a model that includes total NPP capacity and a model that incorporates only grassland area size. The stochastic inputoriented distance function with maximum likelihood estimate (MLE) estimation procedure is developed using household level data for livestock grazing. As there are a growing number of extension and policy programs designed to mitigate the impact of livestock grazing on the environment and social sustainability, the goal is a deeper understanding of the ecological performance of livestock grazing and to support the policies that help sustainable development of the regional environment.

The structure of the chapter is as follows. Section 3.2 presents the theoretical framework, methodology and empirical model specifications. Section 3.3 contains data and statistical descriptions. The empirical model analysis results are presented in section 3.4 , followed by section 3.5 which offers discussion and conclusions.

\subsection{Theoretical framework and methodology}

In order to estimate the technical efficiency, ecological performance indicator and total NPP efficiency of livestock grazing, a multi-input multi-output livestock husbandry production function incorporating the ecological variable as one of the inputs is developed. We estimate the stochastic frontier and technical inefficiency model first, derived from which we get the ecological performance indicator and total NPP capacity efficiency. As livestock grazing on the Qinghai-Tibetan Plateau still adopts a traditional seasonal nomadic pastoral system with rotational stocking (Davies and Hatfield, 2007; Harris, 2010), this might be advantageous for the distance function, not considering the price of inputs and outputs. Given the properties of the output distance function and the input distance function, we use an inputoriented stochastic distance function to address our research questions in this chapter, as traditional livestock husbandry on the Qinghai-Tibetan Plateau heavily relies on grassland area and grass quality and the input-oriented stochastic distance function sheds more light on the input of the total NPP of the grassland. We adopt the stochastic distance function approach instead of a deterministic approach because of the ability to separate random noise from the technical inefficiency term. 


\subsubsection{Conceptual framework}

We followed the distance function methodology developed by Shephard (1970), which treats the outputs as given and adjusts the input vectors as long as the input-output vectors are still technologically feasible in the input distance function. Defining herding households using input sets, $L(y)$, which represent the set of all input vectors, $x \in \mathfrak{R}^{K+}$, can be produced by output vector sets $y \in \mathfrak{R}^{M+}$, which can be written with the input possibility set $L(y)=$ $\{x: x$ can produce $y\}$. This is assumed to satisfy the set of axioms depicted by Färe (1996). The input distance is then defined in the input set, $L(y)$, as $D_{I}(x, y)=\sup \{\rho:(y / \rho) \in$ $L(y)\}$. The translog functional form is used by normalizing the function by one of the inputs, specified as

$$
\begin{aligned}
\ln \left(D_{I i}(x, y) / X_{D i}\right) & \\
= & \alpha_{0}+\sum_{k=1}^{K-1} \alpha_{k} \ln x_{k i}^{*}+\frac{1}{2} \sum_{k=1}^{K-1} \sum_{l=1}^{L-1} \alpha_{k l} \ln x_{k i}^{*} \ln x_{l i}^{*}+\sum_{m=1}^{M} \beta_{m} \ln y_{m i} \\
& +\frac{1}{2} \sum_{m=1}^{2} \sum_{n=1}^{2} \beta_{m n} \ln y_{m i} \ln y_{n i} \\
& +\sum_{k=1}^{K-1} \sum_{m=1}^{M} \delta_{k m} \ln x_{k i}^{*} \ln y_{m i}, i=1,2, \cdots, N
\end{aligned}
$$

where $x_{k i}^{*}=x_{k i} / x_{D i} \cdot x_{D i}$ means the input used for normalization. This equation may be more concisely expressed as:

$$
\ln \left(D_{I i}(x, y) / x_{D i}\right)=T L\left(x_{k i} / x_{D i}, y_{m i}, \alpha, \beta, \delta\right)
$$

Hence we set $u=\ln \left(D_{I i}(x, y)\right)$. According to Aigner, Lovell and Schmidt (1977), we get the stochastic frontier model by adding a term $v_{i}$ to capture noise. Thus, the stochastic output distance function is shown to be: $-\ln \left(x_{D i}\right)=T L\left(x_{k i} / x_{D i}, y_{m i}, \alpha, \beta, \delta\right)+v_{i}-u_{i}$, where $v_{i} \sim$ i.i.d. $N\left(0, \sigma_{v}^{2}\right)$ and $u_{i} \sim N\left(\mu_{i}, \sigma_{u}^{2}\right)^{+}, i=1,2, \cdots, N$.

The mean $\mu_{i}$ is defined as the technical inefficiency model,

$$
\mu_{i}=\tau_{0}+z_{i} * \tau_{i}
$$

where $z_{i}$ is a vector of explanatory variables associated with the technical inefficiency effects, as technical inefficiency related variables can overlap variables in the production function. 
We therefore introduce all the first order parameters' variables in the production function to the technical inefficiency model for better specification; more explicitly, $z_{i}$ includes not only household specific variables, but also variables in the production function (Battese and Broca, 1997; Wang and Schmidt, 2002). $\tau_{0}$ is the constant item of the technical inefficiency model, and $\tau_{i}$ is a vector of unknown parameter to be estimated (Battese and Coelli, 1988, 1995; Battese, et al., 1996; Coelli and Perelman, 2000). Maximum Likelihood Estimation (MLE) could be used to estimate the parameters (Aigner, et al., 1977).

Technical efficiency (TE) is defined as the ratio of the observed output to the corresponding potential maximum output, given the production frontier, specified as $\mathrm{y}_{i}=f\left(x_{i}, \beta\right) \cdot \exp \left(v_{i}-\right.$ $\left.u_{i}\right)$. Therefore the technical efficiency is written as in equation (3-4).

$$
T E_{i}=\frac{f\left(x_{i}, \beta\right) \cdot \exp \left(v_{i}-u_{i}\right)}{f\left(x_{i}, \beta\right) \cdot \exp \left(v_{i}\right)}=\exp \left(-u_{i}\right)=\frac{1}{\ln \left(D_{I i}(x, y)\right)}
$$

The ecological performance indicator (EPI) is defined as the difference between technical efficiencies obtained from the model, taking into account total grassland NPP capacity (both grassland area size and grassland quality), and the model only taking grassland area size into account (Färe, et al., 1993, 1996; Tyteca, 1997; Hailu and Veeman, 2000). The EPI is then written as follows:

$$
E P I_{i}=\frac{D_{I i}(x e c o, y)-D_{I i}(x, y)}{D_{I i}(x, y)}=\frac{T E_{i}(x e c o, y)-T E_{i}(x, y)}{T E_{i}(x, y)}
$$

$T E_{i}(x e c o, y)$ describes the technical efficiency calculated from the production function and technical inefficiency model considering total primary productive capacity of grassland, which is equaled to NPP per unit grassland multiplying grassland area size. $T E_{i}(x, y)$ means technical efficiency calculated from production function and technical inefficiency model only considering grassland area size, not taking into account NPP per unit grassland.

Total grassland NPP capacity efficiency (TNPPE) is defined as the ratio of the minimum feasible total grassland NPP capacity needed to the observed grassland total NPP capacity. This is conditional on observed levels of the other inputs and outputs (Reinhard, et al., 1999; 2000). 


$$
T N P P E_{i}=\frac{\text { input of min. feasible total NPP }}{\text { input of observed total NPP }}
$$

\subsubsection{Empirical model specification and estimation measurement}

Empirically, for livestock grazing on the Qinghai-Tibetan Plateau we set the unlimited functional form for the parametric distance function of livestock grazing as equation (3-7).

$-\ln \left(x_{4 i}\right)=\alpha_{0}$

$+\alpha_{1} \operatorname{lnTNPP_{i}^{*}}+\frac{1}{2} \alpha_{11}\left(\operatorname{lnTNPP} P_{i}^{*}\right)^{2}+\sum_{k=2}^{3} \alpha_{1 k} \ln x_{k i}^{*} \ln T N P P_{i}^{*}+\sum_{m=1}^{2} \delta_{1 m} \ln T N P P_{i}^{*} \ln y_{m i}$

$+\sum_{k=2}^{3} \alpha_{k} \ln x_{k i}^{*}+\frac{1}{2} \sum_{k=2}^{3} \sum_{l=2}^{3} \alpha_{k l} \ln x_{k i}^{*} \ln x_{l i}^{*}+\sum_{m=1}^{2} \beta_{m} \ln y_{m i}+\frac{1}{2} \sum_{m=1}^{2} \sum_{n=1}^{2} \beta_{m n} \ln y_{m i} \ln y_{n i}$

$+\sum_{k=2}^{3} \sum_{m=1}^{2} \delta_{k m} \ln x_{k i}^{*} \ln y_{m i}+v_{i}-u_{i}$

where $x_{k i}^{*}=x_{k i} / x_{4 i}, T N P P_{i}^{*}=T N P P_{i} / x_{4 i} \cdot \mathrm{y}_{\mathrm{m}}$ denotes the vector of outputs: $y_{1}$ describes the output of yak meat during the year and $y_{2}$ denotes the revenue of the other outputs, including the revenue of Tibetan sheep, milk, yak hide, sheep wool and so on. $x_{k}$ is a vector of inputs with $x_{1}=$ total NPP capacity of grassland (TNPP); in order to shed light on the total grassland net primary productive, we use TNPP instead of $x_{1}$ in equation (3-7), $x_{2}=$ labor, $x_{3}=$ household capital, $x_{4}=$ initial yak at the beginning of the year. In order to get the technical efficiency from the production function without incorporating the ecological effect of NPP, we replace TNPP as grassland area size $\left(x_{1}^{\prime}=\right.$ area $)$; in equation (3-8). 


$$
\begin{aligned}
-\ln \left(x_{4 i}\right)=\alpha_{0} & +\alpha_{1}^{\prime} \operatorname{lnarea}_{i}^{*}+\frac{1}{2} \alpha_{11}^{\prime}\left(\text { lnarea }_{i}^{*}\right)^{2} \\
& +\sum_{k=2}^{3} \alpha_{1 k}^{\prime} \ln x_{k i}^{*} \operatorname{lnarea}_{i}^{*}+\sum_{m=1}^{2} \delta_{1 m}^{\prime} \operatorname{lnarea} a_{i}^{*} \ln y \\
& +\sum_{k=2}^{3} \alpha_{k} \ln x_{k i}^{*}+\frac{1}{2} \sum_{k=2}^{3} \sum_{l=2}^{3} \alpha_{k l} \ln x_{k i}^{*} \ln x_{l i}^{*}+\sum_{m=1}^{2} \beta_{m} \ln y_{m i} \\
& +\frac{1}{2} \sum_{m=1}^{2} \sum_{n=1}^{2} \beta_{m n} \ln y_{m i} \ln y_{n i}+\sum_{k=2}^{3} \sum_{m=1}^{2} \delta_{k m} \ln x_{k i}^{*} \ln y_{m i}+v_{i}-u_{i}
\end{aligned}
$$

For the unlimited model, we remove both grassland related variables from the production function. More explicitly, we remove the TNPP related variables from equation (3-7) and remove grassland area size related variables from equation (3-8). We subsequently obtain the limited model, as showed in equation (3-9).

$$
\begin{aligned}
-\ln \left(x_{4 i}\right)=\alpha_{0} & \\
& +\sum_{k=2}^{3} \alpha_{k} \ln x_{k i}^{*}+\frac{1}{2} \sum_{k=2}^{3} \sum_{l=2}^{3} \alpha_{k l} \ln x_{k i}^{*} \ln x_{l i}^{*}+\sum_{m=1}^{2} \beta_{m} \ln y_{m i} \\
& +\frac{1}{2} \sum_{m=1}^{2} \sum_{n=1}^{2} \beta_{m n} \ln y_{m i} \ln y_{n i}+\sum_{k=2}^{3} \sum_{m=1}^{2} \delta_{k m} \ln x_{k i}^{*} \ln y_{m i}+v_{i}-u_{i}
\end{aligned}
$$

We get technical efficiency $T E_{i}(x e c o, y)$ from the MLE estimation of equation (3-7) where the production function incorporates the TNPP. In addition, technical efficiency $T E_{i}(x, y)$ is obtained from the estimation of the production function (3-8). We then calculate the ecological performance indicator as shown in equation (3-5).

For the estimation of TNPP efficiency, we assume that the producer would be most ecologically efficient when they use the minimum optimal amount of TNPP. The logarithm input oriented production function of an ecologically efficient producer is then obtained by replacing the observed TNPP and $u_{i}$ with $\overline{T N P P_{i}}$ and $\overline{u_{i}}$ respectively. The ecologically efficient livestock grazing function is then written as shown in equation (3-10), 


$$
\begin{aligned}
& -\ln \left(x_{4 i}\right)=\alpha_{0} \\
& +\alpha_{1} \ln \overline{T N P P_{i}^{*}}+\frac{1}{2} \alpha_{11}\left(\ln \overline{T N P P_{l}^{*}}\right)^{2}+\sum_{k=2}^{3} \alpha_{1 k} \ln x_{k i}^{*} \ln \overline{T N P P_{i}^{*}}+\sum_{m=1}^{2} \delta_{1 m} \ln \overline{T N P P_{l}^{*}} \ln y_{m i} \\
& +\sum_{k=2}^{3} \alpha_{k} \ln x_{k i}^{*}+\frac{1}{2} \sum_{k=2}^{3} \sum_{l=2}^{3} \alpha_{k l} \ln x_{k i}^{*} \ln x_{l i}^{*}+\sum_{m=1}^{2} \beta_{m} \ln y_{m i}+\frac{1}{2} \sum_{m=1}^{2} \sum_{n=1}^{2} \beta_{m n} \ln y_{m i} \ln y_{n i} \\
& +\sum_{k=2}^{3} \sum_{m=1}^{2} \delta_{k m} \ln x_{k i}^{*} \ln y_{m i}+v_{i}-u_{i}
\end{aligned}
$$

where $\overline{T N P P_{i}}$ means the optimal input and TNPP should be used for full ecological efficiency. Let equation (3-7) be equal to equation (3-10), allowing us to isolate the logarithm of total grassland NPP capacity efficiency (TNPPE) (denoted by equation 3-11) by using equation (3-12).

$$
\ln T N P P E_{i}=\ln \frac{\overline{T N P P_{i}}}{T N P P_{i}}=\ln {\overline{T N P P_{i}}}_{i}-\ln T N P P_{i}
$$

$\left.\frac{1}{2} \alpha_{11}\left[\left(\ln \overline{T N P P}_{i}\right)^{2}-(\operatorname{lnTNPP})_{i}\right)^{2}\right]+$

$$
\left(\alpha_{1}+\sum_{k=2}^{3} \alpha_{1 k} \ln x_{k i}^{*}+\sum_{m=1}^{2} \delta_{1 m} \ln y_{m i}\right)\left(\ln \overline{T N P P}_{i}-\ln T N P P_{i}\right)-\overline{u_{i}}+u_{i}=0
$$

Let $\mathrm{a}=\frac{1}{2} \beta_{11}, \mathrm{~b}=\alpha_{1}+\sum_{k=2}^{3} \alpha_{1 k} \ln x_{k i}^{*}+\sum_{m=1}^{2} \delta_{1 m} \ln y_{m i}, \mathrm{c}=-\overline{u_{i}}+u_{i}$, and let $\overline{u_{i}}=0$ by assuming the yak producer household would operate technically efficiently if they operate most NPP capacity efficiently ${ }^{61}$, therefore we can get the total net primary capacity efficiency (TNPPE) from the following equation.

$$
\ln T N P P E_{i}=\ln \frac{\overline{T N P P_{i}}}{T N P P_{i}}=\ln \overline{T N P P}_{i}-\operatorname{lnTNPP_{i}}=\frac{-b \pm \sqrt{b^{2}-4 a c}}{2 a}
$$

Finally, the grassland total NPP capacity efficiency ${ }^{7}$ is calculated as $T N P P E_{i}=e^{\operatorname{lnTNPPE}_{i}}$.

6 It is a strong assumption that the producer operates ecologically efficiently necessarily being technically efficiently, which is consistent with previous research in environmental efficiency analysis of Reinhard et al. (1999).

7 As for equation (3-13), we could get two TNPPE $E_{i}$ from $\operatorname{lnTNPPE} i=\frac{-b+\sqrt{b^{2}-4 a c}}{2 a}$ and $\operatorname{lnTNPPE} E_{i}=\frac{-b-\sqrt{b^{2}-4 a c}}{2 a}$ respectively. We take the first one for analysis in this chapter as it ranges between 0 and 1 . 


\subsection{Data and descriptive statistics}

Livestock grazing on the Qinghai-Tibetan Plateau depends on seasonally rotational system where a cold season from approximately November to the following May and a warm season from June to October can be identified. Herders graze on winter-spring pasture (winter pasture) and live in a fixed village brick house in the cold season, while they graze on summer-autumn pasture (summer pasture) and live in a tent in the warm season. We illustrate the translog input distance function by calculating the technical efficiency, ecological performance indicator and total grassland net primary productive capacity efficiency of grassland based on a set of 197 yak herder households from the Sanjiangyuan region The social-economic data was drawn from field survey questionnaires conducted by the Center for Chinese Agricultural Policy at the Chinese Academy of Sciences in August and October, 2012. The Net Primary Productivity (NPP) data was computed by the Institute of Geographic Sciences and Natural Resources Research at the Chinese Academy of Sciences by using $1 \mathrm{~km}$ pixel data for the global vegetated land surface from the MODIS GPP/NPP Project at the University of Montana. Detailed computational processes are described in the next paragraph.

We statistically summarized the outputs, inputs and farm-specific variables before estimating the stochastic frontier function and technical inefficiency model (Table 3.1). Classic inputs are aggregated into five categories: total grassland NPP capacity $\left(x_{1}\right)$ of growing season of 2012, grassland area size $\left(x_{1}^{\prime}\right)$, labor $\left(x_{2}\right)$, capital $\left(x_{3}\right)$, and initial yak $\left(x_{4}\right)$. Meanwhile, outputs are aggregated into two categories: yak meat $\left(y_{1}\right)$ and the revenue of the other outputs $\left(y_{2}\right)$. The variable total grassland NPP capacity, input $x_{1}$, is a joint variable representative of both grassland area size and grassland quality in general. We get the total NPP of pastures for each household by multiplying the vegetation NPP per unit grassland by grassland area size. NPP refers to the net production of organic matter assimilated by autotrophic organisms measured in a given unit of area over a specified time; this is equal to the total amount of organic carbon assimilated by grassland vegetation minus organic carbon lost by autotrophic photorespiration (Roxburgh, et al., 2005; Zhao and Running, 2010). Computationally, after matching the rough boundary of summer pasture and winter pasture to the $1 \mathrm{~km}$ NPP raster data file and getting samples of NPP for each pasture according to the pasture area, we summarize the NPP of pastures for each household. The NPP imported in the stochastic distance function and technical inefficiency model in this chapter is the average annual grassland NPP of summer pasture and winter pasture in the 2011/2012 growing season. From this data, we can get the 
change of NPP per hectare. By timing change of NPP per hectare by grassland area size, we obtain the change of total NPP capacity of pastures for each household. As there are two kinds of pastures in the Sanjiangyuan region - summer pasture and winter pasture - grassland area $\left(x_{1}^{\prime}\right)$ is actually the sum of summer pasture area and winter pasture area for each household. Labor $\left(x_{2}\right)$ consists of family labor, measured by herd of person. Capital $\left(x_{3}\right)$ consists of productive machinery, such as irrigation equipment if available, transportation vehicles and so on. It is calculated by summing up the individual items listed in the questionnaires. Initial yak $\left(x_{4}\right)$ means the initial livestock input, represented by yak meat at the beginning of the year; this is calculated by multiplying the average weight of a yak by the yak number per household. The output and input variables are divided by their respective sample means. Thus, the estimated first-order parameters of the translog production frontier can be interpreted as partial production elasticities at the sample mean in the production function.

Household specific variables are introduced into the technical inefficiency model as shown in equation (3). Household size $\left(\mathrm{z}_{1}\right)$ is the population of each family. Summer pasture area $\left(\mathrm{z}_{2}\right)$ is the area size of summer pasture where herders graze in the warm season, and winter pasture area $\left(\mathrm{z}_{3}\right)$ is area size of winter pasture where herders graze in the cold season. For a better interpretation of the estimation results of farm-specific variables, variables excluding outputs and inputs are normalized by subtracting the mean. Grassland on the Qinghai-Tibetan Plateau is self-sufficient for feed production; no hay is imported or exported, no phosphate fertilizers are used and no supplemental feeding takes place in the pastoral zone. It is for this reason that we don't consider variables related to these factors.

Table 3.1 Descriptive characteristics of sample variables

\begin{tabular}{|c|c|c|c|c|}
\hline Variable & Unit & Symbol & Mean & Std. Dev. \\
\hline Yak output & $1000 \mathrm{~kg}$ & $y_{1}$ & 5.69 & 6.93 \\
\hline Others revenue & 1000yuan & $y_{2}$ & 9.43 & 22.31 \\
\hline Total grassland net primary productivity & $1000 \mathrm{kgC}$ & $x_{1}$ & 143 & 193 \\
\hline Labor & herd & $x_{2}$ & 2.30 & 1.27 \\
\hline Capital & 1000yuan & $x_{3}$ & 157.98 & 308.36 \\
\hline Initial yak at the beginning of 2011 & $1000 \mathrm{~kg}$ & $x_{4}$ & 7.91 & 11.58 \\
\hline Household size & herd & $z_{1}$ & 4.71 & 1.66 \\
\hline Summer pasture area & ha & $z_{2}$ & 36.08 & 60.27 \\
\hline Winter pasture area & ha & $z_{3}$ & 26.52 & 43.64 \\
\hline
\end{tabular}




\subsection{Results}

Prior to presenting estimates, we tested whether we should use the Cobb-Douglass production function or translog production function. The null hypothesis that the Cobb-Douglas function is a statistically suitable representation of the data, however this null hypothesis is strongly rejected by the likelihood ratio test. A set of hypotheses are tested before presenting the estimation results; such as, whether we should include explanatory variables in the technical inefficiency model and so on (Appendix table 3.1). All hypothesis test statistics highlight that the specification presented in the chapter is very good and can be used to represent the characteristics of the samples. We used the MLE method to estimate the one-step approach of an input oriented distance function in combination with the technical inefficiency model, and then we calculate the ecological performance indicator and total NPP efficiency of grassland. The general-to-specific modeling method (Hendry, 2000) is used in variable selection to deciding the model specification. We first estimate a model including all control variables, and then we drop the least significant variable and estimate the model again. This procedure is repeated until only variables that are significant enough to pass likelihood ratio tests at a $10 \%$ level remain. The ultimate specification is model 1 presented in Table 3.2 and Table 3.3. 
Table 3.2 Estimates of input orientation distance function

\begin{tabular}{|c|c|c|c|c|}
\hline Parameters & Coef. & Std. Err. & Coef. & Std. Err. \\
\hline Dependent variable: $-\ln (x 4)$ & Model 1 & & Model 2 & \\
\hline $\ln (\mathrm{y} 1)$ & $-0.495 * * *$ & 0.081 & $-0.523 * * *$ & 0.096 \\
\hline $\ln (\mathrm{y} 2)$ & -0.033 & 0.019 & -0.033 & 0.021 \\
\hline $\ln (\mathrm{x} 1)$ & $0.225 * * *$ & 0.066 & & \\
\hline $\ln (x 2)$ & $0.287 * * *$ & 0.083 & $0.363 * * *$ & 0.098 \\
\hline $\ln (\mathrm{x} 3)$ & 0.027 & 0.052 & 0.058 & 0.057 \\
\hline $.5 \ln (\mathrm{y} 1)^{\wedge} 2$ & 0.009 & 0.071 & 0.022 & 0.09 \\
\hline $.5 \ln (\mathrm{y} 2)^{\wedge} 2$ & -0.006 & 0.004 & -0.005 & 0.004 \\
\hline $.5 \ln (\mathrm{x} 1)^{\wedge} 2$ & $0.147^{* *}$ & 0.054 & & \\
\hline $.5 \ln (\mathrm{x} 2)^{\wedge} 2$ & -0.009 & 0.079 & 0.042 & 0.093 \\
\hline $.5 \ln (\mathrm{x} 3)^{\wedge} 2$ & 0.046 & 0.049 & 0.032 & 0.049 \\
\hline $\ln (\mathrm{x} 1)^{*} \ln (\mathrm{x} 2)$ & 0.002 & 0.044 & & \\
\hline $\ln (\mathrm{x} 1)^{*} \ln (\mathrm{x} 3)$ & -0.021 & 0.041 & & \\
\hline $\ln (x 2) * \ln (x 3)$ & 0.003 & 0.039 & -0.006 & 0.043 \\
\hline $\ln (\mathrm{x} 1)^{*} \ln (\mathrm{y} 1)$ & 0.069 & 0.059 & & \\
\hline $\ln (\mathrm{x} 2) * \ln (\mathrm{y} 1)$ & 0.023 & 0.070 & 0.068 & 0.084 \\
\hline $\ln (x 3) * \ln (y 1)$ & -0.036 & 0.042 & -0.054 & 0.046 \\
\hline $\ln (\mathrm{x} 1)^{*} \ln (\mathrm{y} 2)$ & -0.001 & 0.01 & & \\
\hline $\ln (\mathrm{x} 2)^{*} \ln (\mathrm{y} 2)$ & -0.008 & 0.008 & -0.011 & 0.009 \\
\hline $\ln (x 3)^{*} \ln (y 2)$ & -0.001 & 0.007 & 0.002 & 0.008 \\
\hline $\ln (\mathrm{y} 1)^{*} \ln (\mathrm{y} 2)$ & 0.002 & 0.008 & 0.004 & 0.008 \\
\hline Constant & $0.769 * * *$ & 0.070 & $0.743 * * *$ & 0.084 \\
\hline \multicolumn{5}{|l|}{$\ln \operatorname{sig} 2 v$} \\
\hline constant & $-2.997 * * *$ & 0.156 & $-2.711 * * *$ & 0.180 \\
\hline \multicolumn{5}{|l|}{ Statistics } \\
\hline Observations & 197 & & 197 & \\
\hline Likelihood ratio & -20.094 & & -44.634 & \\
\hline Chi2 & 1550.812 & & 1058.247 & \\
\hline AIC & 102.189 & & 137.268 & \\
\hline
\end{tabular}

\subsubsection{Stochastic distance function estimates}

Maximum likelihood estimates of the stochastic distance function are presented in Table 3.2, where model 1 represents the results of the unlimited model incorporating the total grassland NPP capacity into the production function (as equation (3-7) in section 3.2) and the associated technical inefficiency model (model 1 in Table 3.2). Model 2 shows the results of the limited model where neither total grassland NPP capacity nor grassland area size is incorporated into the production function (as equation (3-9) in section 3.2) and the associated technical 
inefficiency model (model 2 in Table 3.3). The overall model's qualities seem satisfactory according to the likelihood ratio tests. By the likelihood ratio test, we can see that model 1 (incorporating total NPP capacity of grassland) is preferable to model 2.

Table 3.3 Estimates of technical inefficiency model

\begin{tabular}{|c|c|c|c|c|c|}
\hline Parameters & Symbol & Coef. & Std. Err. & Coef. & Std. Err. \\
\hline \multicolumn{2}{|c|}{ Dependent variable: lnsig2u } & \multicolumn{2}{|l|}{ Model 1} & \multicolumn{2}{|l|}{ Model 2} \\
\hline Constant & $\tau_{0}$ & $-5.317 * * *$ & 1.099 & $-4.589 * * *$ & 1.197 \\
\hline $\ln (\mathrm{y} 1)$ & $\tau_{1}$ & $-1.710 * * *$ & 0.460 & $-1.306^{* *}$ & 0.438 \\
\hline $\ln (\mathrm{y} 2)$ & $\tau_{2}$ & 0.139 & 0.097 & 0.117 & 0.087 \\
\hline $\ln (x 1)$ & $\tau_{3}$ & $-1.249 * *$ & 0.465 & & \\
\hline $\ln (x 2)$ & $\tau_{4}$ & -0.324 & 0.454 & $-1.057^{*}$ & 0.423 \\
\hline $\ln (x 3)$ & $\tau_{5}$ & $-.633^{*}$ & 0.320 & -0.532 & 0.349 \\
\hline Household size & $\tau_{6}$ & $0.428^{* *}$ & 0.142 & $0.488^{* *}$ & 0.154 \\
\hline Summer pasture area & $\tau_{7}$ & 0.003 & 0.000 & 0.006 & 0.000 \\
\hline \multirow[t]{2}{*}{ Winter pasture area } & $\tau_{8}$ & $0.0019 * *$ & 0.001 & 0.001 & 0.000 \\
\hline & & \multicolumn{2}{|c|}{ TE of Model 1} & \multicolumn{2}{|c|}{ TE of Model 2} \\
\hline \multicolumn{2}{|l|}{ Mean } & \multicolumn{2}{|c|}{0.837} & \multicolumn{2}{|c|}{0.828} \\
\hline \multicolumn{2}{|l|}{ Std. Dev. } & \multicolumn{2}{|c|}{0.151} & \multicolumn{2}{|c|}{0.135} \\
\hline \multicolumn{2}{|l|}{ Min. } & \multicolumn{2}{|c|}{0.059} & \multicolumn{2}{|c|}{0.037} \\
\hline \multicolumn{2}{|l|}{ Max. } & \multicolumn{2}{|c|}{0.991} & \multicolumn{2}{|c|}{0.980} \\
\hline
\end{tabular}

All of the first order coefficients of the inputs and outputs have the expected signs, especially with the coefficients of main output $\left(\mathrm{y}_{1}\right)$, input of grassland total NPP capacity $\left(\mathrm{x}_{1}\right)$ and labor $\left(\mathrm{x}_{2}\right)$ significantly different from zero at the $1 \%$ level. In terms of the magnitude of elasticity at the sample mean, the total grassland NPP $\left(\mathrm{x}_{1}\right)$, labor $\left(\mathrm{x}_{2}\right)$ and main output $\left(\mathrm{y}_{1}\right)$ are all important for livestock grazing. The elasticity of the input oriented distance function with respect to input quantity reflects the relative importance of input to the production potential. The elasticity with respect to total grassland NPP capacity $\left(\mathrm{x}_{1}\right)$ is estimated to be 0.225 at the $1 \%$ statistical level, implying that the cost for change of grassland total NPP capacity represents $22.5 \%$ of the total cost at the sample mean. The elasticity with respect to labor is estimated to be 0.287 at the $1 \%$ statistical level, while the elasticity of capital is estimated to be 0.027 . The highest elasticity comes from the main output $\left(\mathrm{y}_{1}\right)$ which is estimated to be 0.495, in line with our expectation. In comparison with model 2 where all variables relating to total grassland NPP are removed, it is essential to take into account the total grassland NPP in the production function and technical inefficiency model. 


\subsubsection{Technical inefficiency model estimates and technical efficiency}

In comparison of likelihood values of model 1 to the specification without setting of technical inefficiency model, it proves that technical inefficiency exists in livestock grazing behavior and cannot be ignored according to the likelihood ratio test (Appendix table 3.1). The determinants for the variation in the livestock grazing household's technical inefficiency are estimated in the technical inefficiency model (Table 3.3). Because technical inefficiency is the dependent variable in the technical inefficiency model, a negative parameter coefficient for the variables indicates a negative effect on technical inefficiency and conversely a positive effect on technical efficiency.

According to the general-to-specific model selection process and empirical literature, we have a good representing technical inefficiency model. Household size $\left(\mathrm{z}_{1}\right)$ is estimated to be statistically significant in relation to technical inefficiency in both model 1 and model 2 . The coefficient of household size is estimated to be 0.428 , statistically significant at least at a level of $5 \%$, and 0.488 significant at the $5 \%$ statistical level, indicating that the bigger the household is, the less technically efficient their production will be. Grassland area size is represented as summer pasture area size $\left(\mathrm{z}_{2}\right)$ and winter pasture area size $\left(\mathrm{z}_{3}\right)$ in the technical inefficiency model. Not all of these variables are found to be insignificant in model 2, except winter pasture area size, which is estimated to be positive for technical inefficiency, taking a value of 0.002 , significant at the $5 \%$ statistical level. However, these variables are better to be kept in the model according to general-to-specific model test.

After estimating the stochastic distance function and technical inefficiency model, we calculate each household's technical efficiency in both the unlimited model (model 1) and the limited model (model 2). The average estimated technical efficiency for livestock grazing households in model 1 is 0.837 , indicating that on average; livestock grazing households can reduce about $16.3 \%$ of the cost of inputs given the present status of technology and the output level. The average technical efficiency for livestock grazing households in model 2 is about 0.828, which proves that the total grassland NPP is important for technical efficiency and the incorporation of it affects the technical efficiency (lower part of Table 3.3). Consequently, ignoring the role of grassland total NPP capacity would mislead livestock grazing herders and may result in the overuse of resources. From the range distribution of technical efficiencies in models 1 and 2 (Figure 3.1), we can see that about 13.20\% of households have a technical efficiency equal to or more than 0.95 in the unlimited model, with only $3.05 \%$ in limited 
model. Meanwhile, $29.44 \%$ of households have efficiency scores greater than or equal to 0.90 and less than 0.95 in the unlimited model, with $29.95 \%$ in the limited model. $21.32 \%$ of households have efficiency scores more than or equal to 0.85 and less than 0.90 in the unlimited model, with $24.87 \%$ households in the limited model. $13.20 \%$ of the households have efficiency scores more than or equal to 0.80 and less than 0.85 , with about $17.26 \%$ households in the limited model. $22.84 \%$ households operate with a technical efficiency score below 0.80 in the unlimited model, with $24.87 \%$ in the limited model. Differences in the calculation of average technical efficiencies from the unlimited model and limited model show that grassland NPP can affect calculation of technical efficiency, especially to range of technical efficiency distribution. Households are more likely to show higher technical efficiency when take grassland NPP capacity is taken into account in production. It seems to indicate that increasing livestock grazing technical efficiency by an average of $16.3 \%$ could be achieved in the short term by adopting the practices of the best performing households.

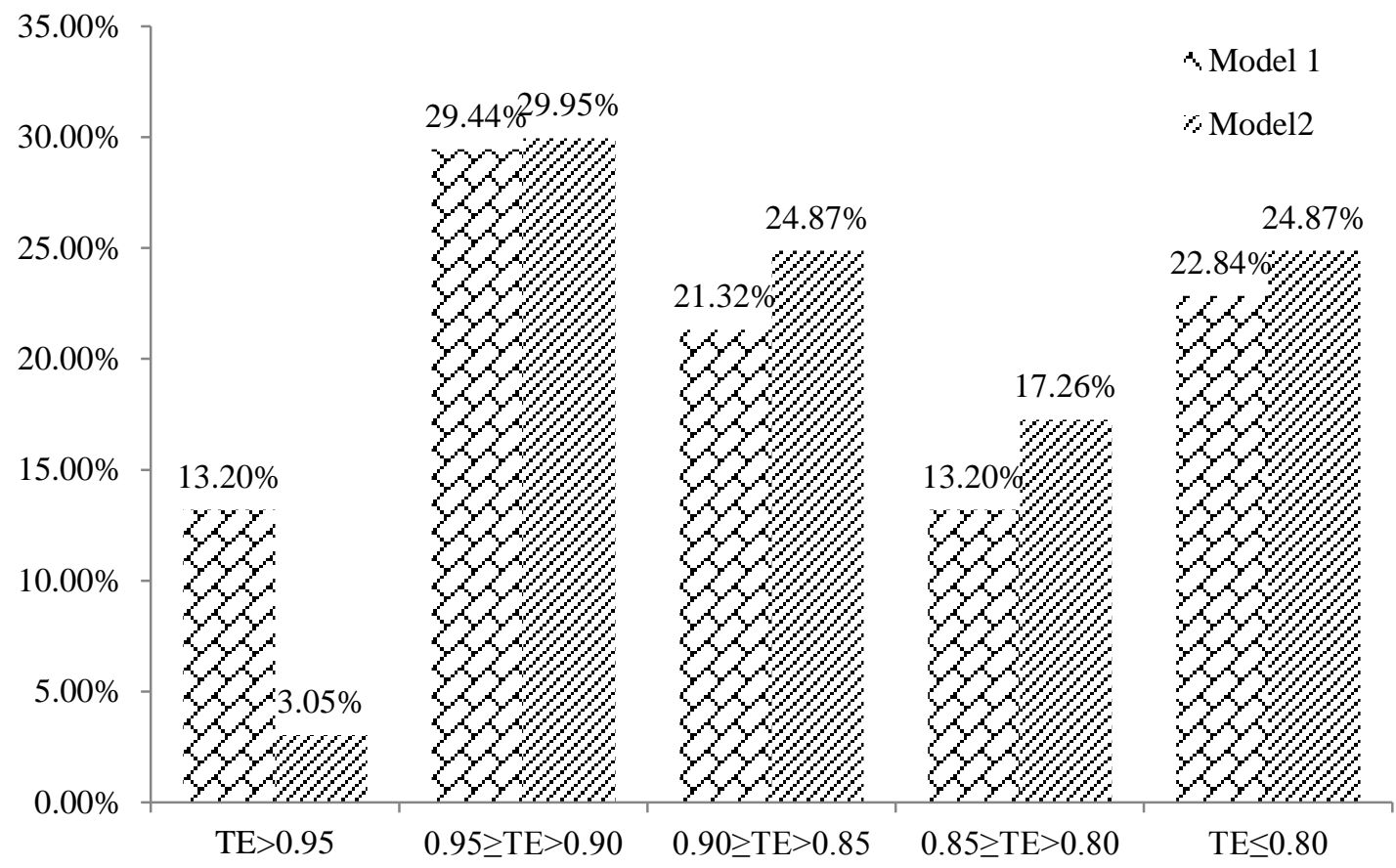

Figure 3.1 Distribution range of technical efficiencies estimated from Model1 and Model2

\subsubsection{The ecological performance indicator and grassland total NPP} efficiency

In order to evaluate livestock grazing on the Qinghai-Tibetan Plateau from an ecological perspective, we measure the ecological efficiency of NPP, represented by ecological 
performance indicator and the grassland total NPP efficiency. The ecological performance indicator (EPI) is defined to be the difference between technical efficiencies from the two unlimited models to technical efficiency from limited model, as showed in equation (3-7) where input $\mathrm{x}_{1}$ is total grassland NPP capacity and equation (3-8) where input $x_{1}^{\prime}$ is grassland area size. In comparison to the technical efficiencies from the two models, the difference of technical efficiency comes from the effects of vegetation NPP of grassland per unit, which are assumed to be associated with grassland quality as well as grassland degradation. Therefore, the larger the EPI, the more important role NPP plays in livestock grazing. When EPI $>0$, it is implied that the NPP of grassland per unit increases the technical efficiency; this also tells us that ignoring the grassland NPP will lead to misunderstanding the livestock grazing efficiency. The EPI mean is about 0.013 (Table 3.4) and 53\% of households or 104 out of 197 households have an EPI $>0$, which implies that for most households, grassland NPP plays a positive role in technical efficiency. From the scatter graph of ecological performance indicator (EPI) on technical efficiency (TE), there is an inverse U shape relationship between EPI and TE for grazing familiars whose TE is smaller than average TE, while the relationship between EPI and TE is not significant for grazing familiars whose TE is larger than average TE (Figure 3.2).

Table 3.4 Statistic summary of ecological performance indicator (EPI) and total NPP efficiency (TNPPE)

\begin{tabular}{|c|c|c|c|c|}
\hline Item & Mean & Std. Dev. & Min. & Max. \\
\hline EPI & 0.013 & 0.054 & -0.087 & 0.388 \\
\hline TNPPE & 0.123 & 0.114 & 0 & 0.618 \\
\hline
\end{tabular}

The grassland total NPP efficiency (TNPPE) is the ratio of the minimum total NPP optimum needed to the observed grassland total NPP, conditional on the other inputs and outputs observed. The mean of TNPPE is 0.123 , with a maximum value of 0.618 (Table 3.4), implying there is still much room to use grassland total NPP in livestock grazing in terms of economic production, which also means that neither grassland area size nor NPP per unit grassland is not overused, a good sign for environmental protection. It is interesting to see scatter graph of total grassland NPP capacity efficiency on technical efficiency (Figure 3.3), there is positive relationship between TNPPE and TE for grazing families whose TE is smaller than average level, while there is inverse U shape between TNPPE and TE for grazing families whose TE is larger than average level. Because TNPPE measures joint information of grassland area size and grassland NPP per unit, this emphasizes the importance of TNPPE to 
production again. According to scatter graph of EPI on TNPPE (Figure 3.4), it seems there is an apparent positive correlation between these two terms, the grazing household with higher EPI tends to have higher TNPPE.
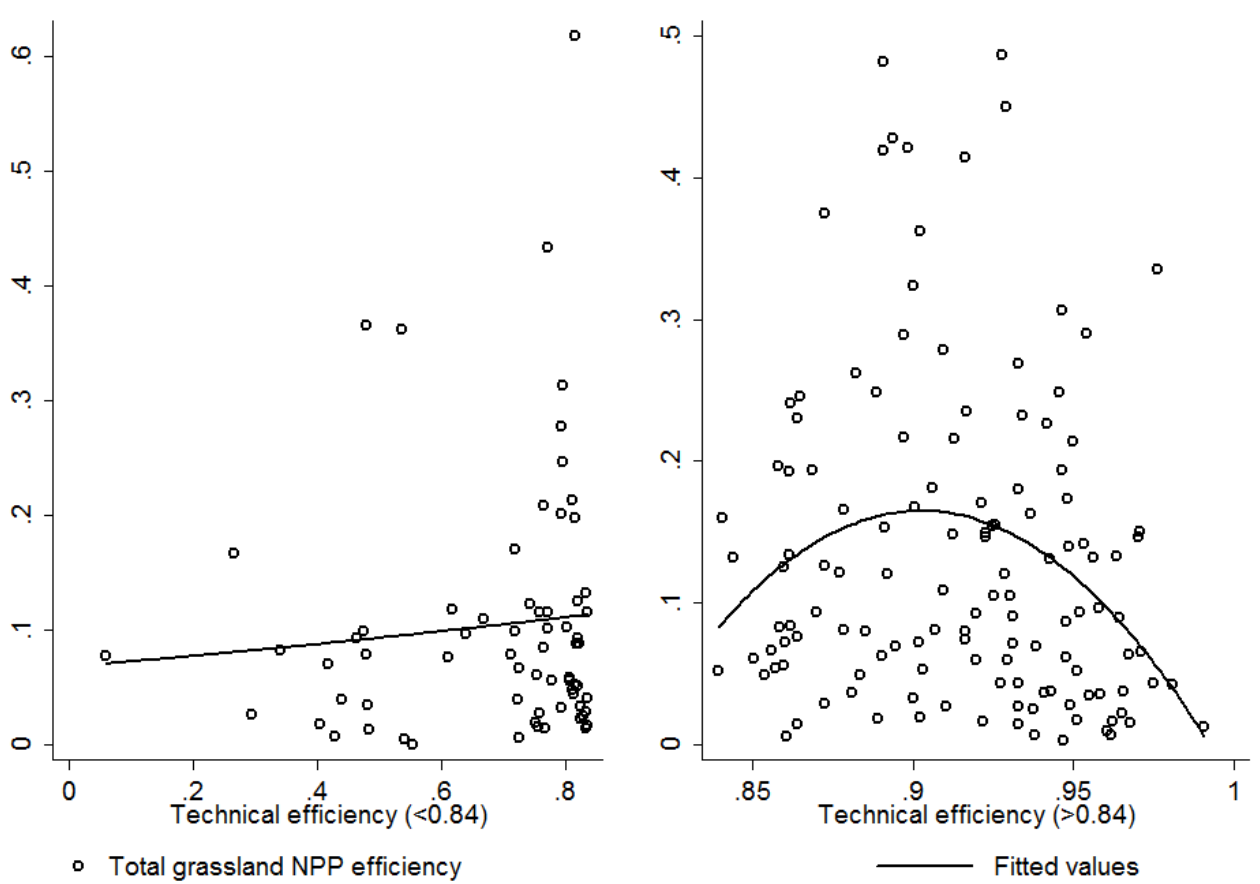

Figure 3.2 Scatter graph of total NPP efficiency (TNPPE) on technical efficiency (TE)

According to the distribution of technical efficiency grouped by EPI and TNPPE (Table 3.5), the average technical efficiency for the smallest ecological performance indicator and smallest grassland total NPP capacity efficiency is 0.808 , for $10.66 \%$ of households (EPI group1 and TNPPE group1 of Table 3.5). The highest average technical efficiency, 0.927, is in EPI group2 and TNPPE group1, with the lowest grassland total NPP efficiency and comparatively lower ecological performance indicator. In accordance with scatter graphs, the average technical efficiency for EPI group 4 is comparatively lowest in the table. Comparing of variation of EPI groups and TNPPE groups, we can see average technical efficiencies for EPI groups varies widely than TNPPE groups. Because TNPPE measures joint information of grassland NPP per unit and grassland area size, while EPI measures only grassland NPP per unit information, the variation among different groups proof grassland NPP per unit would affect technical efficiency largely. 

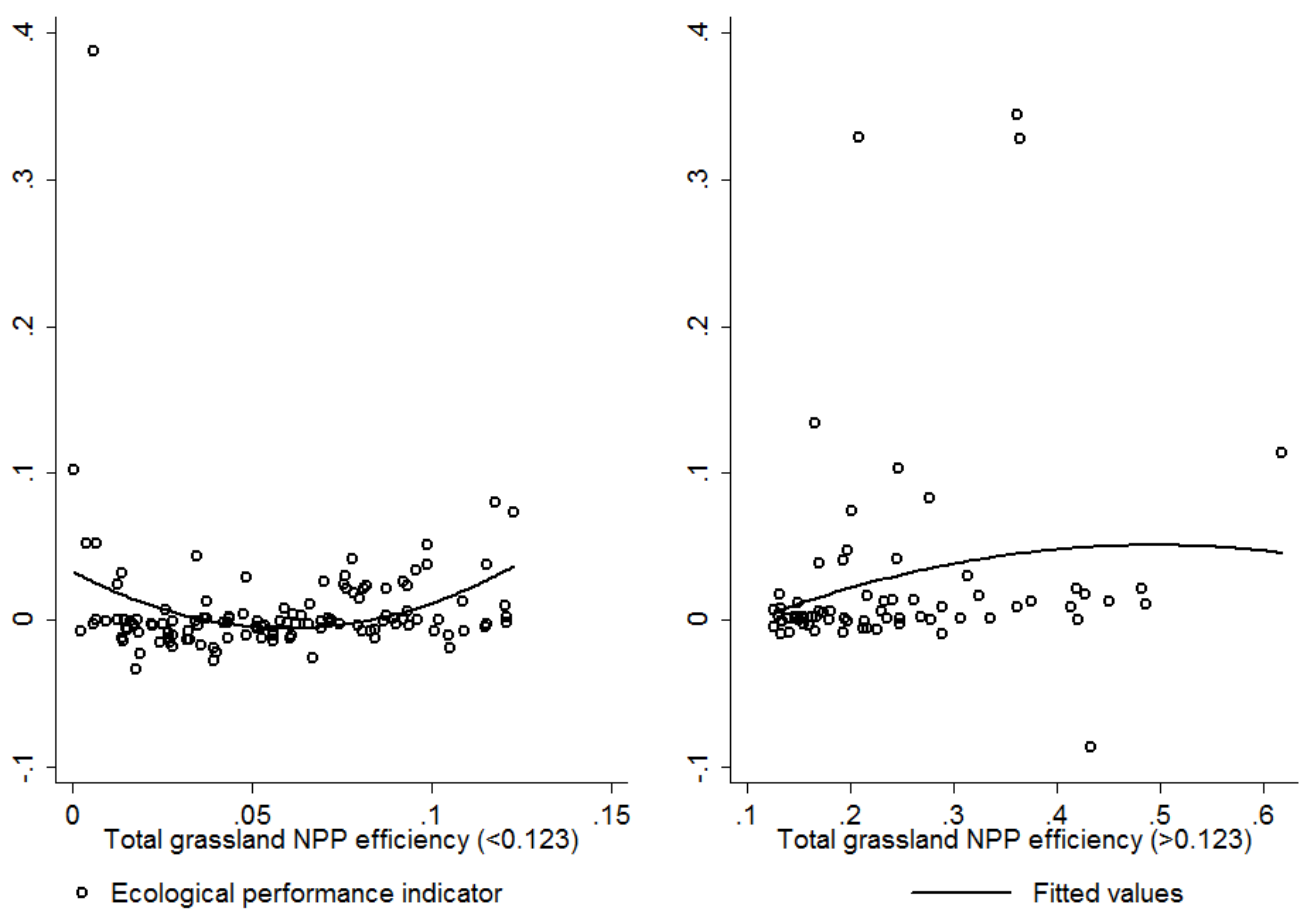

Figure 3.3 Scatter graph of ecological performance indicator (EPI) on total NPP efficiency (TNPPE)
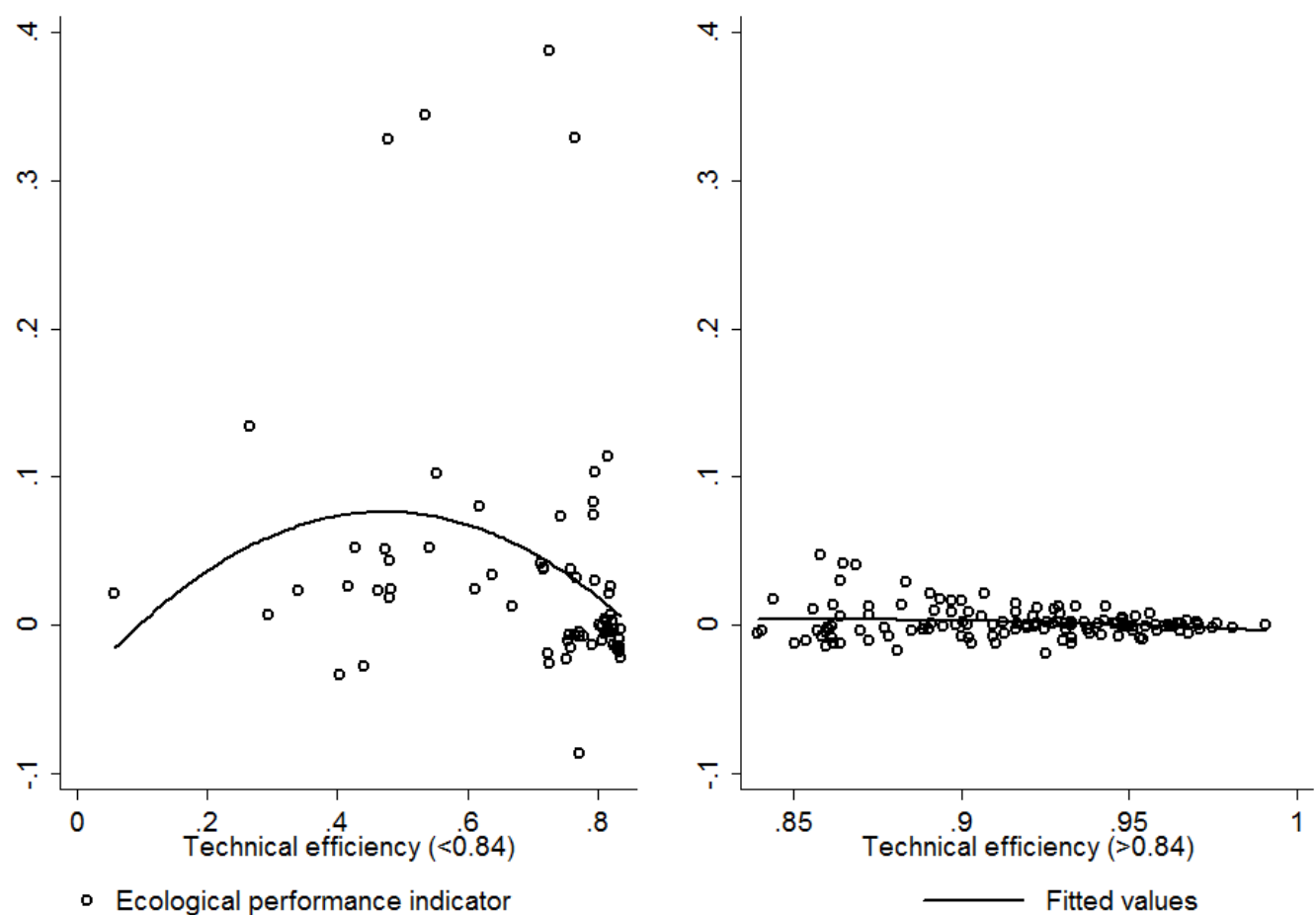

Figure 3.4 Scatter graph of ecological performance indicator (EPI) on technical efficiency (TE) 
Table 3.5 Distribution of technical efficiency (TE) by groups of total NPP efficiency (TNPPE) and ecological performance indicator (EPI)

\begin{tabular}{clllll}
\hline & \multicolumn{5}{c}{ Group of NPPCE } \\
Group of EPI ${ }^{*}$ & $0-25 \%$ & \multicolumn{1}{c}{$25 \%-50 \%$} & $50 \%-75 \%$ & \multicolumn{1}{c}{$75 \%-100 \%$} & Total \\
\hline \multirow{2}{*}{$0-25 \%$} & 0.808 & 0.839 & 0.886 & 0.876 & 0.837 \\
& $10.66 \%{ }^{* *}$ & $8.12 \%$ & $3.55 \%$ & $3.05 \%$ & $25.38 \%$ \\
$25 \%-50 \%$ & 0.927 & 0.905 & 0.879 & 0.888 & 0.904 \\
& $8.12 \%$ & $7.61 \%$ & $6.60 \%$ & $2.03 \%$ & $24.36 \%$ \\
$50 \%-75 \%$ & 0.791 & 0.898 & 0.906 & 0.924 & 0.902 \\
& $2.03 \%$ & $4.06 \%$ & $9.64 \%$ & $9.14 \%$ & $24.87 \%$ \\
$75 \%-100 \%$ & 0.615 & 0.619 & 0.69 & 0.79 & 0.708 \\
& $4.06 \%$ & $5.08 \%$ & $5.08 \%$ & $11.17 \%$ & $25.39 \%$ \\
Total & 0.814 & 0.824 & 0.852 & 0.856 & 0.837 \\
& $24.87 \%$ & $24.87 \%$ & $24.87 \%$ & $25.38 \%$ & $100.00 \%$ \\
\hline
\end{tabular}

Notes: * TNPPE and EPI are ordered from small to large. ** Percentages of household numbers.

\subsubsection{About livestock density}

Livestock intensity is a sensitive issue for livestock grazing, as livestock intensification has been driven by a greater demand for animal products accompanied by population increase and economic growth (McDowell, 2008). On the Qinghai-Tibetan Plateau, where the ecological environment is fragile, how the relationship between livestock intensity and these economic models for livestock grazing would be interesting as well. From the scatter graph of ecological performance indicator, total NPP capacity efficiency and technical efficiency on livestock intensity (Figure 3.5), we can see there are perfectly positive correlations, with the higher the livestock intensity, the higher the EPI and TNPPE, the trend is more apparent for EPI. This relationship is reasonable because higher livestock intensity would mean more intensive use of grassland area size and grassland NPP per unit, and this would certainly lead to higher EPI and TNPPE, not necessarily mean higher technical efficiency and production performance in livestock grazing. 

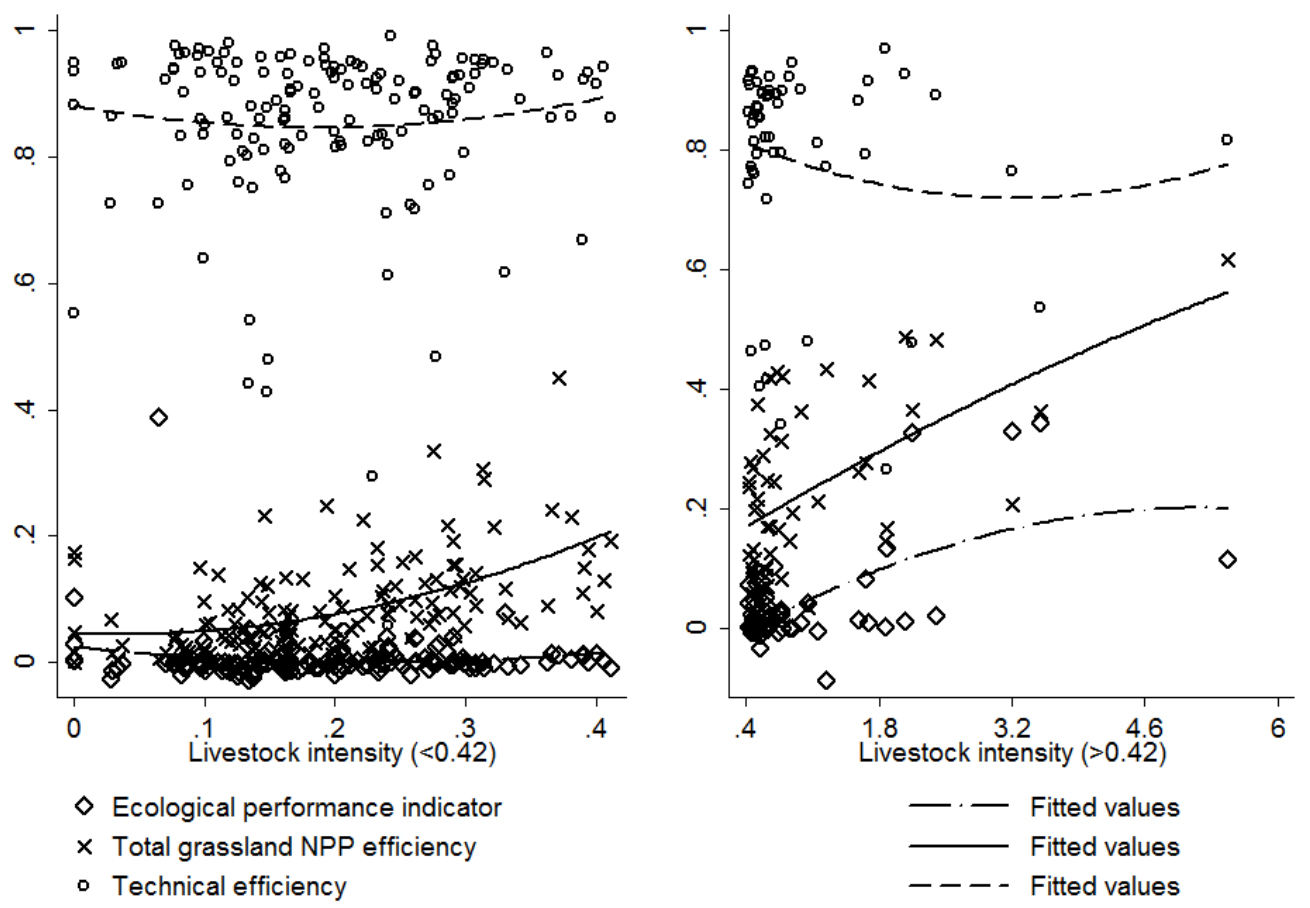

Figure 3.5 Scatter graph of ecological performance indicator (EPI) and total NPP efficiency (TNPPE) on livestock intensity

\subsection{Conclusion and discussion}

Incorporating ecological variables into the production function is a new step toward productivity and efficiency analysis incorporating ecological variables. The findings can be helpful for the development of scientific strategies and programs for local economic development and environmental protection, as well as for assessing the effectiveness of and opportunities for ecological restoration projects. This chapter measures the technical efficiency, ecological performance indicator and total grassland NPP capacity capacity efficiency of grassland grazing using a multi-outputs and multi-inputs stochastic inputoriented distance function by comparing an unlimited model incorporating grassland total NPP capacity to models which incorporate either only the grassland area size or neither of them. The average technical efficiency is estimated to be 0.837 when taking into account the grassland total NPP capacity, implying that the cost of livestock grazing can be decreased by $16.3 \%$ without any reduction of outputs. The average EPI is estimated to be 0.013 , which represents the effects in association with NPP, whereas the average TNPPE is 0.123 , meaning that livestock grazing is still under good control, without overuse of the grassland area or NPP. The total NPP of the available grassland plays a significant role in the stochastic distance function and technical inefficiency model, but grassland total NPP tends to be less 
important for households with comparatively higher technical efficiencies. A high total grassland NPP capacity efficiency may mean overuse of grassland NPP, which may lead to grassland deterioration, thus it is good to see the average TNPPE is comparatively low. As the system of extensive livestock grazing on the Qinghai-Tibetan Plateau is practiced elsewhere around the world, such as in Australia, South Africa and South America (White, 2000; McDowell, 2008), research on the productivity and efficiency analysis using ecological variables can provide important information for environmental management policies for sustainability.

Together with increasing demand for meat and more concerns about food safety, there is demand growth for products from livestock grazing; however, livestock grazing can have negative impacts on the environment if it is not controlled within acceptable limits. The relationship between extensive livestock grazing production and environmental protection calls for scientific research of how to improve production potential at the same time as maintaining sustainable grassland use. It is important that the model be evaluated in the field and ground trothed. In addition, a fuller assessment would also include maintaining other forms of desirable ecosystem service production from the grasslands.

\section{Chapter appendix}

Appendix table 3.1 Hypothesis tests for model specification and statistical assumptions

\begin{tabular}{|c|c|c|c|c|c|}
\hline Test & Null hypothesis & $\begin{array}{l}\text { Log- } \\
\text { likelihood } \\
\text { value }\end{array}$ & $\begin{array}{c}\text { degree } \\
\text { of } \\
\text { freedom }\end{array}$ & AIC & $\mathrm{BIC}$ \\
\hline \multicolumn{6}{|c|}{ For selection of production function } \\
\hline \multirow{2}{*}{1} & $\mathrm{H}_{0}$ : Cobb-Douglass production function & -71.74422 & 8 & 159.4884 & 185.7541 \\
\hline & $\mathrm{H}_{1}$ : Translog production function & -44.52023 & 23 & 135.0405 & 210.5541 \\
\hline \multicolumn{6}{|c|}{ Testing for specification of technical inefficiency model } \\
\hline & $\mathrm{H}_{1}$ : specification as model 1 & -20.09434 & 31 & 102.1887 & 203.968 \\
\hline 2 & $\mathrm{H}_{0}: \tau_{i}=0$, no technical inefficiency & -44.52023 & 23 & 135.0405 & 210.5541 \\
\hline 3 & $\mathrm{H}_{0}: \tau_{1}=\tau_{2}=\tau_{3}=\tau_{4}=\tau_{5}=0$ & -31.5129 & 26 & 115.0258 & 200.3891 \\
\hline 4 & $\mathrm{H}_{0}: \tau_{6}=0$ & -25.72038 & 30 & 111.44 & 209.9369 \\
\hline 5 & $\mathrm{H}_{0}: \tau_{7}=\tau_{8}=0$ & -29.22831 & 29 & 116.4566 & 211.6695 \\
\hline
\end{tabular}




\section{Chapter 4}

\section{Balancing Economic Revenue and Grazing Pressure of Livestock Grazing on the Qinghai-Tibetan-Plateau Using Directional Distance Function}

With the use of first hand field survey data from 193 yak grazing households combined with remotely sensed Net Primary Productivity data on the Qinghai-Tibetan-Plateau, a directional output-orientation distance function is developed with grazing pressure as the undesirable output, in the sense that the more efficient producer would achieve higher productivity at lower grazing pressure. The average efficiency is 0.82 , and the shadow price of grazing pressure to livestock economic revenue is estimated to be between -3.99 and -1.80 . According to the Morishima elasticity of substitution between inputs, there is a significant complementary relationship between grassland, labor and capital. 


\subsection{Introduction}

Concerns about environmental problems caused by economic development in developing countries have received a lot of attention in recent years. Grassland is one of the main land use types on earth and is essential for livestock grazing and grassland ecosystem services; how to find a balance between grassland sustainability and livestock grazing has been a major focus for research (De Haan et al., 1997; White et al., 2000; McDowell, 2008). However, demand for livestock products is growing rapidly in particular in emerging economies, driven by population growth, economic growth and expanding urbanization. This has resulted in increasing grazing pressure on the grasslands, leading to overgrazing and grassland degradation.

Overgrazing occurs when the livestock stocking rate, or livestock per unit area per unit time, exceeds the capacity of the grassland to sustainably produce good quality forage. Overgrazing threatens the long-term use of grasslands in both economic and ecological terms, and can result in grassland degradation, such as soil and productivity loss, increases in populations of undesirable plants, and bare soil. Three quarters of the world's grazing lands are believed to be so degraded that they have lost more than $25 \%$ of their capacity to support animals (White et al., 2000; UNEP, 2005). The Qinghai-Tibetan Plateau is a region heavily affected by advancing grassland degradation over wide areas, with overgrazing as one of the main drivers (Akiyama et al,. 2007; Zhou et al,. 2006; Zhang, 2008; Harris, 2010). Grazing pressure, the ratio of livestock live weight divided by grassland forage biomass at a given point in time, results from increasing livestock stocking rates. As grazing pressure is a reflection of stocking rate and increases with stocking rate, the strong relationship believed to be between overgrazing and grassland degradation made us interested in researching the performance of livestock grazing, by adopting grazing pressure as an undesirable output from livestock grazing using the directional distance function.

The directional distance function approach to efficiency measurement was first proposed by Chung et al. (1997) and Chambers et al. (1998) based on Shephard (1970). It has gained popularity over the last 10 years (Färe et al., 2013; Feng and Serletis, 2014). The directional distance function allows for directional efficiency measurement, i.e., the researcher is not limited to the commonly employed efficiency concept of proportional reductions in inputs or proportional expansion of outputs. A common use of directional distance analysis is the 
modelling of technologies that produce pollution as a byproduct, such as electric utilities producing electricity and air pollution (Atkinson and Dorfman, 2005; Färe et al., 2005; Cuesta et al., 2009; Coelli et al., 2013; Murty et al., 2007; Wang et al., 2013; Yao et al., 2015), and dairy farms producing polluted runoff (Reinhard et al., 1999; 2000; Fernandez et al., 2002; Sauer and Latacz-Lohmann, 2014; Njuki and Bravo-Ureta, 2015). Undesirable outputs in pulp mills have been heavily researched (Brannlund and Chung, 1998; Van Ha et al., 2008).

To evaluate environmental goods such as air pollution emissions, soil pollution, environmental pressure or ecological diversity loss from human economic activity, relative shadow prices of nonmarket goods can be derived from the distance function. Furthermore, elasticities of complementary or substitutionary relationships among inputs or outputs shed light on the interdependencies between the environmental good and the inputs and outputs (Blackorby and Russel, 1989; Du and Hanley, 2015; Färe et al., 1993; 2005; Morrison Paul et al., 2000; 2005; Hailu, 2000; Cuesta, 2009; Rahman, 2010; Serra et al. 2011; Picazo-Tadeo et al., 2014).

In this analysis we employ a unique dataset from a survey of 193 households about livestock grazing in yak production on the Qinghai-Tibetan plateau. We calculate grazing pressure as the ratio between livestock live weight and total grassland Net Primary Productivity (NPP), where total grassland NPP is used as representative of grassland biomass. After the estimates of directional distance function and technical inefficiency model, we derive shadow prices of grazing pressure to grazing economic revenue, and elasticity of complementary or substitutionary relationships among inputs. The goal is to help producer to achieve higher productivity with lower grazing pressure in the use of the available grassland resource.

The structure of the paper is as follows: Section 4.2 presents the theoretical framework, and methodology. Section 4.3 presents the empirical model specification and data description. The results of the empirical analysis are presented in section 4.4 , followed by section 4.5 which concludes with discussion.

\subsection{Theoretical framework and methodology}

A multi-input multi-output directional distance function incorporating grazing pressure as the undesirable output is developed in order to measure the production performance of grassland grazing within the framework of environmental efficiency. As grassland grazing on the 
Tibetan Plateau still is largely the traditional half-nomadic pastoral system (Davies and Hatfield, 2007; Harris, 2010), there are no exact price of inputs and outputs, this might be advantageous for the distance function. We adopt a stochastic frontier distance function approach instead of alternatives based on data envelopment analyses because of the advantage of the stochastic approach in separating random noise from the technical inefficiency term.

\subsubsection{Conceptual framework}

The directional distance function for a technology with inputs $x=\left(x_{1}, \cdots, x_{K}\right) \in \mathfrak{R}^{K+}$ and outputs $y=\left(y_{1}, \cdots, y_{M}\right) \in \mathfrak{R}^{M+}$ can be derived based on the output possibility set $P(x)=$ $\{y: x$ can produce $y\}$, which is assumed to satisfy the set of axioms listed in Färe and Grosskopf (2000). The directional distance function measures the distance from the production unit to the efficiency boundary along a directional vector $g=\left(-g_{x}, g_{y}\right)$ with $g_{x} \in R_{+}^{N}$ and $g_{y} \in R_{+}^{M} . g$ determines which of the inputs should be contracted and which outputs should be expanded, as described in Figure 4.1, when firms adjust the production behavior along the vector from producing point $\mathrm{A}$. The directional distance function is given in (4-1).

$$
\vec{D}\left(x, y ; g_{x}, g_{y}\right)=\sup \left\{\vartheta:\left(x-\vartheta g_{x}, y+\vartheta g_{y}\right) \in P\right\}
$$

where $\vec{D}\left(x, y ; g_{x}, g_{y}\right) \geq 0, \vartheta \in R$, which should fulfill all the properties described in Chambers et al. (1998) and Färe et al. (2005). For stochastic frontier analysis, a specific functional form has to be selected. We opt for a flexible function and choose the quadratic form in (4-2):

$$
\begin{aligned}
\vec{D}\left(x, y ; g_{x}, g_{y}\right) & \\
& =\sum_{k=1}^{N} \alpha_{k} x_{k}+\sum_{j=1}^{M} \beta_{j} y_{j}+\sum_{k=1}^{N} \sum_{l=1}^{N} \alpha_{k l} x_{k} x_{l}+\sum_{j=1}^{M} \sum_{h=1}^{M} \beta_{j h} y_{j} y_{h} \\
& +\sum_{k=1}^{N} \sum_{j=1}^{M} \gamma_{k j} x_{k} y_{j}
\end{aligned}
$$


For the estimation, of (4-2), we make use of the translation property of the directional distance function:

$$
\vec{D}\left(x-\vartheta g_{x}, y+\vartheta g_{y} ; g_{x}, g_{y}\right)=\vec{D}\left(x, y ; g_{x}, g_{y}\right)-\vartheta
$$

This property indicates the producer decreases the distance to efficiency boundary by scalar $\vartheta$, while output is improved by $\vartheta g_{y}$ and input is reduced by $\vartheta g_{x}$ simultaneously, given the technology is available. It is a radial input distance function if $g_{y}=0$, as the firm close to the efficient frontier from point A to point B; and it is a radial output distance function if $g_{x}=0$, when the firm is moving the producing point from point $\mathrm{A}$ to point $\mathrm{C}$, therefore, the radial distance function is - in special cases - the directional distance function (Färe and Grosskopf, 2000). Based on the directional distance function framework, the output oriented directional distance function and the input oriented directional distance function can be derived. We use the output oriented directional distance function for grassland grazing in this paper.

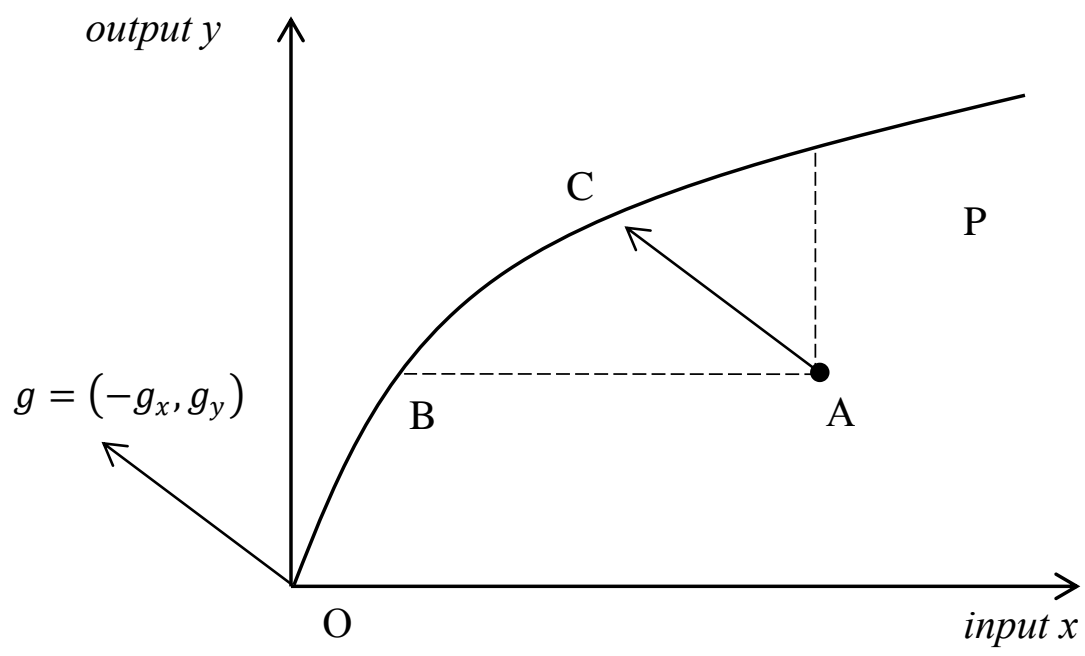

Figure 4.1 Directional distance function

Specifically, the producer is efficient at given direction vector $\left(-g_{x}, g_{y}\right)$ if

$$
0=\vec{D}\left(x, y ; g_{x}, g_{y}\right)+\varepsilon_{i}
$$

where $\varepsilon_{i}=v_{i}-u_{i}, v_{i} \sim$ i.i.d. $N\left(0, \sigma_{v}^{2}\right)$ and $u_{i} \sim N\left(\mu_{i}, \sigma_{u}^{2}\right)^{+}, i=1,2, \cdots, N$.

Hence, by substituting (4-4) into (4-3), we get 


$$
-\vartheta_{i}=\vec{D}\left(x-\vartheta g_{x}, y+\vartheta g_{y} ; g_{x}, g_{y}\right)+v_{i}-u_{i}
$$

By choosing an observation specific value for the translation property, we get variation in the left-hand side variable.

The technical inefficiency model is based on Battese and Coelli (1995), with the mean parameter $\mu_{i}$ linked to a number of potential drivers of technical inefficiency, as given in equation (4-6).

$$
\mu_{i}=\sum_{c=1}^{C} \tau_{c} * Z_{c i}
$$

$Z_{c i}$ are household characteristic variables associated with the technical inefficiency effects, and $\tau_{i}$ are parameters to be estimated (Battese and Coelli, 1988; 1995; Coelli and Battese, 1996). We estimate the model by Maximum Likelihood Estimation (MLE), and obtain individual technical efficiency estimates as the conditional expectation of the exponential of the negative of the one-sided error, given the observed composite error (Aigner, Lovell and Schmidt, 1977).

\subsubsection{Relative shadow prices and the Morishima elasticity of substitution}

Based on duality between the distance function and cost function or revenue function (input distance function for cost minimization function, output distance function for revenue maximization function), shadow prices for non-market goods can be derived (Shephard, 1970; Färe and Primont, 1996). Assuming that the directional input (output) distance function and the cost (revenue) functions are differentiable, application of Shephard's lemma gives the corresponding shadow prices:

$$
\nabla_{x} \vec{D}(x, y)=r^{*}(x, y)
$$

where $r^{*}(x, y)$ is the cost minimizing input price vector.

Because the input prices are not available and optimal cost of production cannot be accurately estimated in this paper, we prefer the use of relative shadow prices according to equation (48): 


$$
R_{k l}=\frac{r_{k}^{*}}{r_{l}^{*}}=\frac{\partial \vec{D}(x, y) / \partial x_{k}}{\partial \vec{D}(x, y) / \partial x_{l}}
$$

where $r_{k}^{*}$ and $r_{l}^{*}$ are the shadow prices of the inputs $x_{k}$ and $x_{l}$, respectively. This ratio is the relative shadow price of input $x_{k}$ with respect to input $x_{l}$. These shadow prices reflect the trade-off between different inputs (Färe et al., 1993; Hailu and Veeman, 2000; Murty, 2007; Misra and Kant, 2007; Rahman, 2010).

Because of the duality between the input distance function and the cost function, the degree of substitutability along the surface frontier, such as frontier curvature, can be calculated. The indirect Morishima elasticity of substitution (MES) from a directional input distance function can be computed according to equation (4-9) (Blackorby and Russell, 1989; Stern, 2011).

$$
M E S_{k l}=-\frac{\partial \ln \left(\vec{D}_{k} / \vec{D}_{l}\right)}{\partial \ln \left(X_{l} /_{X_{k}}\right)}=x_{k}\left(\frac{\vec{D}_{k l}}{\vec{D}_{l}}-\frac{\vec{D}_{k k}}{\vec{D}_{k}}\right)
$$

where the subscripts on the distance functions refer to partial derivatives with respect to inputs. This represents the change in relative marginal products and input prices required to affect substitution under cost minimization. High values reflect low substitutability and low values reflect relative ease of substitution between the inputs (Morrison-Paul et al., 2000). The MES can be simplified as follows:

$$
M E S_{k l}=\varepsilon_{k l}-\varepsilon_{k k}
$$

where $\varepsilon_{k l}$ and $\varepsilon_{k k}$ are the constant output cross and own elasticity of shadow prices with respect to input quantities.

The shadow price elasticities with respect to input quantities are given by:

$$
\begin{gathered}
\varepsilon_{k l}=\left(\alpha_{k l}+S_{k} S_{l}\right) / S_{k} \text { if } k \neq l \\
\varepsilon_{k k}=\left[\alpha_{k k}+S_{k}\left(S_{k}-1\right)\right] / S_{k} \text { if } k=l
\end{gathered}
$$

where $S_{k}$ is the first order derivatives of the distance function with respect to input $x_{k}$, that is

$$
S_{k}=\partial \vec{D} / \partial x_{k}
$$




\subsection{Empirical model specification and data descriptive statistics}

\subsubsection{Empirical model specification and estimation measurement}

Following Chambers et al. (1998; 2002) and Färe et al. (2005), we first build the output oriented directional distance function in equation (4-16). The advantage of the output oriented directional distance function is that it allows us to expand the desirable output while contracting the undesirable output while leaving inputs unchanged, as shown in Figure 2. Assuming point $\mathrm{A}$ is the production point of a household, then the household improves production along the directional vector $g=\left(g_{y},-g_{b}\right)$, that is adding $\vartheta g_{y}$ to desirable output y while subtracting $\vartheta g_{b}$ from the undesirable output b.

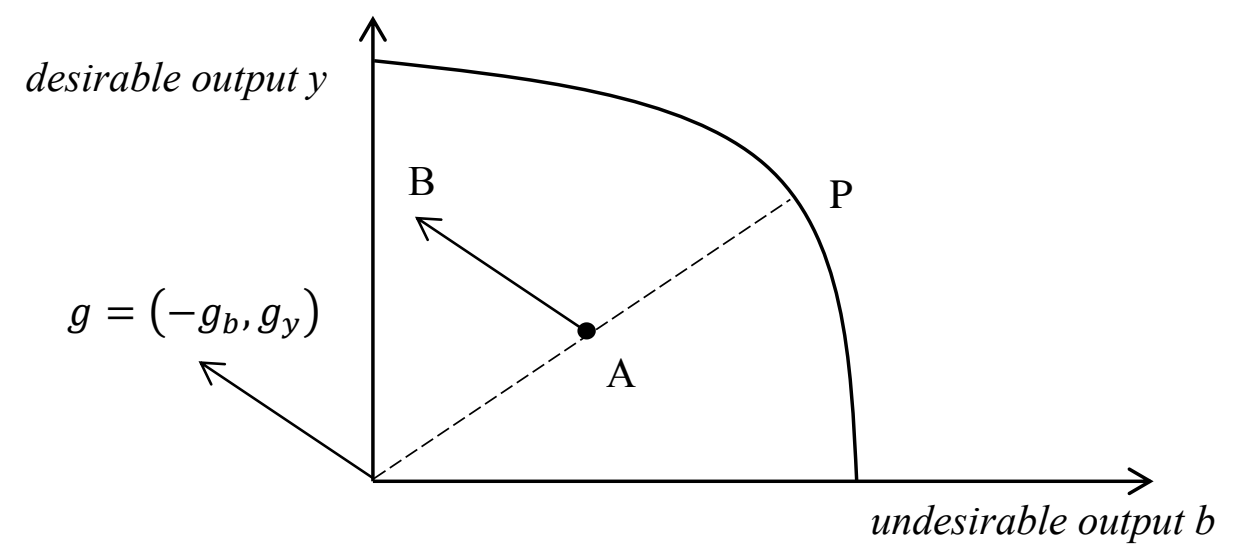

Figure 4.2 Output orientation directional distance function

$$
\overrightarrow{D_{o}}\left(x, y, b ; g_{y},-g_{b}\right)=\sup \left\{\vartheta:\left(y+\vartheta g_{y}, b-\vartheta g_{b}\right) \in P\right\}
$$

While satisfying the translation property, equation (4-14) can be denoted as equation (4-15),

$$
\overrightarrow{D_{o}}\left(x, y+\vartheta g_{y}, b-\vartheta g_{b} ; g_{y},-g_{b}\right)=\overrightarrow{D_{o}}\left(x, y, b ; g_{y},-g_{b}\right)-\vartheta
$$

We parametrically estimate the directional distance using stochastic estimation methods following Kumbhakar and Lovell (2000), then the empirical stochastic specification form is written in equation (4-16).

$$
-\vartheta_{i}=\overrightarrow{D_{o}}\left(x, y+\vartheta g_{y}, b-\vartheta g_{b} ; g_{y},-g_{b}\right)+v_{i}-u_{i}
$$


Assuming $g=\left(g_{y},-g_{b}\right)=(1,-1)$, the quadratic form for our case, 4 inputs and 2 outputs ( 1 good output $y$ and 1 bad output $b$ ), is denoted by equation (4-17).

$\overrightarrow{D_{o}}(x, y, b ; 1,-1)$

$$
\begin{aligned}
& =\alpha_{0}+\sum_{k=1}^{4} \alpha_{k} x_{k}+\beta_{1} y+\beta_{2} b+\frac{1}{2} \sum_{k=1}^{4} \sum_{l=1}^{4} \alpha_{k l} x_{k} x_{l}+\frac{1}{2} \beta_{11}(y)^{2} \\
& +\frac{1}{2} \beta_{22}(b)^{2}+\sum_{k=1}^{4} \gamma_{k 1} x_{k} y+\sum_{k=1}^{4} \gamma_{k 2} x_{k} b+\delta y b
\end{aligned}
$$

To fulfil the translation property, the required restrictions are

$\beta_{1}-\beta_{2}=-1, \beta_{11}=\beta_{22}=\delta, \gamma_{k 1}=\gamma_{k 2}, \mathrm{k}=1,2,3,4$

Additional, symmetry conditions require: $\alpha_{k l}=\alpha_{l k}, k=l=1,2,3,4$.

In our case, we impose these restrictions by choosing $\vartheta=b_{i}$, then the quadratic form of the empirical specification for grassland grazing is

$$
\begin{aligned}
-b_{i}=\overrightarrow{D_{o}}(x, y & +b, 0)+v_{i}-u_{i} \\
& =\sum_{k=1}^{4} \alpha_{k} x_{k}+\beta_{1} y^{*}+\frac{1}{2} \sum_{k=1}^{4} \alpha_{k k}\left(x_{k}\right)^{2}+\frac{1}{2} \beta_{11}\left(y^{*}\right)^{2} \\
& +\sum_{k=1}^{4} \sum_{l=1, k \neq l}^{4} \alpha_{k l} x_{k} x_{l}+\sum_{k=1}^{4} \gamma_{k 1} x_{k} y^{*}+v_{i}-u_{i}
\end{aligned}
$$

where $y^{*}=y+b . y$ describes the desirable output of grassland grazing, denoted by the revenue of livestock meat and milk produced in the year; $b$ denotes the undesirable output, grazing pressure, defined as ratio of livestock live weight divided by grassland forage biomass. $X$ is the vector of inputs with $x_{1}=$ grassland area size, $x_{2}=$ labor, $x_{3}=$ household productive capital and $x_{4}=$ initial yak stock. $v_{i}$ is a random error term, intended to capture events beyond the control of the herdsman and $u_{i}$ is a non-negative random error term, intended to capture technical inefficiency in production. In order to compare different effects 
of the directional vector, we use $g=\left(g_{y},-g_{b}\right)=(1,-1)$ and $g=\left(g_{y},-g_{b}\right)=(1,0)$ in empirical analysis, the setting with $g=(1,0)$ means ignoring the bad output in the production process.

The technical inefficiency model referred to equation (4-6) in this chapter is written as

$$
\mu_{i}=\tau_{0}+\sum_{c=1}^{8} \tau_{c} * Z_{c i}
$$

where $Z$ is a vector of explanatory variables associated with the technical inefficiency effects including total NPP change of each household $\left(z_{1}\right)$, household size $\left(z_{2}\right)$, distance from fixed home to summer pasture $\left(z_{3}\right)$, grazing experience $\left(z_{4}\right)$, summer pasture area $\left(z_{5}\right)$ and winter pasture area size $\left(z_{6}\right)$, dummy variable of pasture plot $\left(z_{7}\right)$ and dummy variable of whether there is leased-in grassland from other households $\left(z_{8}\right)$.

\subsubsection{Data and descriptive statistics}

The social-economic data used in this paper was drawn from field survey data in the Sanjiangyuan region in Qinghai province conducted by the Center for Chinese Agricultural Policy (CCAP) of the Chinese Academy of Sciences in August and October, 2012. The Net Primary Production data is from the MODIS GPP/NPP Project. The Sanjiangyuan region in China, known as the Three-River Headwaters in English, is located in the northeastern Qinghai-Tibetan Plateau, where more than $90 \%$ of the local people are of Tibetan Ethnic Minority. The average elevation of the Sanjiangyuan region is between 3500 and $4800 \mathrm{~m}$. Like other parts of the Tibetan plateau, a cold season from approximately November to the following May and a warm season from June to October can be identified. The stratified random sampling method was used to select observations and 193 of them were available for this analysis.

Classic inputs are aggregated into four categories (grassland area, labor, capital and initial yak) and outputs are aggregated into two categories ( $y$ as the desirable output of revenue from grassland grazing and output $b$, the undesirable output of grazing pressure). There are two kinds of pastures on the Qinghai-Tibetan Plateau: Summer/autumn pasture and winter/spring pasture, where grassland area $\left(x_{1}\right)$ is the sum of summer pasture area and winter pasture area for each household. Labor $\left(x_{2}\right)$ consists of family labor, measured by person. Capital $\left(x_{3}\right)$ consists of productive machinery (irrigation machine, transportation machine and so on). 
Initial yak stock $\left(x_{4}\right)$ means the initial yak input at the beginning of the year and is calculated by multiplying the average weight of a yak by the yak number per household. Desirable output y denotes the revenue of yak meat produced in the year and revenue of the other outputs, including the revenue from Tibetan sheep meat, output of milk, yak hide, Tibetan sheep wool and so on. Undesirable output b denotes the grazing pressure of livestock grazing on the Qinghai-Tibetan Plateau.

Grazing pressure is international terminology for the relationship between animal live weight and forage mass per unit of grassland on grazed land at a specific time (Allen et al., 2011). Grazing pressure is highly positively correlated with the over grazing ratio: The more the livestock stocking rate increases the higher the grazing pressure at a point in time. The grassland of the Qinghai Province of China, one of the largest grasslands in China, was found by researchers to have a high level of overgrazing by comparing the actual to what is believed to be the proper livestock stocking rate (Fan et al., 2011; Zhang et al., 2014). Fan et al. (2011) studied the temporal-spatial dynamics of grazing pressure during the period from 1988 to 2005. Assuming Zhang et al's suggested "proper carrying capacity" or stocking rate as the baseline, the overgrazing ratio was found to be more than $300 \%$ in sample counties with the use of the data from the our field survey, indicating that overgrazing persists (Table 1.2).

As grazing pressure is the animal-to-forage ratio, we calculate grazing pressure as the ratio between livestock live weight and total NPP as a proxy for grassland biomass. Unit NPP is computed with daily MODIS land cover, FPAR/LAI and global GMAO surface meteorology at $1 \mathrm{~km}$ for the global vegetated land surface (Zhao and Running, 2010). Grassland total NPP is computed by multiplying unit NPP by the total grassland area. These variables provide the initial calculation for growing season and carbon cycle analysis, and are used for agriculture, range and forest production estimates. After matching the rough boundary of summer pasture and winter pasture to the $1 \mathrm{~km}$ NPP raster data file, and getting samples of NPP for each pasture according to the pasture area, we summarize the NPP of pastures for each grazing household.

For the technical inefficiency model, operational and farm-specific variables were considered including the total NPP change of each household's pasture $\left(z_{1}\right)$, household size $\left(z_{2}\right)$, distance from fixed home to summer pasture $\left(z_{3}\right)$, grazing experience $\left(z_{4}\right)$, summer pasture area $\left(z_{5}\right)$ and winter pasture area size $\left(z_{6}\right)$, dummy variable of pasture plot $\left(z_{7}\right)$ and dummy variable of whether there is leased-in grassland from other households $\left(z_{8}\right)$. The total NPP change for 
each household $\left(z_{1}\right)$ is calculated by subtracting total NPP in the year 2011 from total NPP in the year 2012. Household size $\left(z_{2}\right)$ is the number of people in the household. Distance from fixed home to summer pasture $\left(z_{3}\right)$ measures the geographic distance from the fixed home to the summer pasture. Grazing experience $\left(z_{4}\right)$ denotes how many years of grazing experience each household head has. Summer pasture area $\left(z_{5}\right)$ and winter pasture area $\left(z_{6}\right)$ are pasture area size in summer and winter respectively, while dummy variable of pasture plot $\left(z_{7}\right)$ means whether the summer pasture and winter pasture are located in the same plot or adjacent plots. The dummy variable of lease-in grassland $\left(z_{8}\right)$ measures whether there is leased-in grassland from other households, which equals 1 if the household uses leased-in grassland, and 0 for otherwise. A statistical description of the variables used in the specification of the directional distance function and the technical inefficiency model is shown in Table 4.1.

Table 4.1 Descriptive statistics

\begin{tabular}{|c|c|c|c|c|}
\hline Variable Description & Symbol & $\begin{array}{l}\text { Measurement } \\
\text { Unit }\end{array}$ & Mean & Std. Dev. \\
\hline \multicolumn{5}{|l|}{ Inputs variables } \\
\hline Grassland area size & $x_{1}$ & $\mathrm{mu}$ & 937.38 & 1413.14 \\
\hline Labor & $x_{2}$ & person & 2.31 & 1.27 \\
\hline Productive capital & $x_{3}$ & 1000yuan & 129.21 & 186.87 \\
\hline Initial yak at the beginning of 2011 & $x_{4}$ & $1000 \mathrm{~kg}$ & 7.17 & 8.15 \\
\hline \multicolumn{5}{|l|}{ Outputs variables } \\
\hline Good output: revenue from livestock grazing & $y$ & 1000yuan & 105.26 & 112.02 \\
\hline Bad output: grazing pressure & $b$ & - & 0.21 & 0.28 \\
\hline \multicolumn{5}{|l|}{ Household characteristics variables } \\
\hline Total NPP change in 2011 & $z_{1}$ & $1000 \mathrm{kgC}$ & 4.94 & 13.57 \\
\hline Household size & $z_{2}$ & head & 4.72 & 1.67 \\
\hline Distance from fixed home to summer pasture & $z_{3}$ & $\mathrm{~km}$ & 15.24 & 19.68 \\
\hline Grazing experience & $z_{4}$ & year & 29.87 & 11.97 \\
\hline Summer pasture area & $z_{5}$ & $1000 \mathrm{mu}$ & 542.98 & 911.04 \\
\hline \multirow[t]{2}{*}{ Winter pasture area } & $z_{6}$ & $1000 \mathrm{mu}$ & 395.65 & 649.29 \\
\hline & & No. of dummy $=1$ & \multicolumn{2}{|c|}{ No. of dummy $=0$} \\
\hline $\begin{array}{l}\text { Dummy variable pasture plot }(1=\text { the winter pasture } \\
\text { and summer pasture are different plots; } 0=\text { other })\end{array}$ & $z_{7}$ & 44 & \multicolumn{2}{|l|}{149} \\
\hline $\begin{array}{l}\text { Dummy variable of whether there is leased-in } \\
\text { grassland }(1=\mathrm{yes} ; 0=\mathrm{no})\end{array}$ & $z_{8}$ & 43 & \multicolumn{2}{|l|}{150} \\
\hline
\end{tabular}




\subsection{Results}

Before presenting the performance of inputs and outputs in the directional distance function, we compared the directional distance functions with different assumptions of directional vectors $g=\left(g_{y},-g_{b}\right)=(1,-1)$ and $g=\left(g_{y},-g_{b}\right)=(1,0)$ (Table 4.2). We assigned model 1 with directional vector $g=(1,-1)$, which means to expand desirable output while subtracting the undesirable output of grazing pressure. In model $2, g=(1,0)$ is assumed, denoting the expansion of desirable output without subtracting the undesirable output of grazing pressure. A Hausman test is used to compare the two models with a null hypothesis that there are no systematic differences between the two. From the Hausman test below Table 3, we can see the null hypothesis is strongly rejected, indicating that there are systematic differences between the estimates of the two models. Taking into account the distributional signals and monotonicity conditions, model 1 with directional vector $g=(1,-1)$ is preferred. Hereafter, all analysis and estimates will be based on the directional vector of $g=\left(g_{y},-g_{b}\right)=(1,-1)$ in model 1 . The $\delta_{u}$ is estimated to be 0.586 , which means relatively inevitable inefficiency term $u_{i}$, which supports us in setting the directional distance function combined with technical inefficiency model, as showed Table 4.3, where the likelihood value is -3.554 with degree of freedom 31 . The likelihood value of model 1 is 36.824 with degree of freedom of 23 . According to the likelihood ratio test, $\operatorname{LR} \operatorname{Chi}^{2}(8)=$ 66.54 , which is significantly larger than the criteria value of $x_{0.005}^{8}(8)=21.955$; this implies that the setting of the technical inefficiency model would definitely improve the model specification. We took likelihood ratio tests for the technical inefficiency model setting (Appendix table 4.1). According to all the likelihood ratio tests and one-sided inefficiency random components, we choose the final model setting in Table 4.3, and consequently calculate the first order conditions, shadow price and Morishima elasticity of substitutions between inputs. 
Table 4.2 Directional distance function with different directional vector

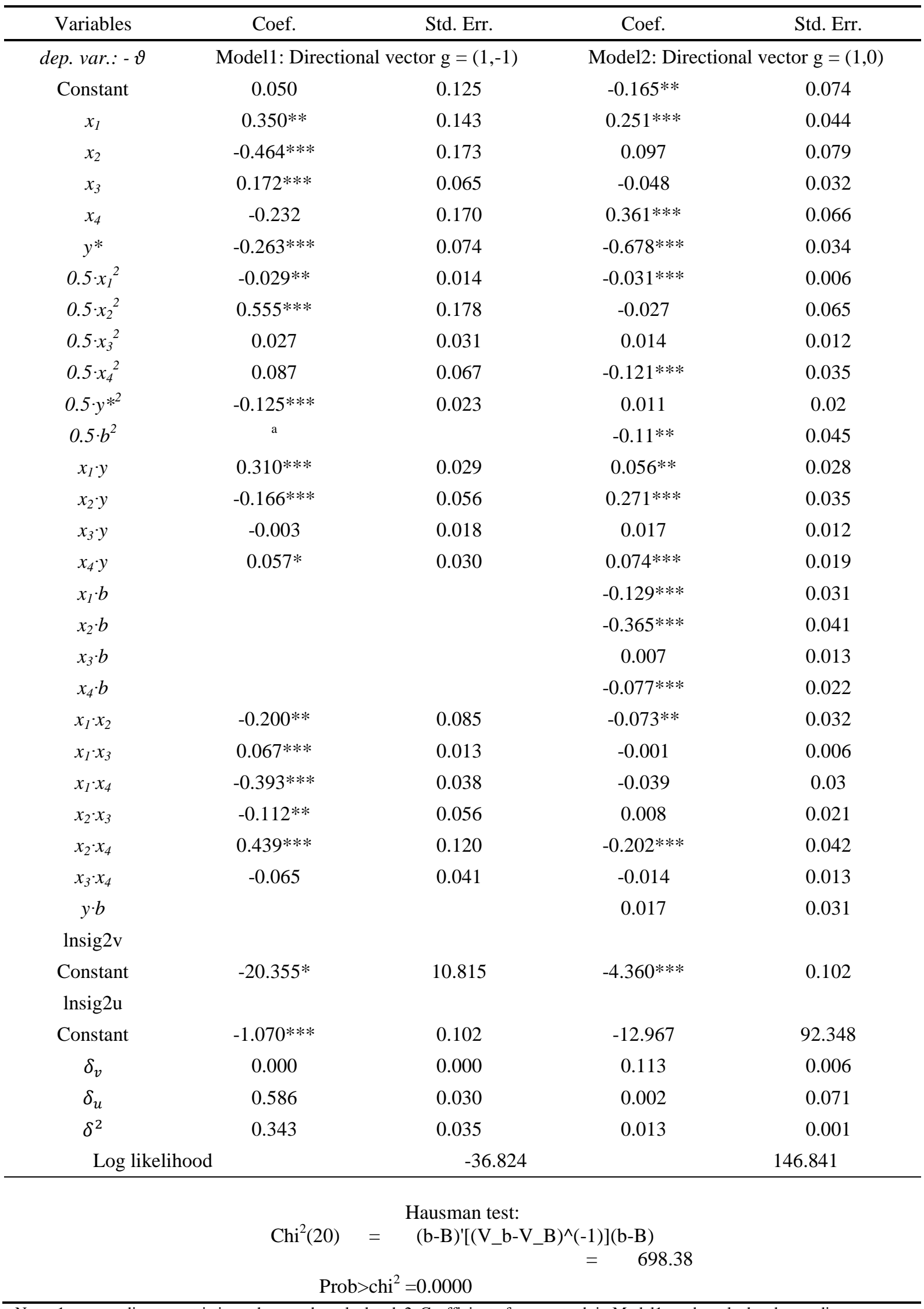

Notes:1. a, according to restrictions, they can be calculated. 2. Coefficient of parameter b in Model1 can be calculated according to restrictions, and parameter $\mathrm{b}$ is transformed to left side variable in Model2. 3. *Significant at $10 \%$ level $(\mathrm{P}<0.10)$, **Significant at $5 \%$ level $(\mathrm{P}<0.05)$, ***Significant at $1 \%$ level $(\mathrm{P}<0.01)$. 
Table 4.3 Estimates of directional distance function and technical inefficiency model

\begin{tabular}{|c|c|c|c|c|c|}
\hline Variables & Coef. & Std. Err. & Variables & Coef & Std. Err. \\
\hline \multicolumn{3}{|c|}{ Stoc. frontier normal/half-normal model } & \multicolumn{3}{|c|}{ Technical inefficiency model } \\
\hline \multicolumn{3}{|c|}{ Dependent variable: - $\vartheta$} & \multicolumn{3}{|c|}{ Dependent variable: $\operatorname{lnsig} 2 \mathrm{u}$} \\
\hline Constant & 0.084 & 0.098 & Constant & $-4.358 * * *$ & 1.662 \\
\hline$x_{1}$ & $0.197^{* *}$ & 0.096 & $z_{1}$ & $-0.265 * * *$ & 0.081 \\
\hline$x_{2}$ & $-0.300 * *$ & 0.135 & $z_{2}$ & $1.176^{* *}$ & 0.548 \\
\hline$x_{3}$ & 0.097 & 0.059 & $z_{3}$ & -0.348 & 0.212 \\
\hline$x_{4}$ & -0.063 & 0.113 & $z_{4}$ & $-1.058 *$ & 0.595 \\
\hline$y^{*}$ & $-0.639 * * *$ & 0.059 & $z_{5}$ & -0.016 & 0.174 \\
\hline $0.5 \cdot x_{1}^{2}$ & $-0.069 * * *$ & 0.016 & $z_{6}$ & $1.033 * * *$ & 0.208 \\
\hline $0.5 \cdot x_{2}^{2}$ & $0.263^{* *}$ & 0.110 & $z_{7}$ & 1.781 & 1.258 \\
\hline $0.5 \cdot x_{3}^{2}$ & $-0.105^{* * *}$ & 0.020 & $z_{8}$ & $-1.947 * * *$ & 0.543 \\
\hline $0.5 \cdot x_{4}^{2}$ & $-0.152 * * *$ & 0.049 & & & \\
\hline $0.5 \cdot y^{2}$ & $-0.071^{* * *}$ & 0.013 & & & \\
\hline$x_{1} \cdot y$ & $0.485^{* * *}$ & 0.031 & & & \\
\hline$x_{2} \cdot y$ & $-0.076^{* *}$ & 0.036 & & & \\
\hline$x_{3} \cdot y$ & $-0.092 * * *$ & 0.014 & & & \\
\hline$x_{4} \cdot y$ & $0.105^{* * *}$ & 0.020 & & & \\
\hline$x_{1}: x_{2}$ & -0.075 & 0.069 & & & \\
\hline$x_{1} \cdot x_{3}$ & 0.023 & 0.022 & & & \\
\hline$x_{1}: x_{4}$ & $-0.409 * * *$ & 0.058 & & & ihood $=-3.554$ \\
\hline$x_{2} \cdot x_{3}$ & $0.134 * * *$ & 0.041 & & Numb & ervation $=193$ \\
\hline$x_{2} \cdot x_{4}$ & $0.214 * * *$ & 0.071 & & Wal & $=5807.730$ \\
\hline$x_{3} \cdot x_{4}$ & $0.157^{* * * *}$ & 0.025 & & & $>\mathrm{Chi}^{2}=0.000$ \\
\hline \multicolumn{6}{|l|}{$\ln \operatorname{sig} 2 v$} \\
\hline Constant & $-3.681 * * *$ & 0.231 & & & \\
\hline
\end{tabular}

Notes: *Significant at $10 \%$ level $(\mathrm{P}<0.10)$, ${ }^{*}$ Significant at $5 \%$ level $(\mathrm{P}<0.05), * * *$ Significant at $1 \%$ level $(\mathrm{P}<0.01)$.

\subsubsection{Parameter estimates of directional distance functions}

The one-step approach for both the directional distance function and technical inefficiency model using maximum likelihood is presented in Table 4.3, with all variables divided by mean. Most coefficients are statistically significant; in particular, all parameter estimates involving the good output $\mathrm{y}$. The directional output distance function is concave in outputs, thus, $\partial^{2}\left(\overrightarrow{D_{o}}(x, y, b ; 1,-1)\right) / \partial y^{2}=\beta_{11} \leq 0$, and according to the restrictions implied by the 
translation property, $\partial^{2}\left(\overrightarrow{D_{o}}(x, y, b ; 1,-1)\right) / \partial b^{2}=\partial^{2}\left(\overrightarrow{D_{o}}(x, y, b ; 1,-1)\right) / \partial y \partial b=\beta_{11}, \beta_{11}$ is estimated to be -0.071 , significant at the $1 \%$ statistical level.

Based on the estimates from the directional distance function, the elasticities of the directional distance function with respect to inputs and outputs are calculated to get a full understanding of the performance of inputs and outputs in the grassland grazing process, elasticities of the sample mean are presented (Table 4.4). A T Test is used to test whether the elasticities are different from zero at the $10 \%$ statistical level. The monotonicity conditions of the directional distance function require $\partial^{2}\left(\overrightarrow{D_{o}}(x, y, b ; 1,-1)\right) / \partial x \geq 0$. With the exception of input $x_{4}$, the initial yak at the beginning of the year, elasticity of distance with respect to inputs grassland area size, labor and capital have expected positive signs, implying that increasing the input of any of these inputs will increase production potential substantially. The largest elasticity of the directional distance with respect to inputs comes from the grassland area, which is estimated to be 0.64 , implying a $1 \%$ increase of grassland area would enhance production potential by $0.64 \%$. The monotonicity conditions of the directional distance function for outputs require $\partial\left(\overrightarrow{D_{o}}(x, y, b ; 1,-1)\right) / \partial y \leq 0$ and $\partial^{2}\left(\overrightarrow{D_{o}}(x, y, b ; 1,-1)\right) / \partial b \geq 0$. The elasticity of distance with respect to desirable output $\varepsilon_{\mathrm{y}}$ is -0.36 and the elasticity of undesirable output grazing pressure $\varepsilon_{\mathrm{b}}$ is estimated to be 0.64 ; both are significant at the $1 \%$ statistical level. A $1 \%$ increase in desirable output would reduce the distance by $0.35 \%$, while a $1 \%$ increase in the undesirable output, grazing pressure, would expand the distance by $0.64 \%$. This means a producer can achieve higher productivity with lower grazing pressure, which is more efficient in the use of the available grassland resource, "ecologically efficient" might be a term to capture this concept. 
Table 4.4 Elasticity of distance with respect to inputs and outputs

\begin{tabular}{ccccc}
\hline Elasticity & Mean & Std. Dev. & Min & Max \\
\hline Inputs elasticity & & & & \\
$\varepsilon_{\mathrm{x} 1}$ & $0.64 * * *$ & 0.68 & -0.73 & 3.93 \\
${ }_{\mathrm{x} 2}$ & $0.08^{* * *}$ & 0.33 & -1.02 & 1.67 \\
$\varepsilon_{\mathrm{x} 3}$ & $0.12^{* * *}$ & 0.18 & -0.71 & 0.57 \\
$\varepsilon_{\mathrm{x} 4}$ & -0.04 & 0.64 & -6.08 & 1.64
\end{tabular}

Outputs elasticity

\begin{tabular}{lllll}
${ }_{\mathrm{E}}^{\mathrm{y}}$ & $-0.36^{* * *}$ & 0.73 & -1.51 & 6.58 \\
${ }_{\mathrm{E}} \mathrm{b}$ & $0.64 * * *$ & 0.73 & -0.51 & 7.58 \\
\hline
\end{tabular}

Notes: T-Test for elasticity different from $0,{ }^{*}$ Significant at $10 \%$ level $(\mathrm{P}<0.10),{ }^{*}$ Significant at $5 \%$ level $(\mathrm{P}<0.05), * * *$ Significant at $1 \%$ level $(\mathrm{P}<0.01)$.

\subsubsection{Shadow price of grazing pressure}

As grazing pressure cannot be traded in the market directly, the relative shadow prices of grazing pressure to revenue of livestock grazing are calculated for a better understanding of their relationship with each other. The relative shadow price of grazing pressure is estimated to be -1.8 at the sample mean, which means the "price" coming from grazing pressure is higher than production of one unit of good output. As there is no reason to interpret a shadow price for observations that violate monotonicity conditions (Färe et al., 2005), we summarize the relative shadow price for a partial sample which meets the monotonicity conditions in the third column of Table 4.5. Thus, we can see that the relative shadow price of grazing pressure is -3.99 , which means that the higher cost household should pay for one unit production of desirable output, again confirming that grazing pressure is an undesirable output from livestock grazing. In previous literature on environmental efficiency analysis, most of the studies of shadow prices of environmental outputs were assumed to be negative (Reinhard, 1999; Färe et al., 1993, 2005; Hailu and Veeman, 2000), which means that these environmental outputs are "undesirable outputs". The value of $\mathrm{M}_{\mathrm{by}}$ is estimated to be -0.55 for all samples, and -0.73 for partial samples which meet the monotonicity condition. A more negative $\mathrm{M}_{\mathrm{by}}$ indicates a greater change in the relative shadow price of grazing pressure for the desirable output of livestock revenue, thus resulting in a greater cost to reduce the undesirable output grazing pressure. 
Table 4.5 Relative shadow price of outputs and elasticity of transformation

\begin{tabular}{ccc}
\hline Variable & $\begin{array}{c}\text { Full sample } \\
(\text { Obs. = 193) }\end{array}$ & $\begin{array}{c}\text { Partial sample } \\
(\text { Obs. = 173) }\end{array}$ \\
\hline Relative shadow price: $\frac{\partial \vec{D}(x, y, b) / \partial y}{\partial \vec{D}(x, y, b) / \partial b}$ & -1.80 & -3.99 \\
$\mathrm{M}_{\text {by }}$ : Morishima elasticity substitution of $b$ to $y$ & -0.55 & -0.73 \\
\hline
\end{tabular}

\subsubsection{Morishima elasticity of substitution between inputs}

Morishima elasticity of substitution (MES) can be used to measure changes in relative output and input quantities as a consequence of changes in relative prices (Färe et al., 2005; Sauer et al., 2012). Using equations (4-11) to (4-15), we calculate MES for substitution or complementarity relations among inputs based on estimates of the directional output distance function (Table 4.6). A positive MES indicates a complementary relationship between two inputs and negative MES indicates a substitutionary relationship between inputs; in terms of absolute value of MES, high values reflect a low degree of complementarity or substitutability and low values reflect a high degree of complementarity or substitution between the inputs (Blackorby and Russell, 1989; Morrison-Paul et al., 2000; Rahman, 2010). Most of the elasticities are positive and are significantly different from zero by the T-test. An exception is the substitution elasticity between the grassland area size and the initial livestock stock which is equal to 0.50 ; there are further complementary relationships among other combinations.

Table 4.6 Morishima elasticity of substitution between inputs

\begin{tabular}{|c|c|c|c|c|}
\hline MES(row, column) & $\begin{array}{l}\mathrm{x} 1 \\
\text { grassland area }\end{array}$ & $\begin{array}{l}\mathrm{x} 2 \\
\text { labor }\end{array}$ & $\begin{array}{l}\mathrm{x} 3 \\
\text { capital } \\
\end{array}$ & $\begin{array}{l}\mathrm{x} 4 \\
\text { initial yaks }\end{array}$ \\
\hline x1 grassland area & - & $0.43 * * *$ & $0.71 * * *$ & $-0.50 * * *$ \\
\hline x2 labor & 0.75 & - & $0.73 * * *$ & $0.75 * * *$ \\
\hline x3 capital & $2.07 * * *$ & $1.99 * *$ & - & $1.96 * *$ \\
\hline x4 initial yaks & 1.02 & 2.07 & 1.96 & - \\
\hline
\end{tabular}

\subsubsection{Estimates for the inefficiency model and for efficiency}

The general-to-specific modeling method (Hendry, 2000) was used in variable selection for deciding on the technical inefficiency model specifications. We first estimate a model 
including all control variables (Appendix table 4.2), and then we drop the least significant variables according to a likelihood ratio test and estimate the model again. This procedure is repeated until only variables that are significant enough to pass the likelihood ratio test at the $10 \%$ level remain. The final determinants for the variation in a grazing household's technical inefficiency are estimated in the technical inefficiency model (right part of Table 4.2). Because technical inefficiency is the dependent variable in the technical inefficiency model, a negative parameter coefficient for the variables indicates a negative effect on technical inefficiency and conversely, a positive effect on technical efficiency.

Total grassland NPP change $\left(z_{1}\right)$ is estimated to be negative in relation to technical inefficiency, -0.265 , significant at the $1 \%$ statistical level. This indicates that the more the total NPP on grassland decreases, the greater the efficiency of the household will be. However, as the total NPP change might be assumed to be consumed by livestock, which would make us aware that the more the total NPP changes, the greater the trend toward it being overgrazed. Household size $\left(z_{2}\right)$ is estimated to be positively related to technical inefficiency, which can be explained as larger household sizes would distract the household head's attention away from grazing, thus resulting in higher inefficiency. There is no significant effect of distance from the fixed home to the summer pasture $\left(z_{3}\right)$ on inefficiency, but it is suggested that this variable be kept in the model by a general-to-specific process. More grazing experience would increase technical efficiency, which was obtained from estimates of grazing experience $\left(z_{4}\right),-1.058$. We treat summer pasture area $\left(z_{5}\right)$, winter pasture area size $\left(z_{6}\right)$ and the dummy variable of pasture plot $\left(z_{7}\right)$ as a variable block, and we can see winter pasture area size is positively related to technical inefficiency, 1.033, significant at the $1 \%$ statistical level. The dummy variable of lease-in grassland $\left(z_{8}\right)$ has a highly positive affect on technical inefficiency, which means leasing in grassland from other households increases technical efficiency.

We calculate each household's technical efficiency after estimation of the stochastic distance function and technical inefficiency model. The average estimated technical efficiency is 0.82 (Table 4.7), which indicates that on average, grazing households can improve technical efficiency by $18 \%$ in terms of expanding livestock revenue and reducing grazing pressure given unchanged inputs. The distribution of technical efficiencies seems satisfactory from the histogram graph (Figure 4.3), and we can see that about $13 \%$ of the households have a technical efficiency smaller than 0.70 , whereas $12 \%$ of households have efficiency greater than or equal to 0.70 and less than $0.80 ; 39 \%$ of households have efficiency greater than or 
equal to 0.80 and less than 0.90 , and $35 \%$ households operate with a technical efficiency larger than 0.90 (Table 4.7).

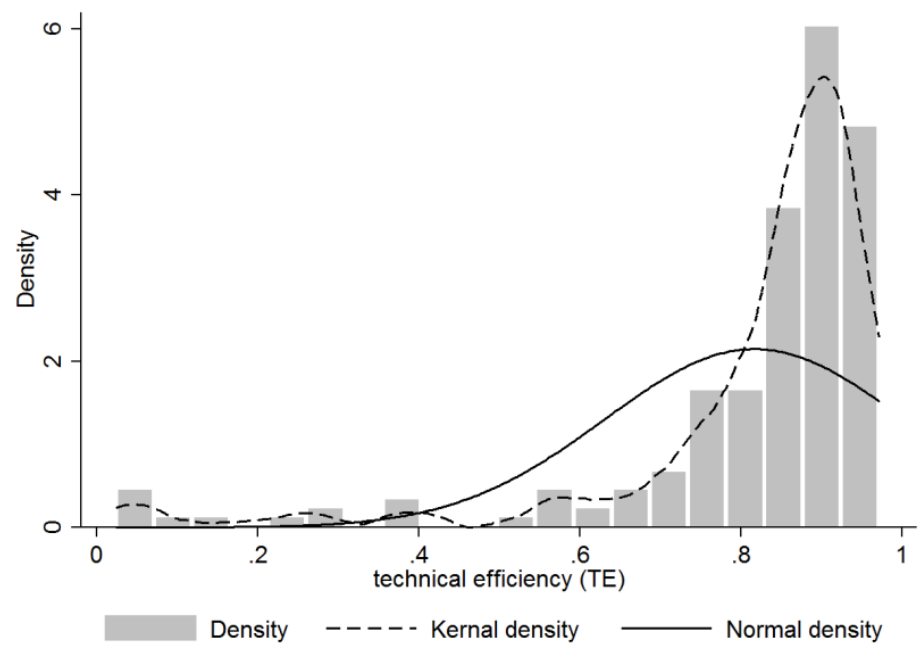

Figure 4.3 Histogram graph of technical efficiency

Table 4.7 Summary of technical efficiency

\begin{tabular}{ccccccc}
\hline Variable & Obs. & Percentage & Mean & Std. Dev. & Min. & Max. \\
\hline TE $<0.70$ & 25 & $13 \%$ & 0.42 & 0.24 & 0.02 & 0.70 \\
$0.70 \leqslant \mathrm{TE}<0.80$ & 24 & $12 \%$ & 0.76 & 0.03 & 0.70 & 0.80 \\
$0.80 \leqslant \mathrm{TE}<0.90$ & 76 & $39 \%$ & 0.86 & 0.03 & 0.80 & 0.90 \\
$\mathrm{TE} \geqslant 0.90$ & 68 & $35 \%$ & 0.93 & 0.02 & 0.90 & 0.97 \\
Technical efficiency (TE) & 193 & $100 \%$ & 0.82 & 0.19 & 0.02 & 0.97 \\
\hline
\end{tabular}

\subsection{Conclusion and discussion}

Incorporating grazing pressure as the undesirable output from livestock grazing using the directional distance function is a new step toward environmental efficiency analysis in the field of productivity and efficiency analysis. The environmental variable, grazing pressure, as the undesirable output from livestock grazing, plays a significant role in the directional distance function and technical inefficiency model. The average technical efficiency is estimated to be 0.82 , implying that grassland production potential can be increased by $18 \%$ with directional adjustment of reduction in grazing pressure.

Overgrazing was considered one of the main factors driving grassland ecosystem degradation, although in fact the grazing pressure steadily decreased during the period studied. In recent 
research on overgrazing in the Sanjiangyuan region, overgrazing was believed to remain a problem in 2010 (Zhang et al., 2014). As from the findings of our study, livestock grazing is probably operating along the line from point A to point $\mathrm{B}$, according to the estimates of the directional distance function, which means we would be better to leave constant or increase the production potential of livestock grazing in the Sanjiangyuan region without increasing the grazing pressure given the amount grassland size, labor, and capital.

Livestock grazing can have negative impacts on the environment if it is not kept within acceptable limits. An efficiency livestock grazing monitor approach is suggested to ensure a proper livestock stocking rate. The tradeoff between traditional livestock grazing production and ecological and environmental protection of grassland calls for more scientific research on how to improve production potential with sustainable grassland use. Finding how environmental variables and grazing pressure affect the production potential and technical inefficiency of livestock grazing in this study would be helpful for the development of scientific strategies and programs for local economic development and environmental protection, as well as for the effectiveness of ecological protection projects.

There are a few limitations in this paper, for example, there is an assumption that the quality of livestock meat is homogenous for different livestock age groups. In terms of the approximate pasture boundary matching the long time period and large scale of remote sensing data to the household scale, there is inevitable measurement error to some extent. For the grazing pressure measurement, we have not considered the grazing pressure from wild stock (Fisher, 2004). The consideration of the impact of both domestic stock and wild stock for analysis of sustainable livestock grazing could be considered in future work when wild stock data is available. 
Chapter 4

\section{Chapter appendix}

Appendix table 4.1 Hypothesis test for model selection

\begin{tabular}{llll}
\hline Model & Description & Likelihood value & Degree of freedom \\
\hline $\mathrm{H}_{0}$ & $\begin{array}{l}\text { Final model presented in paper } \\
\text { directional distance function without setting technical }\end{array}$ & -3.554 & 31 \\
$\mathrm{H}_{1}$ & $\begin{array}{l}\text { inefficiency mode: } \tau_{0}=\tau_{1}=\tau_{2}=\tau_{3}=\tau_{4}=\tau_{5}= \\
\tau_{6}=\tau_{7}=\tau_{8}=0\end{array}$ & -36.823 & 23 \\
$\mathrm{H}_{2}$ & Full model seeting & -1.985 & 35 \\
$\mathrm{H}_{3}$ & $\tau_{1}=0$ & -8.678 & 30 \\
$\mathrm{H}_{4}$ & $\tau_{2}=0$ & -6.888 & 30 \\
$\mathrm{H}_{5}$ & $\tau_{3}=0$ & -5.016 & 30 \\
$\mathrm{H}_{6}$ & $\tau_{4}=0$ & -5.964 & 30 \\
$\mathrm{H}_{7}$ & $\tau_{5}=\tau_{6}=\tau_{7}=0$ & -18.008 & 27 \\
$\mathrm{H}_{8}$ & $\tau_{8}=0$ & -11.782 & 30 \\
\hline
\end{tabular}


Appendix table 4.2 Model setting with all reasonable variables in technical inefficiency model

\begin{tabular}{|c|c|c|c|c|c|}
\hline Variables & Coef. & Std. Err. & Variables & Coef. & Std. Err. \\
\hline \multicolumn{3}{|c|}{ Stoc. frontier normal/half-normal model } & \multicolumn{3}{|c|}{ Technical inefficiency model } \\
\hline \multicolumn{3}{|c|}{ Dependent variable: - $\vartheta$} & \multicolumn{3}{|c|}{ Dependent variable: $\operatorname{lnsig} 2 \mathrm{u}$} \\
\hline Constant & 0.074 & 0.095 & Constant & $-5.404 * * *$ & 2.014 \\
\hline$x_{1}$ & $0.202 * *$ & 0.094 & $z_{1}$ & $-0.246 * * *$ & 0.079 \\
\hline$x_{2}$ & $-0.292 * *$ & 0.133 & $z_{2}$ & $1.131 * *$ & 0.54 \\
\hline$x_{3}$ & 0.097 & 0.059 & $z_{3}$ & -0.234 & 0.173 \\
\hline$x_{4}$ & -0.053 & 0.112 & $z_{4}$ & $-1.031 *$ & 0.566 \\
\hline$y^{*}$ & $-0.631 * * *$ & 0.064 & $z_{5}$ & -0.015 & 0.18 \\
\hline $0.5 \cdot x_{1}^{2}$ & $-0.068 * * *$ & 0.015 & $z_{6}$ & $0.959 * * *$ & 0.202 \\
\hline $0.5 \cdot x_{2}^{2}$ & $0.267 * *$ & 0.111 & $z_{7}$ & 1.764 & 1.295 \\
\hline $0.5 \cdot x_{3}^{2}$ & $-0.107 * * *$ & 0.02 & $z_{8}$ & $-1.662 * * *$ & 0.513 \\
\hline $0.5 \cdot x_{4}^{2}$ & $-0.139 * * *$ & 0.049 & $z_{9}$ & -0.049 & 0.077 \\
\hline $0.5 \cdot y^{* 2}$ & $-0.071 * * *$ & 0.013 & $z_{10}$ & 0.587 & 0.663 \\
\hline$x_{1} \cdot y$ & $0.483 * * *$ & 0.031 & $z_{11}$ & 0.559 & 0.421 \\
\hline$x_{2} \cdot y$ & $-0.080 * *$ & 0.038 & $z_{12}$ & -0.082 & 0.398 \\
\hline$x_{3} \cdot y$ & $-0.090 * * *$ & 0.014 & & & \\
\hline$x_{4} \cdot y$ & $0.100 * * *$ & 0.02 & & & \\
\hline$x_{1} \cdot x_{2}$ & -0.087 & 0.07 & & & \\
\hline$x_{1} \cdot x_{3}$ & 0.025 & 0.022 & Log likelih & 985 & \\
\hline$x_{1} \cdot x_{4}$ & $-0.411 * * *$ & 0.057 & Number of & ion $=193$ & \\
\hline$x_{2} \cdot x_{3}$ & $0.140 * * *$ & 0.042 & Wald chi2 & 30.070 & \\
\hline$x_{2} \cdot x_{4}$ & $0.214 * * *$ & 0.073 & Prob>chi2 & & \\
\hline$x_{3} \cdot x_{4}$ & $0.154 * * *$ & 0.026 & & & \\
\hline \multicolumn{6}{|l|}{$\ln \operatorname{sig} 2 v$} \\
\hline Constant & $-3.742 * * *$ & 0.26 & & & \\
\hline
\end{tabular}

Notes: *Significant at $10 \%$ level $(\mathrm{P}<0.10),{ }^{* *}$ Significant at $5 \%$ level $(\mathrm{P}<0.05),{ }^{* * *}$ Significant at $1 \%$ level $(\mathrm{P}<0.01)$.

Appendix table 4.3 Descriptive statistics for additional variables in appendix table 4.2

\begin{tabular}{|c|c|c|c|c|}
\hline Variable Description & Symbol & Unit & Mean & Std. Dev. \\
\hline \multicolumn{5}{|l|}{ Continuous variables } \\
\hline Total direct subsidy from government & $z_{9}$ & 1000yuan & 9.52 & 21.40 \\
\hline grazed month of summer pasture & $z_{10}$ & month & 5.52 & 1.38 \\
\hline duration of getting the use right of pasture & $z_{11}$ & year & 19.56 & 7.59 \\
\hline Dummy variables & & \multicolumn{2}{|c|}{ No. of dummy $=1$} & No. of dummy $=0$ \\
\hline $\begin{array}{l}\text { Dummy variable of education }(1=\text { has been } \\
\text { education; } 0=\text { no education) }\end{array}$ & $z_{12}$ & 58 & & 135 \\
\hline
\end{tabular}




\section{Chapter 5}

\section{Overall summary}

$\mathrm{T}$ This study has been motivated by the booming environmental issues accompanying the rapid economic development in China such as air pollution, water pollution, biodiversity loss, desertification and erosion, but especially air pollution and water pollution which both have a measureable impact on people's daily life. Emerging environmental problems have stimulated the conscience of the Chinese people and encouraged them to think about environmental protection. China's government has been making efforts to protect the environment with the implementation of more and more eco-environmental programs and environment related regulations. Grasslands in China cover nearly 4 million $\mathrm{km}^{2}$, more than $40 \%$ of China's total land area. In spite of numerous efforts that have been undertaken to arrest grassland desertification in China, grassland degradation is still advancing over wide areas. The main responsibility has been attributed to livestock grazing as the dominant economic activity on grassland. We aim to tackle the environmental efficiency of livestock grazing, researching the performance of livestock grazing with respect to both ecological and environmental perspectives.

The Sanjiangyuan region has been selected as the case study region, as it can be considered to be representative of the livestock grazing system on the Qinghai-Tibetan Plateau, also called "the Third Pole of Earth". The important role played by the Qinghai-Tibetan Plateau in the ecological system and environment means that long term protection is essential; key to that protection must be environmentally friendly livestock grazing. Grasslands play an important role in livestock farming and environmental conservation, but three quarters of the world's 
grazing lands are degraded. The same symptoms of degradation have been detected on the Qinghai-Tibetan Plateau, especially in the Sanjiangyuan region.

In this study, we carry out a productivity and efficiency analysis of livestock grazing with respect to both an ecological and environmental perspective. We first review grassland property rights changes in China and build a productivity and efficiency analysis of yak grazing focusing on grassland property rights. Secondly, we incorporate ecological variables and the total NPP into the production function to calculate the ecological performance indicator and the total NPP efficiency as two new measurements of environmental efficiency. Finally, we consider grazing pressure as an undesirable output from livestock grazing using a directional distance function; we then calculate the shadow price of grazing pressure and the Morishima elasticity of substitution between inputs and between outputs.

\subsection{General findings}

In Chapter 2, we review grassland property rights changes in China and build a productivity and efficiency analysis of yak grazing, focusing on grassland property rights. With respect to the grassland property rights changes in the Sanjiangyuan region, there are five distinct periods up to the present. The first time period was before the establishment of the People's Republic of China, when private pastures were owned by the Three Feudal Landlords and public pastures were owned by households; the private pasture represented the majority scenario. In that time, there were neither laws to guarantee grassland ownership nor clear boundaries in place between pastures; livestock were completely privatized. The second time period was the time of the People's Commune, when both grassland and livestock were owned by the state. The boundaries between pastures were made according to the administrative regional boundaries and no fence was used to mark boundaries. The third time period was from about 1984 to 1994, when livestock was privatized, but common grassland use rights existed for every household located on common state owned pastures. Both China's Grassland Law (promulgated in 1985) and China's Revised Grassland Law (promulgated in 2003) clearly state that the state owns the land. The fourth time period was from 1994, when usage rights for grassland were contracted to households. The HRS divided the grassland into small pieces given to groups or individual households; a fence was used to mark the grassland boundaries. Recently, new management forms such as cooperative household groups and 
grassland use rights leasing have become popular, and fragmented grasslands are being reintegrated in some areas.

In Chapter 2, we introduce the variable of whether the household has leased-in grassland from other households; this lets us see the impact of the grassland lease status on the technical inefficiency. It is found that leasing more grassland than originally assigned improves the technical efficiency of yak grazing. The overall average technical efficiency is estimated to be 0.618 , implying that yak production can be increased by $38.2 \%$ without any requirements for additional resources; this is lower than the value of 0.666 for households who have leased-in grassland from other households. It seems that fragmented grasslands, when in small pieces, reduce the technical efficiency of livestock husbandry in the Sanjiangyuan region because of obstacles caused by grassland use rights privatization, e.g. difficulty of access to livestock drinking water, fuzzy boundaries, and obstacles to grazing mobility. This is also consistent with other research on alpine grasslands, grasslands in arid or semiarid regions, or those in the Central Asian Highlands (Kreutzmann 2013). The variable block of livestock intensity of pasture plays a significant role in yak grazing, especially the dummy variable of whether the summer pasture is located in the same plot as winter pasture. This might indicate that the government and household should pay more attention to pasture location distribution and grassland over-grazing.

In Chapter 3, we incorporate ecological variables and the total NPP into the production function to measure the technical efficiency, the ecological performance indicator and the total grassland NPP capacity efficiency of grassland grazing. This is facilitated by comparing an unlimited model incorporating grassland total NPP capacity to limited models which incorporate either the grassland area size or none of them. The average technical efficiency is estimated to be 0.837 when taking into account the grassland total NPP capacity. This implies that the cost of livestock grazing can be decreased by $16.3 \%$ without any reduction of outputs. The average EPI is estimated to be 0.013 , representing the effects associated with NPP; the average TNPPE is 0.123 , meaning that livestock grazing is still under good control, without any overuse of the grassland area or NPP. The total NPP of the available grassland plays a significant role in the stochastic distance function and technical inefficiency model, but grassland total NPP tends to be less important for households with comparatively higher technical efficiencies. A high total grassland NPP capacity efficiency may mean overuse of grassland NPP, which may lead to grassland deterioration, thus it is good to see the average TNPPE is comparatively low. 
In Chapter 4, we consider grazing pressure as an undesirable output from livestock grazing using a directional distance function. We then calculate the shadow price of grazing pressure and the Morishima elasticity of substitution between inputs and between outputs. The average technical efficiency is estimated to be 0.82 , implying that the grassland production potential can be increased by $18 \%$ with adjustment of directional reduction of grazing pressure. The environmental variable, grazing pressure, is an undesirable output from livestock grazing and plays a significant role in both the directional distance function and technical inefficiency model. The average technical efficiency is estimated to be 0.82 under the control of grazing pressure and the shadow price of grazing pressure to livestock revenue is estimated to be -1.8 . According to the Morishima elasticity of substitution between inputs, there is a significant complementary relationship between grassland area, labor and capital. The elasticity of substitution between grassland and initial livestock stocking is estimated to be 0.50 .

\subsection{Policy implications and research significance}

Together with increasing demand for meat and more concerns about food safety, there is a noticeable growth in demand for products from livestock grazing. In order to improve the production potential of livestock grazing, we suggest a clearer regulation of grassland use rights leasing and use rights turnover among households. More and more conflicts due to the leasing of grassland use rights have happed in the last decade. One noticeable explanation behind the unsatisfactory outcome of grassland HRS is the unclear definition of grassland use rights. Take grassland leasing, for example - a lack of investment on the leased grassland can lead to over grazing. The short term economic revenue goals of pastoralist households are in conflict with the government's long term sustainable development goals. China's policy makers should take into account various characteristics of different regions and the grassland property rights policy should be implemented appropriately.

Even if the livestock grazing is technically efficient from an economic perspective, it may lead to overgrazing and degradation of grasslands from an environment science perspective. There is a tradeoff between traditional extensive livestock grazing production and the ecological and environmental protection of grassland. This is due to the fact that the traditional livestock grazing system relies on the use of grassland areas. The extensive grazing system is usually based on a low carrying capacity native pasture, without irrigation, and usually in an arid or semiarid area. Such a system has a number of advantages over intensive 
grazing; it requires less rainfall, less labor per unit area and lower requirements for inputs such as fertilizer, pesticides and modern machinery (McDowell, 2008).

Livestock grazing can have a negative impact on the environment if it is not controlled within acceptable limits. With reference to Figure 4, there is a reverse U-shape relationship between cumulative grazing pressure and livestock production per unit area grassland. The livestock production per unit area increases according to cumulative grazing pressure until point $\mathrm{A}$, and then begins to decline at the critical cumulative grazing pressure. However, the ecological risk is monotonously positively increasing as cumulative grazing pressure is increasing, which is strongly associated with overgrazing. A higher probability of ecological risk would result in a higher probability of grassland degradation (McDowell, 2008). As from the findings of our study, livestock grazing is probably operating along a line from point A to point B, according to the estimates of the directional distance function, which means we would be better to leave constant or increase the production potential of livestock grazing in the Sanjiangyuan region without increasing the grazing pressure given the amount grassland size, labor, and capital.

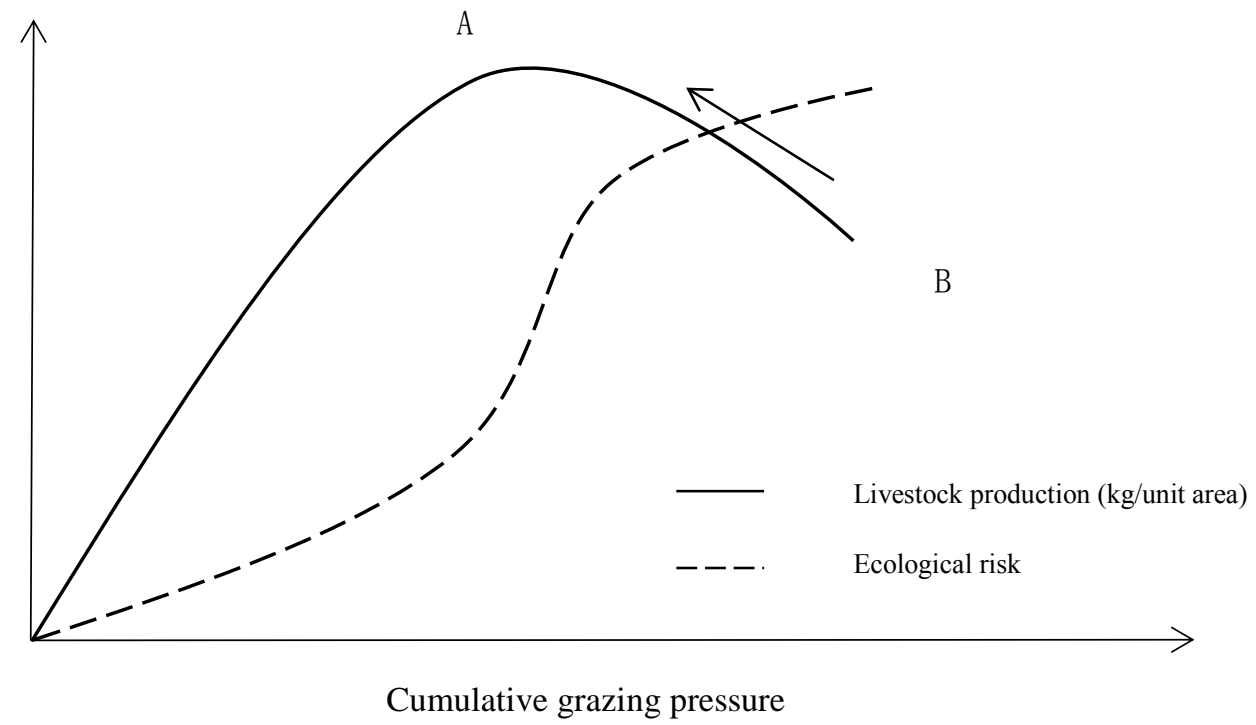

Figure 5.1 Relationship between cumulative grazing pressure, ecological risk and livestock production

Overall, grazing pressure is treated as an undesirable output of livestock grazing in the directional distance function. Meanwhile, livestock grazing is a new step in the general direction of better accounting for natural resource use/depletion in the efficiency and production analysis. 
Empirically, we aim to reflect the relationship between overgrazing and grassland degradation from an environmental efficiency perspective. We stress a deeper understanding of the significance of grassland protection and support the policy maker in continuing or making new suitable long term policies to protect the grassland and ecological system for sustainable development; this is important for both the regional ecological environment and the natural ecological environment.

The system of extensive livestock grazing on the Qinghai-Tibetan Plateau is practiced elsewhere around the world, such as in mid-latitude sections of most continents, as well as in desert regions where water for cropping is not available (White, 2000; McDowell, 2008). Although our case study area has been limited to the Sanjiangyuan region, the issue discussed could be of relevance to a wider range of extensive livestock grazing on the Qinghai-Tibetan Plateau, even extending to the extensive livestock grazing system on the central Asian highlands as well as in other regions in Africa, Latin America, and in Western Australia.

\subsection{Limitations}

There is an assumption that the quality of livestock meat is homogenous for different livestock age groups. This in turn implies that estimates might be more reasonable if we were provided with the quality of yak meat.

Inevitable measurement errors come from the matching process. Pasture boundary is approximate draw from long time schedule and large scale level remote sensing data. Matching the remote data to minor scale household level data might cause errors.

Although animal welfare is said to be generally improved in comparison to intensive grazing where livestock is raised in limited conditions, we haven't taken the animal welfare into account. Indeed, other animal science perspectives are also absent.

For the measurement of grazing pressure, we have not considered the grazing pressure from wild stock. This could be improved if we include the impact of both domestic stock and wild stock for any analysis of sustainable livestock grazing (Fisher, 2004). 


\section{Bibliography}

Abdulai, A., Owusu, V., and Goetz, R. (2011). Land tenure differences and investment in land improvement measures: Theoretical and empirical analyses. Journal of Development Economics 96(1): 66-78.

Aigner, D., Lovell, C. A. K., and Schmidt, P. (1977). Formulation and estimation of stochastic fromtier production function models. Journal of Econometrics 6: 21-37.

Akiyama, T., and Kawamura, K. (2003). Vegetation changes and land degradation of steppe in Inner Mongolia. Journal of Japan Agricultural System 19(3): 12-22.

Akiyama, T., and Kawamura, K. (2007). Grassland degradation in China: Methods of monitoring, management and restoration. Japanese Society of Grassland Science 53: 1-17.

Allen, V. G., Batello, C., Berretta, E. J., Hodgson, J., Kothmann, M., Li, X., and Sanderson, M. (2011). An international terminology for grazing lands and grazing animals. Grass and Forage Science 66(1): 2-28.

Asante, B. O., Wiredu, A. N., and Martey, E., et al., (2014). NERICA Adoption and Impacts on Technical Efficiency of Rice Producing Households in Ghana : Implications for Research and Development. American Journal of Experimental Agriculture 4: 244-262.

Atkinson, S. E., and Dorfman, J. H. (2005). Bayesian measurement of productivity and efficiency in the presence of undesirable outputs: crediting electric utilities for reducing air pollution.
Journal of Econometrics 126 (2): 445468.

Banks, T. (2003). Property Rights Reform in Rangeland China: Dilemmas On the Road to the Household Ranch. World Development 31(12): 2129-2142.

Banks, T., Richard, C., Li, P., Yan, Z., Experience, P. P., and Implications, $\mathrm{P}$. (2003). Community-Based Grassland Management in Western China. Mountain Research and Development 23(2): 132-140.

Battese, G. E., and Coelli, T. J. (1988). Prediction of Firm-Level Technical Efficiencies with a Generalized Frontier Production Function and Panel Data. Journal of Econometrics 38(3): 387-399.

Battese, G. E., and Coelli, T. J. (1995). A Model for Technical Inefficiency Effects in a Stochastic Frontier Production Function for Panel Data. Empirical Economics 20: 325-332.

Battese, G. E., Malik, S. J., and Gill, M. A. (1996). An investigation of technical inefficiencies of production of wheat farmers in four districts of Pakistan. Journal of Agricultural Economics 47(1): 37-49.

Battese, G.E., and Broca, S.S., 1997. Functional Forms of Stochastic Frontier Production Functions and Models for Technical Inefficiency Effects : A Comparative Study for Wheat Farmers in Pakistan. Journal of Productivity Analysis 414: 395-414.

Beltrán-Esteve, M., Gómez-Limón, J. a., and Picazo-Tadeo, A. J., et al., 2014. A metafrontier directional distance function approach to assessing eco- 
efficiency. Journal of Productivity Analysis, 41(1), 69-83.

Blackorby, C., and Russell, R. (1989). Will the Real Elasticity of Substitution Please Stand Up? (A Comparison of the Allen/Uzawa and Morishima Elasticities). The American Economic Review 79(4): 882-888.

Blench, R. (2001). "You can't go home again" Pastoralism in the new millennium.

Bozoglu, M. and Ceyhan, V., (2007). Measuring the technical efficiency and exploring the inefficiency determinants of vegetable farms in Samsun province, Turkey. Agricultural Systems 94: 649656.

Brower, B., and Dennis, A. (2000). Yak grazing and forest dynamics in Sagarmatha National Park, Nepal. In J. Han, C. Richard, O. Hanotte, C. McVeigh, \& J. E. O. Rege (Eds.), Proceedings of the third international congress on yak. Lhasa, P.R. China.

Brümmer, B., Glauben, T., and Lu, W. (2006). Policy reform and productivity change in Chinese agriculture: A distance function approach. Journal of Development Economics 81(1): 61-79.

Brümmer, B., Glauben, T., and Thijssen, G., (2002). Decomposition of Productivity Growth Using Distance Functions: The Case of Dairy Farms inThree European Countries. American Journal of Agricultural Economics 84: 628-644.

Brümmer, B. and Loy, J. (2000). The Technical Efficiency Impact of Farm Credit Programmes: A Case Study of Northern Germany. Journal of Agricultural Economics.

Campos, J., Ericsson, N. R., and Hendry, D. F. (2005). General-To-Specific Modeling: An Overview and Selected Bibliography(838).

Cencetti, E. (2010). Tibetan Plateau Grassland Protection: Tibetan Herders Ecological Conceptions Versus State Policies. Himalaya39-50.
Chambers, R. G. (2002). Exact nonradial input, output, and productivity measurement. Economic Theory 20(4): 751-765.

Chambers, R. G., Chung, Y., and Färe , R. (1998). Profit , Directional Distance Functions ,. Journal of Optimization and Application 98(2): 351-364.

Chand, S. and Yala, C. (2009). Land Tenure and Productivity: Farm-Level Evidence from Papua New Guinea. Land Economics 85(3): 442-453.

Chen, Z., Huffman, W. E. and Rozelle, S., (2009). Farm technology and technical efficiency: Evidence from four regions in China. China Economic Review 20: 153-161.

Chertkov, B., and Kasmaliev, M. (2000). Possibility of increasing yak number and productive efficiency in Kyrgyzstan. In J. Han, C. Richard, O. Hanotte, C. McVeigh, \& J. E. O. Rege (Eds.), The third international congress on yak. Lhasa, P. R. China.

Chung, Y. H., Färe, R., and Grosskopf, S. (1997). Productivity and Undesirable Outputs: A Directional Distance Function Approach. Journal of Environmental Management 51: 229240.

Coelli, T. J. (1995). Recent developments in frontier modelling and efficiency measurement. Australian Journal of Agricultural Economics 39(3): 219245.

Coelli, T. J., Gautier, A., Perelman, S., and Saplacan-Pop, R. (2013). Estimating the cost of improving quality in electricity distribution: A parametric distance function approach. Energy Policy 53: 287-297.

Coelli, T., and Battese, G. (1996). Identification of factors which influence the technical inefficiency of Indian farmers. Australian Journal of Agricultural Economics 40(2): 103128. 
Coelli, T., and Perelman, S. (2000). Technical efficiency of European railways: a distance function approach. Applied Economics 32(15): 1967-1976.

Coelli, T., Lauwers, L., and Huylenbroeck, G., (2007). Environmental efficiency measurement and the materials balance condition. Journal of Productivity Analysis. 28: 3-12.

Cropper, M. L., and Oates, W. E. (1992). Environmental Economics. Journal of Economic 30(2): 675-740.

Cuesta, R. a., Lovell, C. A. K., Zofío, J. L., and Zofio, J. L. (2009). Environmental efficiency measurement with translog distance functions: A parametric approach. Ecological Economics 68(89): 2232-2242.

Davies, J., and Hatfield, R. (2007). The Economics of Mobile Pastoralism: A Global Summary. Nomadic Peoples 11(1): 91-116.

De Haan, C., Steinfeld, H., and Blackburn, H. (1997). Livestock \& the environment: finding a balance. Rome, Italy.: European Commission DirectorateGeneral for Development, Development Policy Sustainable Development and Natural Resources.

Deininger, K., and Ali, D. A. (2008). Do overlapping land rights reduce agricultural investment? evidence from Uganda. American Journal of Agricultural Economics 90(4): 869882.

Deininger, K., and Jin, S. (2005). The potential of land rental markets in the process of economic development: Evidence from China. Journal of Development Economics 78(1): 241270.

Deininger, K., and Jin, S. (2006). Tenure security and land-related investment: Evidence from Ethiopia. European Economic Review 50(5): 1245-1277.

Deininger, K., Jin, S., Xia, F., and Huang, J. (2014). Moving off the farm: Land institutions to facilitate structural transformation and agricultural productivity growth in China. World Development 59: 505-520.

Du, L., and Hanley, A. (2015). Estimating the Marginal Abatement Costs of Carbon Dioxide Emissions in China: A Parametric Analysis. Environmental and Resource Economics(1883): 191216.

Fan, J.W., Shao, Q.Q., and Wang, J.B. et al., (2011). An analysis of temporal spatial dynamics of grazing pressure on grassland in Three Rivers Headwater Region. Chinese Journal of Grassland, 33(3): 64-72. (in Chinese).

Fan, S. G. (1991). Effects of TechnologicalChange and Institutional Reform on Production Growth in Chinese Agriculture. American Journal of Agricultural Economics 73(2): 266275.

Färe, R., and Grosskopf, S. (2000). Theory and Application of Directional Distance Functions. Journal of Productivity Analysis 13: 93-103.

Färe, R., and Karagiannis, G. (2013). Radial and directional measures of the rate of technical change. Journal of Economics 112(2): 183-199.

Färe, R., and Primont, D. (1996). The opportunity cost of duality. Journal of Productivity Analysis 7(2-3): 213-224.

Färe, R., Grosskopf, S., and Pasurka, C. (1989). The Effect of EnvironmentalRegulations on the Efficiency of Electric Utilities - 1969 Versus 1975. Applied Economics 21(2): 225-235.

Färe, R., Grosskopf, S., Lovell, C. A. K., and Yaisawarng, S. (1993). Derivation of Shadow Prices for Undesirable Outputs - a Distance Function-Approach. Review of Economics and Statistics 75(2): 374-380.

Färe, R., Grosskopf, S., Noh, D.-W., and Weber, W. (2005). Characteristics of a polluting technology: theory and 
practice. Journal of Econometrics 126(2): 469-492.

Färe, R., Grosskopf, S., Pasurka, C., and Färe , R. (1986). Effects on relative efficiency in electric power generation due to environmental controls. Resources and Energy 8(2): 167-184.

Färe, R., Grosskopf, S., and Tyteca, D., (1996). An activity analysis model of the environmental performance of firms - Application to fossil-fuel-fired electric utilities. Ecological Economics 18: 161-175.

Feng, G., and Serletis, A. (2014). Undesirable outputs and a primal Divisia productivity index based on the directional output distance function. Journal of Econometrics 183(1): 135146.

Feng, S., Heerink, N., Ruben, R., and Qu, F. (2010). Land rental market, off-farm employment and agricultural production in Southeast China: A plotlevel case study. China Economic Review 21(4): 598-606.

Fernandez, C., Koop, G., and Steel, M. F. (2002). Multiple output production with undesirable outputs: an application to nitrogen surplus in agriculture. Journal of the American Statistical Association 97(458): 432442.

Fisher, A., Hunt, L., James, C., Landsberg, J., Phelps, D., Smyth, A., and Watson, I. (2004). Management of total grazing pressure Managing for biodiversity in the rangelands.

Foggin, J. M. (2000). Biodiversity Protection and the search for sustainability in Tibetan Plateau Grasslands (Qinghai,China). Arizona State University.

Foggin, J. M., and Torrance-Foggin, M. E. (2011). How can social and environmental services be provided for mobile Tibetan herders? Collaborative examples from Qinghai Province,
China. Pastoralism: Research, Policy and Practice 1(1): 21.

Galdeano-Gómez, E., Céspedes-Lorente, J., 2008. Environmental spillover effects on firm productivity and efficiency: An analysis of agri-food business in Southeast Spain. Ecological Economics 67: 131-139.

Gaynor, M., and Putterman, L. (1993). Productivity consequences of alternative land division methods in China's decollectivization An econometric analysis. Journal of Development Economics 42(2): 357386.

Glauben, T., Thijssen, G., and Brümmer, B. (2002). Decomposition of Productivity Growth Using Distance Functions: The Case of Dairy Farms inThree European Countries. American Journal of Agricultural Economics 84(3): 628644.

Guesmi, B., and Serra, T., (2015). Can We Improve Farm Performance? The Determinants of Farm Technical and Environmental Efficiency. Applied Economic Perspectives and Policy, 0(0): 1-26. (incoming) http://doi.org/10.1093/aepp/ppv004

Guo, Z., and Ma, H. (2005). Institutional Choice of the Sustainble Development in the Sanjiangyuan District of Qinghai province (in Chinese). Reform 10: 4650 .

Hailu, A., and Veeman, T. S. (2000). Environmentally Sensitive Productivity Analysis of the Canadian Pulp and Paper Industry , 1959 . 1994 : Journal of Environmental Economics and Management(40): 251-274.

Hardin, G. (1968). The Tragedy of the Commons. Science 162(13): 12421248.

Harris, R. B. (2010). Rangeland degradation on the Qinghai-Tibetan plateau: A review of the evidence of its magnitude and causes. Journal of Arid Environments 74(1): 1-12. 
Hendry, D. F. (1980). Econometrics-alchemy or science? Economica 47(188): 387406.

Hendry, David F., (2000). Econometrics: alchemy or science?: essays in econometric methodology. OUP Catalogue.

Hoang, V.-N., and Alauddin, M., (2012). Input-Orientated Data Envelopment Analysis Framework for Measuring and Decomposing Economic , Environmental and Ecological Efficiency : An Application to OECD Agriculture. Environmental Resource Economics 51: 431-452.

Huang, J. K., and Rozelle, S. (1996). Technological change: Rediscovering the engine of productivity growth in China's rural economy. Journal of Development Economics 49(2): 337369.

Huppes, G., and Ishikawa, M., (2005). Ecoefficiency and Its Terminology. Journal of Industrial Ecology 9: 43-46.

Kreutzmann, H. (2013). The tragedy of responsibility in High Asia: modernizing traditional pastoral practices and preserving modernist worldviews. Pastoralism: Research, Policy and Practice 3(1): 1.

Kumbhakar, S., and Lovell, C. A. K. (2000). Stochastic frontier analysis. Cambridge, UK.: Cambridge University Press.

Kumbhakar, S., and Lovell, C. A. K. (2000). Stochastic frontier analysis. Cambridge, UK.: Cambridge University Press.

Kuosmanen, T., and Kortelainen, M., (2005). Measuring eco-efficiency of production with data envelopment analysis. $\mathbf{J}$ Industrial Ecology 9(4): 59-72.

Lansink, A. O., Pietola, K., and Backman, S., (2002). Efficiency and productivity of conventional and organic farms in Finland 1994-1997. European Review of Agricultural Economics 29: 51-65.

Latruffe, L., and Nauges, C. (2013). Technical efficiency and conversion to organic farming: the case of France. European Review of Agricultural Economics 41(2): 227-253.

Latruffe, L., Balcombe, K., Davidova, S., and Zawalinska, K. (2005). Technical and scale efficiency of crop and livestock farms in Poland: does specialization matter? Agricultural Economics 32(3): 281-296.

Latruffe, L., Balcombe, K., and Davidova, S., et al., (2004). Determinants of technical efficiency of crop and livestock farms in Poland. Applied Economics 36: 1255-1263.

Li, G., Rozelle, S., and Huang, J. (1998). Tenure, Land Rights, and Farmer Investment Incentives in China. Agricultural Economics 19: 63-71.

Li, J. (2012). Land Tenure Change and Sustainable Management of Alpine Grasslands on the Tibetan Plateau: A Case from Hongyuan County, Sichuan Province, China. Nomadic Peoples 16(1): 36-49.

Li, W., Ali, S.H. and Zhang, Q. (2007). Property rights and grassland degradation: A study of the Xilingol Pasture, Inner Mongolia, China, Journal of Environmental Management, 85:461-470.

Li, W. and Huntsinger, L., (2012) China' s Grassland Contract Policy and its Impacts on Herder Ability to Benefit in Inner Mongolia: Tragic Feedbacks, Ecology and Society. 16:1.

Li, M., Wu, J., and Deng, X., (2013). Identifying Drivers of Land Use Change in China : A Spatial Multinomial Logit Model Analysis. Land Economics 89: 632-654.

Lovell Richardson, S., Travers, P., Wood, L., C. A. K. (1994). Resources and Functionings: A New View of Inequality in Australia, Models and Measurement of Welfare and Inequality. Berlin. Springer. 
Lu, Y, Liu, X., and Zhang, Z. (2010). An analysis of characteristics and driving forces of land desertification in Sanjiangyuan region. Remote Sensing For Land \& Resources 86: 72-76.

Ma, H. (2007). Explanation about the Causes of Ecological Degradation in the Sanjiangyuan District Under the Perspectives of New Institutional Economics (in Chinese). Tibetan Studies 3: 88-96.

Ma, X. (2012). Change of rangeland use and rangeland tenure, based on field survey in Tongde County in Qinghai Province (in Chinese). Chaidamu Kaifa Yanjiu (Research and Development of Chaidamu) 2: 33-37.

Marchand, S., (2012). The relationship between technical efficiency in agriculture and deforestation in the Brazilian Amazon. Ecological Economics 77: 166-175.

Marchand, S., and Guo, H., (2014). The environmental efficiency of noncertified organic farming in China : a case study of paddy rice production. China Economic Review, 31, 201-216.

McDowell, R. W. (2008). Environmental Impacts of Pasture-based Farming. Wallingford, UK: CABI International.

McMillan, J., Whalley, J., and Zhu, L. (1989). The Impact of China's Economic Reforms on Agricultural Productivity Growth. Journal of Political Economy 97(4): 781.

Miller, D. J. (2006). The Tibetan Steppe. Grassland of the World. In S. Reynolds (Ed.), Grassland of the World. Rome: FAO.

Misra, D., and Kant, S. (2007). Shadow prices and input-oriented production efficiency analysis of the village-level production units of joint forest management (JFM) in India. Forest Policy and Economics 9(7): 799-810.

Morey, E. R. (1986). An introduction to checking, testing, and imposing curvature properties : the true function and the estimated function. The Canadian Journal of Economics 19(2): 207-235.

Morrison Paul, C. J., Johnston, W. E., and Frengley, G. A. G., (2000). Efficiency in new zealand sheep and beef farming: the impacts of regulatory reform. The review of economics and statistics 82 : 325-337.

Morrison-Paul, C. J., and Nehring, R. (2005). Product diversification, production systems, and economic performance in U.S. agricultural production. Journal of Econometrics 126(2): 525-548.

Murty, M. N., Kumar, S., and Dhavala, K. K. (2007). Measuring environmental efficiency of industry: A case study of thermal power generation in India. Environmental and Resource Economics 38(1): 31-50.

Newman, C., Tarp, F., and Broeck, K. Van Den. (2015). Property Rights and Productivity: The Case of Joint Land Titling in Vietnam. Land Economics.

Njuki, E., and Bravo-Ureta, B. E. (2015). The Economic Costs of Environmental Regulation in U.S. Dairy Farming: A Directional Distance Function Approach. American Journal of Agricultural Economics1-20.

Nkonya, E., N. Gerber, J. And von Braun et al., (2011). Economics of Land Degradation: Costs of Action versus Inaction. IFPRI report.

OECD, (1998). Eco-efficiency. Paris.

Otieno, D. J., Hubbard, L., and Ruto, E., (2014). Assessment of technical efficiency and its determinants in beef cattle production in Kenya. Journal of Development and Agricultural Economics 6: 267-278.

Pascual, U., (2005). Land use intensification potential in slash-and-burn farming through improvements in technical efficiency. Ecological Economics 52: 497-511. 
Paul, C. J. M., Johnston, W. E., Frengley, G. a. G., Morrison, C. J., Johnston, W. E., Frengley, G. a. G., ... Morrison Paul, C. J. (2000). Efficiency in new zealand sheep and beef farming: the impacts of regulatory reform. The Review of Economics and Statistics 82(2): 325337.

Pérez Urdiales, M., Lansink, A. O., and Wall, A. (2015). Eco-efficiency Among Dairy Farmers: The Importance of Socio-economic Characteristics and Farmer Attitudes. Environmental and Resource Economics.

Picazo-Tadeo, A. J., Castillo-Giménez, J., and Beltrán-Esteve, M. (2014). An intertemporal approach to measuring environmental performance with directional distance functions: Greenhouse gas emissions in the European Union. Ecological Economics 100: 173-182.

Pittman, R. W. (1981). Issue in PollutionControl - Interplant Cost Differences and Economies of Scale. Land Economics 57(1): 1-17.

Pittman, R. W. (1983). Multilateral Productivity Comparisons with Undesirable Outputs. The Economic Journal 93(372): 883-891.

Place, F. (2009). Land Tenure and Agricultural Productivity in Africa: A Comparative Analysis of the Economics Literature and Recent Policy Strategies and Reforms. World Development 37(8): 1326-1336.

Place, F., and Hazell, P. (1993). Productivity Effects of Indigenous Land Tenure Systems in Sub-Saharan Africa. American Journal of Agricultural Economics 75(1): 10-19.

Policies, N., Province, Q., and Foggin, J. M. (2008). Depopulating the Tibetan Grasslands. Mountain Research and Development 28(1): 26-31.

Qin, D. (2003). Weather systems change and human activities. Beijing: Meteorology Press.
Rae, A. N., Ma, H. Y., Huang, J. K., and Rozelle, S. (2006). Livestock in China: Commodity-specific total factor productivity decomposition using new panel data. American Journal of Agricultural Economics 88(August): 680-695.

Rahman, S. (2010). Women's Labour Contribution to Productivity and Efficiency in Agriculture: Empirical Evidence From Bangladesh. Journal of Agricultural Economics 61(2): 318342.

Rao, E. J. O., Brümmer, B., and Qaim, M., et al., (2012). Farmer Participation in Supermarket Channels, Production Technology, and Efficiency: The Case of Vegetables in Kenya. American Journal of Agricultural Economics 94: 891-912.

Reinhard, S., Knox Lovell, C. a., Thijssen, G. J., Lovell, C. A. K., and Thijssen, G. J. (2000). Environmental efficiency with multiple environmentally detrimental variables; estimated with SFA and DEA. European Journal of Operational Research 121(2): 287-303.

Reinhard, S., Lovell, C. A. K., and Thijssen, G. (1999). Econometric estimation of technical and environmental efficiency: An application to Dutch dairy farms. American Journal of Agricultural Economics 81(1): 44-60.

Reinhard, S., Lovell, C. A. K., and Thijssen, G. (2002). Analysis of environmental efficiency variation. American Journal of Agricultural Economics 84(4): 1054-1065.

Richard, C., Yan, Z., and Du, G. (2006). The Paradox of the Individual Household Responsibility System in the Grasslands of the Tibetan83-91.

Roxburgh, S. H., Berry, S. L., and Buckley, T. N., et al., (2005). What is NPP? Inconsistent accounting of respiratory fluxes in the definition of net primary production. Functional Ecology 19: 378-382. 
Sauer, J., and Latacz-Lohmann, U. (2014). Investment, technical change and efficiency: empirical evidence from German dairy production. European Review of Agricultural Economics125.

Serra, T., Lansink, a. O., and Stefanou, S. E. (2011). Measurement of Dynamic Efficiency: A Directional Distance Function Parametric Approach. American Journal of Agricultural Economics 93(3): 756-767.

Shephard, R. W. (1970). Theory of cost and production functions. Princeton: Princeton University Press.

Stern, D. I. (2011). Elasticities of substitution and complementarity. Journal of Productivity Analysis 36(1): 79-89.

Taboada, M. A., Rubio, G., and Chaneton, E. J., (2011). Grazing impacts on soil physical, chemical, and ecological properties in forage production systems. Soil Management: Building a Stable Base for Agriculture, 301-320.

Tian, X., and Yu, X. (2012). The Enigmas of TFP in China: A meta-analysis. China Economic Review 23(2): 396-414.

Tyteca, D., (1996). On the Measurement of the Environmental Performance of Firms - A literature review and a productive efficiency perspective. Journal of Environmental Management 46: 281-308.

Tyteca, D., 1997. Linear Programming Models for the Measurement of Environmental Performance of Firms Concepts and Empirical Results. Journal of Productivity Analysis 8: 183-197.

UNEP. (2005). One Planet Many People: Atlas of Our Changing Environment. Division of Early Warning and Assessment. Nairobi, Kenya: United Nations Environment Program (UNEP).

Van Ha, N., Kant, S., Madaren, V., and Maclaren, V. (2008). Shadow prices of environmental outputs and production efficiency of household-level paper recycling units in Vietnam. Ecological Economics 65(1): 98-110.

Wang, H., and Schmidt, P., (2002). One-Step and Two-Step Estimation of the Effects of Exogenous Variables on Technical Efficiency Levels. Journal of Productivity Analysis 18: 129-144.

Wang, H., Zhou, P., and Zhou, D. Q. (2013). Scenario-based energy efficiency and productivity in China: A non-radial directional distance function analysis. Energy Economics 40: 795-803.

Wang, S. L., Tuan, F., Gale, F., Somwaru, A., and Hansen, J. (2013). China's regional agricultural productivity growth in 1985-2007: A multilateral comparison 1. Agricultural Economics 44(2): 241251.

Wangchuk, K., and Wangdi, J. (2015). Mountain pastoralism in transition: Consequences of legalizing Cordyceps collection on yak farming practices in Bhutan. Pastoralism 5(4).

WBCSD,(1992). See under Cross cutting themes: Eco-efficiency, International Food Policy Research Institute (IFPRI). Washington DC: IFPRI.

Weikard, H. P., and Hein, L. (2011). Efficient versus Sustainable Livestock Grazing in the Sahel. Journal of Agricultural Economics 62(1): 153171.

White, R., Murray, S., and Rohweder, M. (2000). Pilot analysis of global ecosystems: Grassland ecosystem. Washington, D.C.: World Resources Institute.

Yaisawarng, S., and Klein, J. D. (1994). The Effects of Sulfur-Dioxide Controls on Productivity Change in the UnitedStates Electric-Power Industry. Review of Economics and Statistics 76(3): 447-460.

Yang, C.-C., Hsiao, C.-K., and Yu, M.-M., (2008). Technical efficiency and impact of environmental regulations in 
farrow-to-finish swine production in Taiwan. Agricultural Economics, 39(1), 51-61.

Yao, X., Zhou, H., Zhang, A., and Li, A. (2015). Regional energy efficiency, carbon emission performance and technology gaps in China: A metafrontier non-radial directional distance function analysis. Energy Policy 84: 142-154.

Zhang, J. (2008). Ecological Current Situation of Grassland and Its Countermeasures in the Three Rivers District of Qinghai. Pruataculture \& Animal Husbandry 1: 30-32.

Zhang, J., Zhang, L., Liu, W., Qi, Y., and Wo, X. (2014). Livestock-carrying capacity and overgrazing status of alpine grassland in the Three-River Headwaters region, China. Journal of Geographical Sciences 24(2): 303-312.

Zhang, Y. J., Wang, X. B., Glauben, T., and Brümmer, B. (2011). The impact of land reallocation on technical efficiency: evidence from China.
Agricultural Economics 42(4): 495507.

Zhang, Y., and Brümmer, B. (2011). Productivity change and the effects of policy reform in China's agriculture since 1979. Asian-Pacific Economic Literature 25(2): 131-150.

Zhao, M., and Running, S. W. (2010). Response to Comments on "DroughtInduced Reduction in Global Terrestrial Net Primary Production from 2000 Through 2009." Science 333(6046): 1093-1093.

Zhaoli, Y., Ning, W., Dorji, Y., and Jia, R. (2005). A Review of Rangeland Privatisation and its Implications in the Tibetan Plateau, China. Nomadic Peoples 9(1): 31-51.

Zhou, H. K., Zhou, L., Zhao, X. Q., Liu, W., Li, Y. N., Gu, S., and Zhou, X. M. (2006). Stability of alpine meadow ecosystem on the Qinghai-Tibetan Plateau (in Chinese). Chinese Science Bulletin 51(3): 320-327. 


\section{Appendix}

Appendix 1. Household level field survey questionnaire 

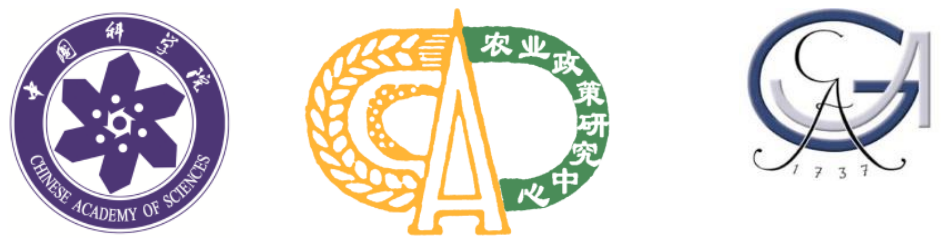

Georg-August-Universität Göttingen

\section{Field Survey Questionnaires}

\section{Household Lever}

\begin{tabular}{|l|l|}
\hline No. of questionnaire: & \\
\hline Time (YYMMDD): & \\
\hline
\end{tabular}

\begin{tabular}{|l|l|}
\hline Interviewer & \\
\hline Telephone & \\
\hline Mobile & \\
\hline Reporter & \\
\hline Reviewer & \\
\hline
\end{tabular}

\section{Location:}

Sanjiangyuan region, Qinghai Province, China

\section{Prefectures:}

01. Guoluo $\quad \square \quad$ 02.Huangnan $\square \quad$ 03.Hainan $\square \quad$ 04.Yushu $\square$

\section{County:}

$\begin{array}{llllllllllll}\text { 01.HenanmengguAP } & \square & \text { 04.Geermu } & \square & \text { 07. Qumalai } & \square & \text { 10.Jiuzhi } & \square & \text { 13.Zaduo } & \square & \text { 16.Zhiduo } \quad \square \\ \text { 02.Maqin } & \square & \text { 05.Banma } & \square & \text { 08.Nangqian } & \square & \text { 11.Tongde } & \square & \text { 14.Xinghai } & \square & \text { 17.Gande } \quad \square \\ \text { 03.Zeku } & \square & \text { 06.Yushu } & \square & \text { 09.Chenduo } & \square & \text { 12.Maduo } & \square & \text { 15.Dari } & \square & \end{array}$




\section{Part 1 - Household Characteristics}

\subsection{Home demographics 2011}

\section{How many persons in your home?}

\section{People}

\begin{tabular}{|c|c|c|c|c|c|c|c|c|c|c|c|}
\hline \multirow{3}{*}{ code } & 02 & 03 & 04 & 05 & 06 & 07 & 08 & 09 & 10 & 11 & 12 \\
\hline & \multirow{2}{*}{ 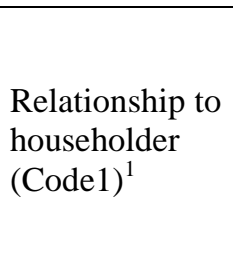 } & \multirow{2}{*}{$\begin{array}{l}\text { Sex } \\
\begin{array}{l}1=\text { male } \\
2=\text { female }\end{array}\end{array}$} & \multirow{2}{*}{ Age (year) } & $\begin{array}{l}\text { Education (year) } \\
\text { Whether stay at } \\
\text { home }\end{array}$ & \multirow{2}{*}{$\begin{array}{l}\text { Village } \\
\text { cadre } \\
(1=\text { yes, } \\
2=\text { no })\end{array}$} & \multirow{2}{*}{$\begin{array}{l}\begin{array}{l}\text { Whether it is } \\
\text { farmer? }\end{array} \\
1=\text { yes;0=no, }\end{array}$} & \multirow{2}{*}{$\begin{array}{l}\text { If it is farmer, } \\
\text { The time of } \\
\text { being farmer } \\
\text { (year) }\end{array}$} & \multirow{2}{*}{$\begin{array}{l}\text { If it is not farmer, } \\
\text { what is the other } \\
\text { job? (Code2 })^{2}\end{array}$} & \multirow{2}{*}{$\begin{array}{l}\text { If it is not farmer, } \\
\text { Where is the work } \\
\text { place (Code } 3)^{3}\end{array}$} & \multicolumn{2}{|c|}{$\begin{array}{l}\text { For Labor time } \\
\text { share }(\%)\end{array}$} \\
\hline & & & & $\begin{array}{l}1=y e s ; 0=\text { no. if } \\
\text { no, where is it? }\end{array}$ & & & & & & $\begin{array}{l}\text { Agr. } \\
\text { (1) }\end{array}$ & $\begin{array}{l}\text { Non } \\
\text { Agr. }^{4} \\
\text { (2) }\end{array}$ \\
\hline \multicolumn{12}{|c|}{01} \\
\hline \multicolumn{12}{|l|}{02} \\
\hline \multicolumn{12}{|l|}{03} \\
\hline \multicolumn{12}{|l|}{04} \\
\hline \multicolumn{12}{|l|}{05} \\
\hline \multicolumn{12}{|l|}{06} \\
\hline \multicolumn{12}{|l|}{07} \\
\hline 08 & & & & & & & & & & & \\
\hline
\end{tabular}

1. Code1: 1 =household, $2=$ =spouse; $3=$ son; $4=$ daughter; $5=$ grandson or daughter; $6=$ parents; $7=$ brother or sister; $8=$ brother or sister in law; $9=$ parents in law; $10=$ relatives; $11=$ other

2. Code2:1=worker in mill; $2=$ worker in building/construction; $3=$ crafts man (carpenter/plasterer); $4=$ =worker in mining industry; $5=$ other worker; $6=$ commerce; $7=$ service industry (beauty culture, head cut, restaurant, driver, cooker, safety guard, etc.); 8=clerk (administrations); $9=$ technical (teacher, doctor); 10=leader in State-owned com.; 11=self-employed businessman; 12=boos of private company; 13=manager Company; $14=$ other career (please clarify)

3. Code $3: 1=$ in his own village; $2=$ the other village in the same town (please clarify); $3=$ the other town in the same county (please clarify); $4=$ the other county in the same province (please clarify); $5=$ the other province (please clarify)

4. Non Agr..: employed in non agricultural jobs with salary more than 1 month, including house side occupation. 


\subsection{Animal husbandry herdsman ability construction}

01. Is there any person in your home participated in the training or study of agricultural production? $1=y e s, 2=$ no. If no, skip following table.

\begin{tabular}{|c|c|c|c|c|}
\hline 01 & 02 & 03 & 04 & 05 \\
\hline \multirow{2}{*}{ year } & \multirow{2}{*}{$\begin{array}{c}\text { The relationship of the person } \\
\text { with the family host (Code1) }\end{array}$} & \multicolumn{3}{|c|}{ Train content (Code4) } \\
\cline { 3 - 5 } & & The 1st content & The 2nd content & The 3rd content \\
\hline 2012 & & & & \\
\hline 2013 & & & & \\
\hline 2014 & & & & \\
\hline
\end{tabular}

Notes:

Code4: 1=agricultural technology skill; 2=market sale; 3= drought resisting; 4= Rat resistance skill; 5= antifreeze skill; $6=$ pest resistance skill; $7=$ the plague technology; $8=$ fire prevention; $9=$ other (please clarify).

Agricultural production technique indicates input production technique and grassland management technique related to pesticide, seeds, chemical fertilizer etc. Market sale indicates the sale skill related to agricultural products.

\subsection{Details of governmental subsidy (Yuan/year)}

\begin{tabular}{|c|l|l|l|}
\hline Code & \multicolumn{1}{|c|}{ Subsidy type } & Amount in 2011 & When did it start (year) \\
\hline 01 & Directive subsidy for growing food plant & & \\
\hline 02 & Complex subsidy for agricultural capital & & \\
\hline 03 & Excellent seeds subsidy & & \\
\hline 04 & Subsidy for purchasing agricultural machinery & & \\
\hline 05 & Subsidy for return the arable land to grassland & & \\
\hline 06 & Housing subsidy & & \\
\hline 07 & Insurance subsidy & & \\
\hline 08 & Others (please clarify) & & \\
\hline
\end{tabular}

\subsection{Other characteristics}

\begin{tabular}{|c|l|c|c|}
\hline Code & \multicolumn{1}{|c|}{ Detail } & Unit & Amount \\
\hline 01 & The smallest distance to the nearest agricultural products market? & Km & Times/month \\
\hline 02 & The frequency of shopping & Unit & Kg \\
\hline 03 & How many agricultural capital stores in your village? & $\mathrm{Km}$ & \\
\hline 04 & How much tee does your household drink in the year? & $\mathrm{Km}$ & \\
\hline 05 & $\begin{array}{l}\text { The smallest distance to the nearest agricultural capital (the fertilizer, } \\
\text { forage etc.) stores }\end{array}$ & & \\
\hline 06 & The smallest distance to the nearest drinking water resource? & & \\
\hline
\end{tabular}




\subsection{Household social relationship}

\begin{tabular}{|c|c|c|c|}
\hline Code & Detail & Unit & Amount \\
\hline 01 & How many relative families inside 3 generations? & $\mathrm{Hu}$ & \\
\hline 02 & How many relatives or familiars is village cadre during 5 years? & People & \\
\hline 03 & How many people is village cadre during 5 years? & People & \\
\hline 04 & How many telephone numbers do you have in your phone directory? & $\begin{array}{l}1=0-20 ; \quad 2=20- \\
50 ; \quad 3=50-100 ; \\
4=100 \text { and more }\end{array}$ & \\
\hline 05 & The distance between your home and your longest neighbor home? & Kilometers & \\
\hline 06 & Whether you joined in the farmer cooperation organization? & $1=$ yes; $2=$ no & \\
\hline 07 & If is, when did you join in? & year & \\
\hline
\end{tabular}

\subsection{Household Loan and credits}

\begin{tabular}{|c|l|c|c|c|c|}
\hline Code & \multicolumn{1}{|c|}{ Loan resource } & $\begin{array}{c}\text { Is it easy to loan } \\
(1=\text { yes; 2=no })\end{array}$ & $\begin{array}{c}\text { Amount } \\
\text { (Yuan) }\end{array}$ & $\begin{array}{c}\text { Interest } \\
\text { (Yuan/100Yuan/Year) }\end{array}$ & $\begin{array}{c}\text { Duration } \\
\text { (year) }\end{array}$ \\
\hline 01 & From friends/relatives & & & & \\
\hline 02 & From local bank & & & & \\
\hline 03 & $\begin{array}{l}\text { From agricultural } \\
\text { cooperation organization }\end{array}$ & & & & \\
\hline 04 & Other & & & & \\
\hline
\end{tabular}

\section{Land use situation}

\begin{tabular}{|c|c|c|c|}
\hline Code & Land use type & Unit & Of 2011 \\
\hline 01 & Total land area & $\mathrm{Mu}$ & \\
\hline 02 & Cultivated land area & $\mathrm{Mu}$ & \\
\hline 03 & Grassland land area & $\mathrm{Mu}$ & \\
\hline 04 & Natural grassland & $\mathrm{Mu}$ & \\
\hline 05 & artificially sown pastures & $\mathrm{Mu}$ & \\
\hline 06 & If there is grassland rented in & $1=$ yes, $2=$ no (it should be $\%$ ) & \\
\hline 07 & who is the loaner & $\begin{array}{l}1=\text { farmer in the same village; } 2=\text { farmer in the } \\
\text { other village; } \\
3=\text { outside person }\end{array}$ & \\
\hline 08 & Rent in fee & Yuan & \\
\hline 09 & If there is grassland rented out & $\%$ & \\
\hline 10 & Who is the tenant? & $\begin{array}{l}1=\text { farmer in the same village; } 2=\text { farmer in the } \\
\text { other village; } 3=\text { outside person }\end{array}$ & \\
\hline 11 & Rented out fee & Yuan & \\
\hline 12 & Use of land & $\begin{array}{l}1=\text { grassland; } 2=\text { economic plant growing; } \\
3=\text { building or mill; } 4=\text { other }\end{array}$ & \\
\hline
\end{tabular}




\section{Crops table in 2011}

\begin{tabular}{|c|c|c|c|c|c|c|c|c|c|c|}
\hline \multirow[b]{2}{*}{ Code } & \multirow{2}{*}{$\begin{array}{l}\text { Crop } \\
\text { type }\end{array}$} & \multirow{2}{*}{$\begin{array}{l}\text { Cultivated } \\
\text { area }(\mathrm{mu})\end{array}$} & \multirow{2}{*}{$\begin{array}{l}\text { Output } \\
\text { (kg) }\end{array}$} & \multirow{2}{*}{$\begin{array}{c}\text { Percentage } \\
\text { of sale out } \\
(\%)\end{array}$} & \multirow{2}{*}{$\begin{array}{l}\text { Sale price } \\
\text { (Yuan/kg) }\end{array}$} & \multirow[b]{2}{*}{ Sale method (Code5) } & \multirow{2}{*}{$\begin{array}{l}\text { Agricultural } \\
\text { capital input } \\
\text { (yuan) }\end{array}$} & \multicolumn{3}{|c|}{ Labor input } \\
\hline & & & & & & & & $\begin{array}{c}\text { Amount } \\
\text { (person*day) }\end{array}$ & $\begin{array}{l}\text { Work hours } \\
\text { (hours/day) }\end{array}$ & $\begin{array}{c}\text { Salary } \\
\text { (Yuan/person) }\end{array}$ \\
\hline 01 & $\begin{array}{l}\text { highland } \\
\text { barley }\end{array}$ & & & & & & & & & \\
\hline 02 & rape & & & & & & & & & \\
\hline 03 & Tomato & & & & & & & & & \\
\hline 04 & wheat & & & & & & & & & \\
\hline 05 & other 1 & & & & & & & & & \\
\hline 06 & other 2 & & & & & & & & & \\
\hline
\end{tabular}

Code5: 1=retail, personal; $2=$ agricultural cooperation organization; $3=$ government; $4=$ other. 


\section{Animal husbandry}

4.1 Animal husbandry products in 2011

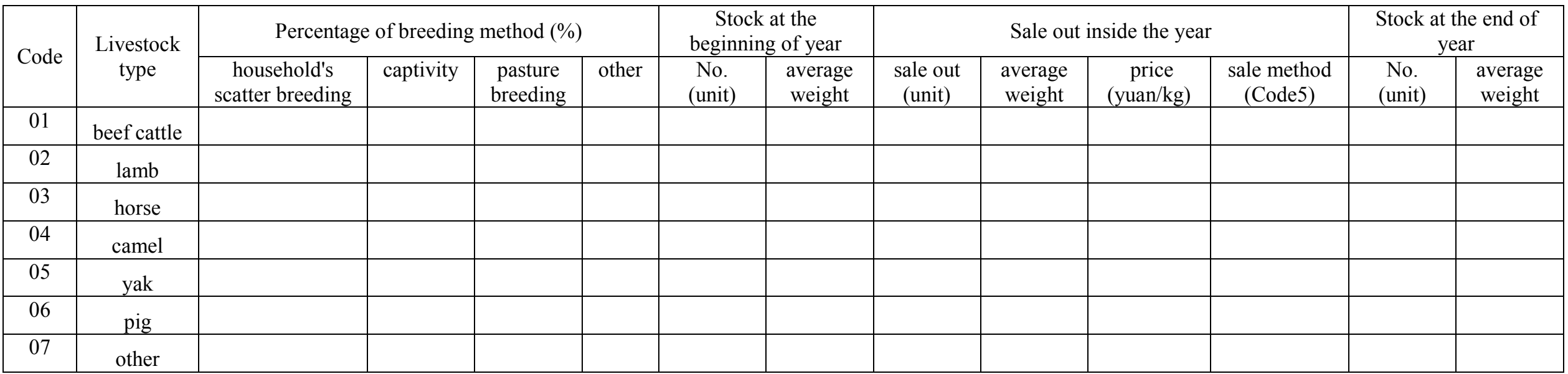




\subsection{Animal husbandry products in 2011 (continued)}

\begin{tabular}{|c|c|c|c|c|c|c|c|c|c|c|}
\hline \multirow[b]{2}{*}{ Code } & \multirow[b]{2}{*}{ Livestock type } & \multicolumn{5}{|c|}{ Dynamic structure of animal husbandry of 2011 (unit) } & \multicolumn{4}{|c|}{ Climatic disaster impact } \\
\hline & & Born & Buy & Dead & Sold & Slaughter & $\begin{array}{l}\text { Disaster type } \\
\quad(\text { Code6) }\end{array}$ & $\begin{array}{c}\text { Main } \\
\text { loss type } \\
(\text { Code } 7)\end{array}$ & $\begin{array}{c}\text { Adaptation } \\
\text { implementation } \\
\text { measures (Code8) }\end{array}$ & $\begin{array}{l}\text { Decrease loss after adaptation } \\
\text { implementation }(\%)\end{array}$ \\
\hline 01 & beef cattle & & & & & & & & & \\
\hline 02 & lamb & & & & & & & & & \\
\hline 03 & horse & & & & & & & & & \\
\hline 04 & camel & & & & & & & & & \\
\hline 05 & yak & & & & & & & & & \\
\hline 06 & pig & & & & & & & & & \\
\hline 07 & other & & & & & & & & & \\
\hline
\end{tabular}

Notes:

1. Code6: Disaster type code: $1=$ =flood; $2=$ drought; $3=$ =ice freezing; 4=fire disaster; $5=$ hailstone; $6=$ powerful windy; 7=rape disaster; 8=pest disaster; 9=landslide; $10=$ debris flow; $11=$ other (please clarify)

Code7: main loss type: $1=$ dead; $2=$ selling problem; $3=$ not enough breeding livestock; $4=$ too young or too light to sell; $5=0$ other (please clarify)

Code8: adaptation measures. Engineering measures: 1=fixed shelter; $2=a$ artificial grassland technical generalization; $3=l i v e s t o c k$ breeding improvement; Non-engineering measures: $4=$ site walk breeding;

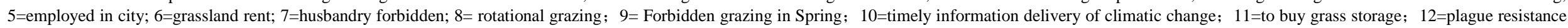

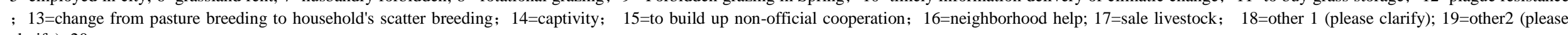
clarify); $20=$ none 
Appendix

4.2 About the other animal husbandry products of 2011

\begin{tabular}{|c|l|l|l|l|l|l|l|l|l|}
\hline Code & \multicolumn{1}{|c|}{ Type } & $\begin{array}{c}\text { Output } \\
(\mathrm{kg})\end{array}$ & $\begin{array}{c}\text { Weight of } \\
\text { sale (kg) }\end{array}$ & $\begin{array}{c}\text { Sale price } \\
\text { (Yuan/kg) }\end{array}$ & $\begin{array}{c}\text { Sale } \\
\text { method } \\
\text { (Code5) }\end{array}$ & $\begin{array}{c}\text { Disaster type } \\
\text { (Code6) }\end{array}$ & $\begin{array}{c}\text { Main loss type } \\
\text { (Code7) }\end{array}$ & $\begin{array}{c}\text { Adaptation implementation } \\
\text { measures (Code8) }\end{array}$ & $\begin{array}{c}\text { Decrease loss after } \\
\text { adaptation implementation } \\
(\%)\end{array}$ \\
\hline 01 & Sheep milk & & & & & & & & \\
\hline 02 & Cattle milk & & & & & & & & \\
\hline 03 & Wool & & & & & & & & \\
\hline 04 & Sheep hide & & & & & & & & \\
\hline 05 & Ox hide & & & & & & & & \\
\hline 06 & Other & & & & & & & & \\
\hline
\end{tabular}




\section{About the forage use of 2011}

\begin{tabular}{|c|c|c|c|c|c|c|c|}
\hline \multirow{3}{*}{ Code } & \multirow{3}{*}{$\begin{array}{l}\text { Livestock } \\
\text { name }\end{array}$} & \multicolumn{6}{|c|}{ Fine forage } \\
\hline & & \multirow[b]{2}{*}{$\begin{array}{l}\text { Type (maize, } \\
\text { dregs of bean) }\end{array}$} & \multirow{2}{*}{$\begin{array}{c}\text { Average } \\
\text { daily use } \\
\text { amount }(\mathrm{kg})\end{array}$} & \multirow[b]{2}{*}{$\begin{array}{c}\text { price } \\
\text { (Yuan) }\end{array}$} & \multicolumn{3}{|c|}{ Labor input } \\
\hline & & & & & $\begin{array}{c}\text { Amount } \\
\text { (person*day) }\end{array}$ & $\begin{array}{l}\text { Work } \\
\text { hours } \\
(\mathrm{h} / \mathrm{d})\end{array}$ & $\begin{array}{c}\text { Salary } \\
\text { (Yuan/person) }\end{array}$ \\
\hline 1 & beef cattle & & & & & & \\
\hline 02 & lamb & & & & & & \\
\hline 03 & horse & & & & & & \\
\hline 04 & camel & & & & & & \\
\hline 05 & yak & & & & & & \\
\hline 06 & pig & & & & & & \\
\hline 07 & other & & & & & & \\
\hline \multirow{3}{*}{ Code } & \multirow{3}{*}{$\begin{array}{l}\text { Livestock } \\
\text { name }\end{array}$} & \multicolumn{6}{|c|}{ Rough forage } \\
\hline & & \multirow[b]{2}{*}{$\begin{array}{c}\text { Type (grass, } \\
\text { straw) }\end{array}$} & \multirow{2}{*}{$\begin{array}{c}\text { Average } \\
\text { daily use } \\
\text { amount }(\mathrm{kg})\end{array}$} & \multirow[b]{2}{*}{$\begin{array}{l}\text { price } \\
\text { (Yuan) }\end{array}$} & \multicolumn{3}{|c|}{ Labor input } \\
\hline & & & & & $\begin{array}{c}\text { Amount } \\
\text { (person*day) }\end{array}$ & $\begin{array}{l}\text { Work } \\
\text { hours } \\
(\mathrm{h} / \mathrm{d})\end{array}$ & $\begin{array}{c}\text { Salary } \\
\text { (Yuan/person) }\end{array}$ \\
\hline 1 & beef cattle & & & & & & \\
\hline 02 & lamb & & & & & & \\
\hline 03 & horse & & & & & & \\
\hline 04 & camel & & & & & & \\
\hline 05 & yak & & & & & & \\
\hline 06 & pig & & & & & & \\
\hline 07 & other & & & & & & \\
\hline \multirow{3}{*}{ Code } & \multirow{3}{*}{$\begin{array}{l}\text { Livestock } \\
\text { name }\end{array}$} & \multicolumn{6}{|c|}{ Additive forage } \\
\hline & & \multirow[b]{2}{*}{$\begin{array}{c}\text { Type (vitamin, } \\
\text { mineralogy) }\end{array}$} & \multirow{2}{*}{$\begin{array}{c}\text { Average } \\
\text { daily use } \\
\text { amount }(\mathrm{kg})\end{array}$} & \multirow[b]{2}{*}{$\begin{array}{l}\text { price } \\
\text { (Yuan) }\end{array}$} & \multicolumn{3}{|c|}{ Labor input } \\
\hline & & & & & $\begin{array}{c}\text { Amount } \\
\text { (person*day) }\end{array}$ & $\begin{array}{l}\text { Work } \\
\text { hours } \\
(\mathrm{h} / \mathrm{d})\end{array}$ & $\begin{array}{c}\text { Salary } \\
\text { (Yuan/person) }\end{array}$ \\
\hline 1 & beef cattle & & & & & & \\
\hline 02 & lamb & & & & & & \\
\hline 03 & horse & & & & & & \\
\hline 04 & camel & & & & & & \\
\hline 05 & yak & & & & & & \\
\hline 06 & pig & & & & & & \\
\hline 07 & other & & & & & & \\
\hline
\end{tabular}




\section{Drink water resource of livestock}

\begin{tabular}{|c|c|c|c|c|}
\hline \multirow[b]{2}{*}{ Code } & \multirow{2}{*}{$\begin{array}{l}\text { Livestock } \\
\text { name }\end{array}$} & Drink water resource & \multirow{2}{*}{$\begin{array}{l}\text { The nearest } \\
\text { distance to get } \\
\text { it }(\mathrm{km})\end{array}$} & \multirow{2}{*}{$\begin{array}{l}\text { How is the change of the distance to get the drink water } \\
\qquad 1=\text { farer; } 2=\text { no change; } 3=\text { nearer }\end{array}$} \\
\hline & & $\begin{array}{c}1=\text { underground water/well; } 2=\text { lake; } 3=\text { river; } 4=\text { channel water/tap } \\
\text { water; } 5=\text { other }\end{array}$ & & \\
\hline 1 & beef cattle & & & \\
\hline 02 & lamb & & & \\
\hline 03 & horse & & & \\
\hline 04 & Yak & & & \\
\hline 05 & pig & & & \\
\hline 06 & other & & & \\
\hline
\end{tabular}

\section{Disposal method of feces}

\begin{tabular}{|c|c|c|c|c|c|c|c|c|c|c|c|c|c|c|}
\hline \multirow[b]{2}{*}{ Code } & \multirow[b]{2}{*}{$\begin{array}{l}\text { Livestock } \\
\text { name }\end{array}$} & \multicolumn{7}{|c|}{ Percentage of processing method $(\%)$} & \multicolumn{2}{|c|}{ When to be sold } & \multicolumn{4}{|c|}{ When to be threw away, the percentage of throwing method (\%) } \\
\hline & & fertilizer & biogas & $\begin{array}{l}\text { throw } \\
\text { away }\end{array}$ & Selling & forage & fuel & other & $\begin{array}{l}\text { the sale } \\
\text { method } \\
(\text { Code } 5)\end{array}$ & $\begin{array}{c}\text { Price } \\
\text { (Yuan/kg) }\end{array}$ & $\begin{array}{c}\text { Specific place for } \\
\text { particular person to collect }\end{array}$ & Lake/river & No disposal & other \\
\hline 1 & beef cattle & & & & & & & & & & & & & \\
\hline 02 & lamb & & & & & & & & & & & & & \\
\hline 03 & horse & & & & & & & & & & & & & \\
\hline 04 & Yak & & & & & & & & & & & & & \\
\hline 05 & pig & & & & & & & & & & & & & \\
\hline 06 & other & & & & & & & & & & & & & \\
\hline
\end{tabular}




\section{About pasture farm}

\subsection{Pasture basic characteristics}

\section{1) Is there pasture equipments construction?}

$\square$ There are fixed pasture fencing, shelter building, forage huts, feed storage etc.

$\checkmark$ There are electronic equipments, telecommunication equipments

$\square$ There are energy equipments, including biogas, sun energy, wind energy and geothermal energy

2) Is there pasture grassland disposals aiming to enhance the productivity performance?

$\square$ Turn the soil regularly $\quad \square$ Grass seeds replanting $\square$ Fertilization

口Irrigation and there is irrigation equipments and water conservation skill

3) Weeds disposal

$\square$ Machinery method: manual and machinery disposal

$\square$ Chemical method: herbicides

$\square$ Biological method: select particular insect, parasitic plant and selection livestock variety

$\square$ Burn the grass in late autumn or spring to kill the poisonous weeds

\section{4) Grassland degradation prevention method}

$\square$ Grassland enclosure and soil fixation to accelerate the natural grass refresh

$\square$ Irrigation to improve and adjust soil moisture

$\square$ Fertilization to enhance the quality and output of grass

$\square$ Killing rat

$\square$ Turning the soil and scratching the grass sod to adjust soil air ventilation and water permeability

$\square$ Grass seed replanting and increase the percentage of excellent grass type to improve the quality of grass

5) Which characteristic should be improved?
$\square$ Drought resisting
$\square$ Saline-alkali enduring
$\square$ Nutrition quality
$\square$ Cold resisting
$\square$ Trample enduring
$\square$ Other (please clarify)
$\square$ Soil barren enduring
$\square$ Mowing enduring
$\square$ Pest resisting
$\square$ Yield of grass

6) Grass ensiling method
$\square$ High moisture
$\square$ Mixture silage
$\square$ Whole plant silage
$\square$ Hay silage
$\square$ Coordinate silage
$\square$ Singleness silage
$\square$ Short cut silage

\section{7) Problems in grass ensiling}

$\square$ Hard to control the grass mowing time

$\square$ Quality problem with hay

$\square$ Grass moisture adjustment

$\square$ The feed way of hay

$\square$ Method to dry grass

$\square$ Detoxication of low toxicity

$\square$ Wet-resisting in drying process

$\square$ The additive use of hay

$\square$ Other (please clarify) 


\subsection{Pasture information according to plots}

\section{1) Winter meadow}

\begin{tabular}{|c|c|c|}
\hline Code & Year & 2011 \\
\hline 01 & Area (mu) & \\
\hline 02 & No. of plots (unit) & \\
\hline
\end{tabular}

Note: definition of one plot: 1.plots are not geographically bordering; 2.plots are geographically bordering, but obtained in different time and rent fees.

Is there any change of winter meadow from 2006? $\square$ 1=yes, and the reason is $\square 0=$ no change

\begin{tabular}{|c|c|c|c|c|c|c|c|c|}
\hline \multirow[b]{2}{*}{$\begin{array}{l}\text { Plots } \\
\text { code }\end{array}$} & \multicolumn{2}{|c|}{ Geographic } & \multirow[b]{2}{*}{$\begin{array}{l}\text { Area } \\
(\mathrm{mu})\end{array}$} & \multicolumn{2}{|c|}{ Percentage } & \multicolumn{2}{|c|}{$\begin{array}{l}\text { Grass quality (according to the average height of } \\
\text { grass) }\end{array}$} & \multirow{2}{*}{$\begin{array}{c}\text { How to use } \\
1=\text { husbandry; } 2=\text { for } \\
\text { forage; } 3=\text { for mowing } \\
\text { grass; } 4=\text { other }\end{array}$} \\
\hline & $\begin{array}{c}\text { Direction from your } \\
\text { home (directional code, } \\
\text { Code9) }\end{array}$ & $\begin{array}{c}\text { Distance to } \\
\text { your home } \\
(\mathrm{km})\end{array}$ & & $\begin{array}{l}\text { Can be ate } \\
\text { by livestock }\end{array}$ & $\begin{array}{l}\text { Can't } \\
\text { be ate }\end{array}$ & $\begin{array}{c}2011 \text { year } \\
(1=\text { good, } 0=\text { plain, } \\
-1=\text { bad })\end{array}$ & $\begin{array}{c}\text { Change in the past } 10 \text { years }(1=\text { it } \\
\text { is better now; } 0=\text { no change; - } \\
1=\text { it is worse now })\end{array}$ & \\
\hline \multicolumn{9}{|l|}{01} \\
\hline \multicolumn{9}{|l|}{02} \\
\hline \multicolumn{9}{|l|}{03} \\
\hline 04 & & & & & & & & \\
\hline
\end{tabular}




\begin{tabular}{|c|c|c|c|c|c|c|}
\hline $\begin{array}{l}\text { Plots } \\
\text { code }\end{array}$ & $\begin{array}{c}\text { Time of } \\
\text { husbandry }\end{array}$ & $\begin{array}{c}\text { Use price } \\
\text { Yuan/mu/year }\end{array}$ & \multicolumn{2}{|r|}{ Basic facility } & $\begin{array}{c}\text { Time of get it } \\
\text { YY-MM }\end{array}$ & $\begin{array}{c}\text { Method of get it } \\
\begin{array}{c}1=\text { collective owned; } 2=\text { rent from } \\
\text { others; } 3=\text { other }\end{array}\end{array}$ \\
\hline \multicolumn{7}{|l|}{02} \\
\hline \multicolumn{7}{|l|}{03} \\
\hline 04 & & & & & & \\
\hline
\end{tabular}

\begin{tabular}{|c|c|c|c|c|c|c|c|c|}
\hline \multirow[b]{2}{*}{$\begin{array}{l}\text { Plots } \\
\text { code }\end{array}$} & \multirow{2}{*}{$\begin{array}{c}\text { Drink water resource } \\
\text { 1=underground water/well; } \\
2=\text { lake; } 3=\text { river; } 4=\text { channel } \\
\text { water/tap water; } 5=\text { other }\end{array}$} & \multicolumn{3}{|c|}{ Labor input } & \multicolumn{4}{|c|}{ Climatic disaster impact } \\
\hline & & $\begin{array}{c}\text { Amount } \\
\text { (person*day) }\end{array}$ & $\begin{array}{l}\text { Work hours } \\
(\mathrm{h} / \mathrm{d})\end{array}$ & $\begin{array}{c}\text { Salary } \\
\text { (Yuan/person) }\end{array}$ & $\begin{array}{l}\text { Disaster } \\
\text { type } \\
\text { (Code6) }\end{array}$ & $\begin{array}{c}\text { Main loss } \\
\text { type } \\
\text { (Code7) }\end{array}$ & $\begin{array}{c}\text { Adaptation } \\
\text { implementation } \\
\text { measures (Code8) }\end{array}$ & $\begin{array}{l}\text { Decrease loss after } \\
\text { adaptation } \\
\text { implementation (\%) }\end{array}$ \\
\hline 01 & & & & & & & & \\
\hline 02 & & & & & & & & \\
\hline 03 & & & & & & & & \\
\hline
\end{tabular}

Note:

Code9: $1=$ =ast; $2=$ =est; $3=$ south; $4=$ north; $5=$ southeast; $6=$ =southwest; $7=$ northeast; $8=$ northwest. 
2) Artificial meadow in winter meadow. If there is artificial meadow in winter meadow, please fill in the following table, otherwise, skip it.

\begin{tabular}{|c|c|c|c|c|c|c|c|c|}
\hline \multirow[b]{2}{*}{$\begin{array}{l}\text { Plots } \\
\text { code }\end{array}$} & \multicolumn{2}{|c|}{ Geographic } & \multirow[b]{2}{*}{$\begin{array}{l}\text { Area } \\
(\mathrm{mu})\end{array}$} & \multicolumn{2}{|c|}{ Percentage } & \multicolumn{2}{|c|}{$\begin{array}{l}\text { Grass quality (according to the average height of } \\
\text { grass) }\end{array}$} & \multirow{2}{*}{$\begin{array}{c}\text { How to use } \\
\begin{array}{c}1=\text { husbandry; } 2=\text { for } \\
\text { forage; } 3=\text { for mowing } \\
\text { grass; } 4=\text { other }\end{array}\end{array}$} \\
\hline & $\begin{array}{c}\text { Direction from your } \\
\text { home (directional code, } \\
\text { Code9) }\end{array}$ & $\begin{array}{c}\text { Distance to } \\
\text { your home } \\
(\mathrm{km})\end{array}$ & & $\begin{array}{l}\text { Can be ate } \\
\text { by livestock }\end{array}$ & $\begin{array}{l}\text { Can't } \\
\text { be ate }\end{array}$ & $\begin{array}{c}2011 \text { year } \\
(1=\text { good, } 0=\text { plain, } \\
-1=\text { bad })\end{array}$ & $\begin{array}{c}\text { Change in the past } 10 \text { years }(1=\mathrm{it} \\
\text { is better now; } 0=\text { no change; - } \\
1=\mathrm{it} \text { is worse now })\end{array}$ & \\
\hline \multicolumn{9}{|l|}{01} \\
\hline \multicolumn{9}{|l|}{02} \\
\hline 03 & & & & & & & & \\
\hline
\end{tabular}

\begin{tabular}{|c|c|c|c|c|c|c|}
\hline \multirow[b]{2}{*}{$\begin{array}{l}\text { Plots } \\
\text { code }\end{array}$} & \multirow{2}{*}{$\begin{array}{l}\text { Time of husbandry } \\
\text { No. of month/year }\end{array}$} & \multirow{2}{*}{$\begin{array}{c}\text { Use price } \\
\text { Yuan/mu/year }\end{array}$} & \multicolumn{2}{|r|}{ Basic facility } & \multirow{2}{*}{$\begin{array}{c}\text { Time of get it } \\
\text { YY-MM }\end{array}$} & \multirow{2}{*}{$\begin{array}{c}\text { Method of get it } \\
\begin{array}{c}1=\text { collective owned; } 2=\text { rent from } \\
\text { others; } 3=\text { other }\end{array}\end{array}$} \\
\hline & & & $\begin{array}{c}1=\text { good, } 0=\text { plain } \\
-1=\text { bad }\end{array}$ & $\begin{array}{c}1=\text { no cowshed; } 2=\text { cowshed with brick; } \\
3=\text { cowshed made from soil }\end{array}$ & & \\
\hline \multicolumn{7}{|l|}{01} \\
\hline \multicolumn{7}{|l|}{02} \\
\hline 03 & & & & & & \\
\hline
\end{tabular}

\begin{tabular}{|c|c|c|c|c|c|c|c|c|}
\hline \multirow[b]{2}{*}{$\begin{array}{l}\text { Plots } \\
\text { code }\end{array}$} & \multirow{2}{*}{$\begin{array}{c}\text { Drink water resource } \\
\text { 1=underground water/well; } \\
2=\text { lake; } 3=\text { river; } 4=\text { channel } \\
\text { water/tap water; } 5=\text { other }\end{array}$} & \multicolumn{3}{|c|}{ Labor input } & \multicolumn{4}{|c|}{ Climatic disaster impact } \\
\hline & & $\begin{array}{c}\text { Amount } \\
\text { (person*day) }\end{array}$ & $\begin{array}{l}\text { Work hours } \\
(\mathrm{h} / \mathrm{d})\end{array}$ & $\begin{array}{c}\text { Salary } \\
\text { (Yuan/person) }\end{array}$ & $\begin{array}{l}\text { Disaster } \\
\text { type } \\
(\text { Code6) }\end{array}$ & $\begin{array}{l}\text { Main loss } \\
\text { type } \\
\text { (Code } 7)\end{array}$ & $\begin{array}{c}\text { Adaptation } \\
\text { implementation } \\
\text { measures (Code8) }\end{array}$ & $\begin{array}{l}\text { Decrease loss after } \\
\text { adaptation } \\
\text { implementation }(\%)\end{array}$ \\
\hline \multicolumn{9}{|l|}{01} \\
\hline \multicolumn{9}{|l|}{02} \\
\hline 04 & & & & & & & & \\
\hline
\end{tabular}




\section{3) Summer meadow}

\begin{tabular}{|c|c|c|}
\hline Code & Year & 2011 \\
\hline 01 & Area (mu) & \\
\hline 02 & No. of plots (unit) & \\
\hline
\end{tabular}

Note: definition of one plot: 1.plots are not geographically bordering; 2.plots are geographically bordering, but obtained in different time and rent fees.

Is there any change of winter meadow from 2006? $\square$ 1=yes, and the reason is $\square 0=$ no change.

\begin{tabular}{|c|c|c|c|c|c|c|c|c|}
\hline \multirow[b]{2}{*}{$\begin{array}{l}\text { Plots } \\
\text { code }\end{array}$} & \multicolumn{2}{|c|}{ Geographic } & \multirow[b]{2}{*}{$\begin{array}{l}\text { Area } \\
(\mathrm{mu})\end{array}$} & \multicolumn{2}{|c|}{ Percentage } & \multicolumn{2}{|c|}{$\begin{array}{l}\text { Grass quality (according to the average height of } \\
\text { grass) }\end{array}$} & \multirow{2}{*}{$\begin{array}{c}\text { How to use } \\
1=\text { husbandry; } 2=\text { for } \\
\text { forage; } 3=\text { for mowing } \\
\text { grass; } 4=\text { other }\end{array}$} \\
\hline & $\begin{array}{c}\text { Direction from your } \\
\text { home (directional code, } \\
\text { Code9) }\end{array}$ & $\begin{array}{c}\text { Distance to } \\
\text { your home } \\
(\mathrm{km})\end{array}$ & & $\begin{array}{l}\text { Can be ate } \\
\text { by livestock }\end{array}$ & $\begin{array}{l}\text { Can't } \\
\text { be ate }\end{array}$ & $\begin{array}{c}2011 \text { year } \\
(1=\text { good, } 0=\text { plain, } \\
-1=\text { bad })\end{array}$ & $\begin{array}{c}\text { Change in the past } 10 \text { years }(1=\text { it } \\
\text { is better now; } 0=\text { no change; - } \\
1=\text { it is worse now })\end{array}$ & \\
\hline \multicolumn{9}{|l|}{01} \\
\hline \multicolumn{9}{|l|}{02} \\
\hline \multicolumn{9}{|l|}{03} \\
\hline 04 & & & & & & & & \\
\hline
\end{tabular}




\begin{tabular}{|c|c|c|c|c|c|c|}
\hline \multirow{2}{*}{$\begin{array}{l}\text { Plots } \\
\text { code }\end{array}$} & \multirow{2}{*}{$\begin{array}{c}\begin{array}{c}\text { Time of } \\
\text { husbandry }\end{array} \\
\text { No. of month/year }\end{array}$} & \multirow{2}{*}{$\begin{array}{c}\text { Use price } \\
\text { Yuan/mu/year }\end{array}$} & \multicolumn{2}{|r|}{ Basic facility } & \multirow{2}{*}{$\frac{\text { Time of get it }}{\text { YY-MM }}$} & \multirow{2}{*}{$\begin{array}{c}\text { Method of get it } \\
\begin{array}{c}1=\text { collective owned; } 2=\text { rent from } \\
\text { others; } 3=\text { other }\end{array}\end{array}$} \\
\hline & & & $\begin{array}{c}1=\text { good, } 0=\text { plain, } \\
-1=\text { bad }\end{array}$ & $\begin{array}{c}1=\text { no cowshed; } 2=\text { cowshed with brick; } \\
3=\text { cowshed made from soil }\end{array}$ & & \\
\hline \multicolumn{7}{|l|}{01} \\
\hline \multicolumn{7}{|l|}{02} \\
\hline \multicolumn{7}{|l|}{03} \\
\hline 04 & & & & & & \\
\hline
\end{tabular}

\begin{tabular}{|c|c|c|c|c|c|c|c|c|}
\hline \multirow[b]{2}{*}{$\begin{array}{l}\text { Plots } \\
\text { code }\end{array}$} & \multirow{2}{*}{$\begin{array}{c}\text { Drink water resource } \\
\text { =underground water/well; } \\
2=\text { lake; } 3=\text { river; } 4=\text { channel } \\
\text { water/tap water; } 5=\text { other }\end{array}$} & \multicolumn{3}{|c|}{ Labor input } & \multicolumn{4}{|c|}{ Climatic disaster impact } \\
\hline & & $\begin{array}{c}\text { Amount } \\
\text { (person*day) }\end{array}$ & $\begin{array}{l}\text { Work hours } \\
(\mathrm{h} / \mathrm{d})\end{array}$ & $\begin{array}{c}\text { Salary } \\
\text { (Yuan/person) }\end{array}$ & $\begin{array}{l}\text { Disaster } \\
\text { type } \\
(\text { Code6) }\end{array}$ & $\begin{array}{l}\text { Main loss } \\
\text { type } \\
\text { (Code7) }\end{array}$ & $\begin{array}{c}\text { Adaptation } \\
\text { implementation } \\
\text { measures (Code8) }\end{array}$ & $\begin{array}{l}\text { Decrease loss after } \\
\text { adaptation } \\
\text { implementation }(\%)\end{array}$ \\
\hline 01 & & & & & & & & \\
\hline 02 & & & & & & & & \\
\hline 03 & & & & & & & & \\
\hline 04 & & & & & & & & \\
\hline
\end{tabular}

Note:

Code9: 1=east; 2 =west; $3=$ =south; $4=$ north; $5=$ =southeast; $6=$ =southwest; $7=$ northeast; $8=$ =northwest. 
8.9 Labor input in animal husbandry in 2011

\begin{tabular}{|c|c|c|c|c|c|}
\hline Code & Work type & Amount (person) & Work time (hours/day) & Average work days (day) & Salary (Yuan/day) \\
\hline 01 & Herd & & & & \\
\hline 02 & Wool cut & & & & \\
\hline 03 & Milk & & & & \\
\hline 04 & Grass plant & & & & \\
\hline 05 & Other & & & & \\
\hline
\end{tabular}

\subsection{Health care of livestock}

\begin{tabular}{|c|c|c|c|c|c|c|c|c|}
\hline \multirow[b]{2}{*}{ Code } & \multirow[b]{2}{*}{$\begin{array}{l}\text { Livestock } \\
\text { name }\end{array}$} & \multicolumn{2}{|r|}{ Disease cure fee } & \multicolumn{2}{|r|}{ Epidemic prevention fee } & \multicolumn{3}{|c|}{ Labor input } \\
\hline & & $\begin{array}{l}\text { Amount } \\
\text { (Yuan) }\end{array}$ & $\begin{array}{l}\text { Changes in last } 10 \text { years } \\
(1=\text { expensive than past; } 0=\text { no } \\
\text { change; }-1=\text { cheaper than past })\end{array}$ & $\begin{array}{l}\text { Amount } \\
\text { (Yuan) }\end{array}$ & $\begin{array}{c}\text { Changes in last } 10 \text { years } \\
(1=\text { expensive than past; } 0=\text { no } \\
\text { change; }-1=\text { cheaper than past })\end{array}$ & $\begin{array}{c}\text { Amount } \\
\text { (person*day) }\end{array}$ & $\begin{array}{l}\text { Work hours } \\
(\mathrm{h} / \mathrm{d})\end{array}$ & $\begin{array}{c}\text { Salary } \\
\text { (Yuan/person) }\end{array}$ \\
\hline 01 & beef cattle & & & & & & & \\
\hline 02 & lamb & & & & & & & \\
\hline 03 & horse & & & & & & & \\
\hline 04 & yak & & & & & & & \\
\hline 05 & camel & & & & & & & \\
\hline 06 & pig & & & & & & & \\
\hline 07 & other & & & & & & & \\
\hline
\end{tabular}


Appendix

\section{Loss investigation from climatic disaster}

\subsection{The restrict factors to adaptation measures}

If there are climatic disaster adaptation measures, please answer question 1-6 in following table; otherwise, please answer the question 7 .

\begin{tabular}{|c|c|c|c|c|c|}
\hline Code & Questions & Details & 2012 & 2011 & 2010 \\
\hline 01 & $\begin{array}{l}\text { Who is responsible for } \\
\text { decision? }\end{array}$ & $\begin{array}{l}\text { Fill in the relationship of family host to } \\
\text { decision maker (Code1) }\end{array}$ & & & \\
\hline 02 & $\begin{array}{l}\text { The main restrict factor of } \\
\text { implementing the } \\
\text { adaptations }\end{array}$ & $\begin{array}{l}\text { restrict factor: } 1=\text { fund; } 2=\text { labor; } \\
3=\text { technology information; } 4=\text { official } \\
\text { policy; 5=other; } 6=\text { no reason. }\end{array}$ & & & \\
\hline 03 & $\begin{array}{l}\text { Please order the restrict } \\
\text { factors }\end{array}$ & $\begin{array}{l}\text { From the most important factor to the } \\
\text { least important factor }\end{array}$ & & & \\
\hline 04 & $\begin{array}{l}\text { Is there any organization } \\
\text { applied support to the } \\
\text { adaptation measures? }\end{array}$ & $\begin{array}{l}\text { 1=village collective; } 2=\text { town government; } \\
3=\text { higher government than town; } 4=\text { other } \\
\text { (please clarify); } 5=\text { no support (if it is no } \\
\text { support, please skip the following } 2 \text { ). }\end{array}$ & & & \\
\hline 05 & $\begin{array}{l}\text { If there is support, which } \\
\text { kind of supports is being } \\
\text { supplied? }\end{array}$ & $\begin{array}{l}1=\text { technical guidance; } 2=\text { money funding; } \\
3=\text { goods supports; } 4=\text { other (please } \\
\text { clarify) }\end{array}$ & & & \\
\hline 06 & $\begin{array}{l}\text { If there is support, what is } \\
\text { the value of it? }\end{array}$ & Yuan & & & \\
\hline 07 & $\begin{array}{l}\text { If there is no support, } \\
\text { please answer the reason } \\
\text { why these is no supports. }\end{array}$ & $\begin{array}{l}\text { 1=lack technical guidance; } 2=\text { lack } \\
\text { funding; } 3=\text { lack labors; } 4=\text { no need to take } \\
\text { it; } 5=\text { other (please clarify) }\end{array}$ & & & \\
\hline
\end{tabular}

\subsection{The impact of climatic disasters}

\begin{tabular}{|c|c|c|c|c|c|}
\hline Code & Loss details & Unit & 2012 & 2011 & 2010 \\
\hline 01 & Loss of living property & Yuan & & & \\
\hline 02 & Loss of productive property & Yuan & & & \\
\hline 03 & $\begin{array}{l}\text { Whether do you get the } \\
\text { compensation for the disasters (not } \\
\text { include the agricultural disaster } \\
\text { insurance) }\end{array}$ & $\begin{array}{l}1=y e s ; 2=\text { no, and then skip the } \\
\text { following } 2 \text { questions in this } \\
\text { table. }\end{array}$ & & & \\
\hline 04 & Who paid the compensation? & $\begin{array}{l}\text { 1=village collective; } 2=\text { town } \\
\text { government; } 3=\text { higher } \\
\text { government than town; } 4=\text { other } \\
\text { (please clarify) }\end{array}$ & & & \\
\hline 05 & $\begin{array}{l}\text { How much/ The value is the } \\
\text { compensation? }\end{array}$ & Yuan & & & \\
\hline
\end{tabular}




\section{Property investigation}

10.1 stock of self-employed company (self-employed company includes the households cooperation company)

\begin{tabular}{|c|l|l|}
\hline code & $\begin{array}{l}\text { How much of your family property (If you sold } \\
\text { them in 2011, the actual amount of the } \\
\text { price)(Yuan) }\end{array}$ & $\begin{array}{l}\text { How much of your family debt?(If you } \\
\text { sold them in 2011, the actual amount of } \\
\text { the debt) (Yuan) }\end{array}$ \\
\hline 01 & & \\
\hline 02 & & \\
\hline
\end{tabular}

10.2 House. Here are some questions about your houses. "Houses" compose of all the buildings you living(including the courtyards, except the ones for animals).

\begin{tabular}{|c|c|c|c|c|}
\hline code & House condition & $\begin{array}{l}\text { The } \\
\text { first one }\end{array}$ & $\begin{array}{l}\text { The } \\
\text { second } \\
\text { one }\end{array}$ & $\begin{array}{l}\text { The } \\
\text { third } \\
\text { one }\end{array}$ \\
\hline 01 & Do you share your house with others? $1=$ yes; $2=$ no & & & \\
\hline 02 & House type $1=$ house; $2=$ apartment & & & \\
\hline 03 & How many floors of your house? (floors) & & & \\
\hline 04 & How many rooms of your house? & & & \\
\hline 05 & $\begin{array}{l}\text { House's raw material: } 1=\text { grass; } 2=\text { mud; } 3=\text { brick; } \\
4=\text { concrete; } 5=\text { brick and wood; } 6=\text { wood; } 7=\text { mud and wood; } \\
8=\text { suite apartment in community; } 9=\text { brick }+ \text { mud+wood; } \\
10=\text { birck mixed; } 11=\text { others(Please describe it) }\end{array}$ & & & \\
\hline 06 & House land area (including courtyard) $\left(\mathrm{m}^{2}\right)$ & & & \\
\hline 07 & $\begin{array}{l}\text { When the house was built?(If they are built in many years, } \\
\text { fill in the lastest year) }\end{array}$ & & & \\
\hline 08 & $\begin{array}{l}\text { How much did you spent on the house when you bought or } \\
\text { built it?(RMB } 10 \text { thousands Yuan) }\end{array}$ & & & \\
\hline 09 & $\begin{array}{l}\text { Have you spent more than } 3 \text { thousands on maintaining or } \\
\text { sprucing up the house? } 1=y s e ; 2=\text { no } \rightarrow 11\end{array}$ & & & \\
\hline 10 & How much have you totally spent? (Yuan) & & & \\
\hline 11 & How much does your house cost now? (10 thousands Yuan) & & & \\
\hline
\end{tabular}


10.32011 life durable goods (mainly including the ones that price up to 500 yuan)

\begin{tabular}{|c|l|l|l|l|}
\hline code & \multicolumn{1}{|c|}{ item } & amount & $\begin{array}{c}\text { Which year did you } \\
\text { buy it? (year) } \\
\text { If there are more than } \\
\text { one, write down the } \\
\text { lastest one }\end{array}$ & $\begin{array}{c}\text { How much is it if } \\
\text { you sell it now? }\end{array}$ \\
\hline 01 & Car & & & \\
\hline 02 & Colorful TV set & & & \\
\hline 03 & Bridge or ice cuber & & & \\
\hline 04 & Washmachine & & & \\
\hline 05 & Moterbike & & & \\
\hline 06 & Electromobile & & & \\
\hline 07 & Computer & & & \\
\hline 08 & Digital devices like camera & & & \\
\hline 09 & Air conditioner & & & \\
\hline 10 & Bed & & & \\
\hline 11 & Jewelry & & & \\
\hline 12 & Cellphone & & & \\
\hline 13 & Others 1 & & & \\
\hline 14 & Others 2 & & & \\
\hline 15 & Others 3 & & \\
\hline
\end{tabular}


Ph.D. dissertation of Wei Huang

10.42011 production machines (mainly including the ones costing over 500 yuan)

\begin{tabular}{|c|c|c|c|c|c|}
\hline Code & & Item & amount & $\begin{array}{l}\text { Which year did you buy it? } \\
\text { (year) if there are more than }\end{array}$ & $\begin{array}{l}\text { How much is it } \\
\text { if you sell it }\end{array}$ \\
\hline 01 & \multirow{5}{*}{$\begin{array}{l}\text { Motive } \\
\text { power } \\
\text { machine }\end{array}$} & Diesel engine & & & \\
\hline 02 & & Gasoline engine & & & \\
\hline 03 & & electromoter & & & \\
\hline 04 & & Wind engine & & & \\
\hline 05 & & Tractor & & & \\
\hline 06 & \multirow{5}{*}{$\begin{array}{c}\text { soil } \\
\text { cultivating } \\
\text { machine }\end{array}$} & Plough & & & \\
\hline 07 & & Harrow & & & \\
\hline 08 & & Scarifier & & & \\
\hline 09 & & rotary cultivator & & & \\
\hline 10 & & Roller & & & \\
\hline 11 & \multirow{5}{*}{$\begin{array}{l}\text { planting } \\
\text { machine }\end{array}$} & seed-cleaning apparatus & & & \\
\hline 12 & & seed dresser & & & \\
\hline 13 & & Seed surface processor & & & \\
\hline 14 & & planter & & & \\
\hline 15 & & pasture drill & & & \\
\hline 16 & \multirow{3}{*}{$\begin{array}{l}\text { sprinkler } \\
\text { equipment }\end{array}$} & solid sprinkler system & & & \\
\hline 17 & & semifixed sprinkler system & & & \\
\hline 18 & & portable sprinkler system & & & \\
\hline 19 & \multirow{6}{*}{$\begin{array}{c}\text { grass } \\
\text { harvesting } \\
\text { machine }\end{array}$} & $\begin{array}{l}\text { Animal hay harvest } \\
\text { machinery }\end{array}$ & & & \\
\hline 20 & & Machinery hay harvest & & & \\
\hline 21 & & $\begin{array}{l}\text { hay raking and stacking } \\
\text { machine }\end{array}$ & & & \\
\hline 22 & & Baling machinery & & & \\
\hline 23 & & briquetting machine & & & \\
\hline 24 & & packaging machine & & & \\
\hline 25 & \multirow{3}{*}{$\begin{array}{c}\text { Animal } \\
\text { husbandry } \\
\text { transport } \\
\text { machinery }\end{array}$} & $\begin{array}{l}\text { hay loading and } \\
\text { transporting machine }\end{array}$ & & & \\
\hline 26 & & Animal transport vehicles & & & \\
\hline 27 & & Milk transport vehicles & & & \\
\hline 28 & \multicolumn{2}{|l|}{ Other 1} & & & \\
\hline 29 & \multicolumn{2}{|l|}{ Other 2} & & & \\
\hline
\end{tabular}


Appendix

\section{Knowledge and perception of climate change}

\begin{tabular}{|c|c|c|}
\hline code & Questions description & $\begin{array}{c}\text { Answers } \\
\text { (comments) }\end{array}$ \\
\hline 01 & $\begin{array}{l}\text { How do you feel for temperature changes in rencent } 10 \text { years? } \\
1=\text { increase; } 2=\text { decrease; } 3=\text { stable; } 4=\text { no idea }\end{array}$ & \\
\hline 02 & $\begin{array}{l}\text { Are you sure for question } 1 ? \\
1=\text { quite sure; } 2=\text { sure; } 3=\text { not sure }\end{array}$ & \\
\hline 03 & $\begin{array}{l}\text { Do you know the grassland ecosystem could be helpful for adjusting } \\
\text { temperature? } \\
1=\text { Yes, } 2=\mathrm{No}\end{array}$ & \\
\hline 04 & $\begin{array}{l}\text { How do you think for the importance of grassland adjusting } \\
\text { temperature? } \\
1=\text { very important, } 2=\text { =important, } 3=\text { midle, } 4=\text { not important, } \\
5=\text { totally not important }\end{array}$ & \\
\hline 05 & $\begin{array}{l}\text { How do you feel for rainfull changes in rencent } 10 \text { years? } \\
1 \text { =increase; } 2=\text { decrease; } 3=\text { stable; } 4=\text { no idea }\end{array}$ & \\
\hline 06 & $\begin{array}{l}\text { Are you sure for question } 5 ? \\
1=\text { quite sure; } 2=\text { sure; } 3=\text { not sure }\end{array}$ & \\
\hline 07 & $\begin{array}{l}\text { Do you know the grassland ecosystem could be helpful for adjusting } \\
\text { rainfull? } \\
1=\text { Yes, } 2=\text { No }\end{array}$ & \\
\hline 08 & $\begin{array}{l}\text { How do you think for the importance of grassland adjusting rainfull } ? \\
1=\text { very important, } 2=\text { important, } 3=\text { midle, } 4=\text { not important, } \\
5=\text { totally not important }\end{array}$ & \\
\hline 09 & $\begin{array}{l}\text { disaster frenquency change? } \\
1=\text { increase; } 2=\text { decrease; } 3=\text { stable; } 4=\text { no idea }\end{array}$ & \\
\hline 10 & $\begin{array}{l}\text { Do you know grassland ecosystem is important for migaration } \\
\text { disaster? } 1=\text { Yes, } 2=\mathrm{No}\end{array}$ & \\
\hline 11 & $\begin{array}{l}\text { How do you think the degree of importance for migaration disaster? } \\
1=\text { very important, } 2=\text { important, } 3=\text { midle, } 4=\text { not important, } \\
5=\text { totally not important }\end{array}$ & \\
\hline 12 & $\begin{array}{l}\text { How do you feel for drought degree in rencent } 10 \text { years? } \\
1=\text { increase; } 2=\text { decrease; } 3=\text { stable; } 4=\text { no idea }\end{array}$ & \\
\hline 13 & $\begin{array}{l}\text { Are you sure for question } 12 ? \\
1=\text { quite sure; } 2=\text { sure; } 3=\text { not sure }\end{array}$ & \\
\hline 14 & $\begin{array}{l}\text { How do you feel for sandstorm degree in rencent } 10 \text { years? } \\
1=\text { increase; } 2=\text { decrease; } 3=\text { stable; } 4=\text { no idea }\end{array}$ & \\
\hline 15 & $\begin{array}{l}\text { Are you sure for question } 14 ? \\
1=\text { quite sure; } 2=\text { sure; } 3=\text { not sure }\end{array}$ & \\
\hline 16 & $\begin{array}{l}\text { How do you feel for big wind in rencent } 10 \text { years? } \\
1=\text { increase; } 2=\text { decrease; } 3=\text { stable; } 4=\text { no idea }\end{array}$ & \\
\hline 17 & $\begin{array}{l}\text { Are you sure for question } 16 ? \\
1=\text { quite sure; } 2=\text { sure; } 3=\text { not sure }\end{array}$ & \\
\hline 18 & $\begin{array}{l}\text { How do you feel for frozen disaster in rencent } 10 \text { years? } \\
1=\text { increase; } 2=\text { decrease; } 3=\text { stable; } 4=\text { no idea }\end{array}$ & \\
\hline 19 & $\begin{array}{l}\text { Are you sure for question } 18 ? \\
1=\text { quite sure; } 2=\text { sure; } 3=\text { not sure }\end{array}$ & \\
\hline 20 & $\begin{array}{l}\text { What do you think of effect of temperature rising on grass growing? } \\
1=\text { improve; } 2=\text { =restraint; } 3=\text { no effects; } 4=\text { no idea }\end{array}$ & \\
\hline 21 & $\begin{array}{l}\text { What do you think of effect of rainfull rising on grass growing? } \\
1=\text { improve; } 2=\text { restraint; } 3=\text { no effects; } 4=\text { no idea }\end{array}$ & \\
\hline 22 & $\begin{array}{l}\text { Mean reason of grass degeneration? } \\
1=\text { climate change; } 2=\text { human activities }\end{array}$ & \\
\hline
\end{tabular}




\begin{tabular}{|c|c|}
\hline 23 & $\begin{array}{l}\text { Have you heard about climate change? } \\
1=\text { Yes; } 2=\text { No } \rightarrow 27\end{array}$ \\
\hline 24 & $\begin{array}{l}\text { if heard, where or how? } \\
\text { 1=TV show; 2=Newspaper; 3=internet; 4=relations; 5=local } \\
\text { government; } 6=\text { =thers (discribe): }\end{array}$ \\
\hline 25 & $\begin{array}{l}\text { Temperature change in discussing climate change } \\
1=\text { increase } ; \quad 2=\text { decrease; } 3=\text { no idea }\end{array}$ \\
\hline 26 & $\begin{array}{l}\text { impact of climate change on livestock production? } \\
1=\text { positive; } 2=\text { negetive; } 3=\text { no effects; } 4=\text { no idea }\end{array}$ \\
\hline 27 & $\begin{array}{l}\text { Have you heard about green house gas emission? } \\
1=\text { Yes; } 2=\text { No } \rightarrow 29\end{array}$ \\
\hline 28 & $\begin{array}{l}\text { if heard, where or how? } \\
\text { 1=TV show; } 2=\text { =Newspaper; } 3=\text { =internet; } 4=\text { relations; } 5=\text { local } \\
\text { government; } 6=\text { =thers (discribe): }\end{array}$ \\
\hline 29 & $\begin{array}{l}\text { Do the fertilization have relationship to green house gas? } \\
1=\text { Yes; } \quad 2=\text { No; } 3=\text { no idea }\end{array}$ \\
\hline 30 & $\begin{array}{l}\text { Does fertilizing much impact water qualit? } \\
1=\text { Yes; } 2=\mathrm{No} ; \quad 3=\text { no idea }\end{array}$ \\
\hline 31 & $\begin{array}{l}\text { Do you know grassland ecosystem can help migerate the climate } \\
\text { change through carbon sink? } 1=\text { Yes; } \quad 2=\mathrm{No} \rightarrow 33\end{array}$ \\
\hline 32 & $\begin{array}{l}\text { Importance degree for grassland ecosystem migerates climate change } \\
\text { by carbon sink? } \\
1=\text { very important, } 2=\text { important, } 3=\text { midle, } 4=\text { not important, } \\
5=\text { totally not important }\end{array}$ \\
\hline 33 & $\begin{array}{l}\text { do you know the importance of grassland ecosystem for clear water } \\
\text { and air? } \\
1=\text { Yes, } 2=\text { No } \rightarrow 35\end{array}$ \\
\hline 34 & $\begin{array}{l}\text { Importance degree of grassland ecosystem for clean water and air? } \\
1=\text { very important, } 2=\text { important }, 3=\text { midle, } 4=\text { not important, } \\
\text { 5=totally not important }\end{array}$ \\
\hline 35 & $\begin{array}{l}\text { do you know the importance of grassland ecosystem for perserving soil } \\
\text { and water } ? 1=\text { Yes, } 2=\text { No } \rightarrow 37\end{array}$ \\
\hline 36 & $\begin{array}{l}\text { Importance degree of grassland ecosystem for perserving soil and } \\
\text { water? } \\
1=\text { very important, } 2=\text { =important, } 3=\text { midle, } 4=\text { not important, } \\
5=\text { totally not important }\end{array}$ \\
\hline 37 & $\begin{array}{l}\text { Do you agree with the economic compensation for giving up } \\
\text { husbandary on grassland? } 1=\text { Yes } \rightarrow 38, \quad 2=\text { No } \rightarrow 39\end{array}$ \\
\hline 38 & $\begin{array}{l}\text { How much the lowest compensation you want for grazing ban? 500, } \\
1000,1500,2000,2500,3000,4000,5000,6000,8000, \\
10000,15000,20000,25000,30000,40000,50000\end{array}$ \\
\hline 39 & $\begin{array}{l}\text { What are your reasons for disagreeing grazing ban? } \\
1=\text { income decreasing; } 2=\text { the result of grazing ban is not obvious; } \\
3=\text { lost of living security; } 4=\text { low comoensation; } 5=\text { no confidence for } \\
\text { government and related organizations; } 6=\text { my current condition is in } \\
\text { proper grazing, so it is good for grassland; } 7=\text { others }\end{array}$ \\
\hline
\end{tabular}


Appendix

Part 5 - Comments and suggestions

5.1 Which questions are hard and complicated to reply?

5.2 What problem is serious in local area but not mentioned?

5.3 What's your opinion to this questionnaire?

Thanks so much for your help.

Best wishes for you and your family.

\section{Contact information:}

Center for Chinese Agricultural Policy, Chinese Academy of Sciences

No. Jia 11, Datun Road, Chaoyang Dist., Peking, China, 100101

Tel.: 0086-10-6488 $8385 \quad$ Fax.: 0086-10-64856533

Email: yinf.10s@igsnrr.ac.cn; whuang@gwdg.de

All rights reserved. 